\title{
Knowledge, learning, and teaching: Studies on the application of constructivist principles in higher education
}

Citation for published version (APA):

Otting, H. (2009). Knowledge, learning, and teaching: Studies on the application of constructivist principles in higher education. [Doctoral Thesis, Maastricht University]. Maastricht University.

https://doi.org/10.26481/dis.20091208ho

Document status and date:

Published: 01/01/2009

DOI:

10.26481/dis.20091208ho

Document Version:

Publisher's PDF, also known as Version of record

\section{Please check the document version of this publication:}

- A submitted manuscript is the version of the article upon submission and before peer-review. There can be important differences between the submitted version and the official published version of record.

People interested in the research are advised to contact the author for the final version of the publication, or visit the DOI to the publisher's website.

- The final author version and the galley proof are versions of the publication after peer review.

- The final published version features the final layout of the paper including the volume, issue and page numbers.

Link to publication

\footnotetext{
General rights rights.

- You may freely distribute the URL identifying the publication in the public portal. please follow below link for the End User Agreement:

www.umlib.nl/taverne-license

Take down policy

If you believe that this document breaches copyright please contact us at:

repository@maastrichtuniversity.nl

providing details and we will investigate your claim.
}

Copyright and moral rights for the publications made accessible in the public portal are retained by the authors and/or other copyright owners and it is a condition of accessing publications that users recognise and abide by the legal requirements associated with these

- Users may download and print one copy of any publication from the public portal for the purpose of private study or research.

- You may not further distribute the material or use it for any profit-making activity or commercial gain

If the publication is distributed under the terms of Article $25 \mathrm{fa}$ of the Dutch Copyright Act, indicated by the "Taverne" license above, 
KNOWLEDGE, LEARNING, AND TEACHING:

STUDIES ON THE APPLICATION OF CONSTRUCTIVIST PRINCIPLES

IN HIGHER EDUCATION 
Copyright: J. M. Otting

ISBN: 978-90-9024865-3

Cover design: Joop Bos

Druk: Dekkerdrukwerken 


\title{
KNOWLEDGE, LEARNING, AND TEACHING:
}

\section{STUDIES ON THE APPLICATION OF CONSTRUCTIVIST PRINCIPLES}

IN HIGHER EDUCATION

\author{
PROEFSCHRIFT \\ Ter verkrijging van de graad van doctor \\ aan de Universiteit Maastricht \\ op gezag van de Rector Magnificus, \\ Prof. Mr. G. P. M. F. Mols \\ volgens het besluit van het College van Decanen, \\ in het openbaar te verdedigen \\ op dinsdag 8 december 2009 om 16.00 uur \\ door \\ JOHANNES MARINUS OTTING
}


Promotor:

Prof. Dr. W. H. Gijselaers

Beoordelingscommissie:

Prof. Dr. M. S. R. Segers, Maastricht University (voorzitter)

Prof. Dr. J. A. D. Kasper, Maastricht University

Prof. Dr. R. G. Milter, Johns Hopkins University, Baltimore MD, USA 


\section{Table of contents}

Preface

Chapter 1: Introduction $\quad 9$

Chapter 2: $\quad$ The structural relationship between students' epistemological beliefs and conceptions of teaching and learning

Accepted for publication (2010) in: Studies in Higher Education.

Chapter 3: International hospitality management students' epistemological beliefs and conceptions of teaching and learning

Accepted for publication (2009) in: Journal of Hospitality and Tourism Education.

Chapter 4: The identification of constructivist pedagogy in different learning environments

Published in: M. K. McCuddy, H. van den Bosch, Wm. B. Martz, A. V. Matveev \& K. O. Morse (Eds.), The Challenges of Educating People to Lead in a Challenging World (pp. 171-196). Dordrecht: Springer.

Chapter 5: Critical task characteristics in problem-based learning Published in: Industry and Higher Education, 20(5), 347-357.

Chapter 6: $\quad$ General conclusions and discussion 


\section{Preface}

This dissertation has evolved out of my involvement and interest in higher professional education and more specifically in problem-based learning. The studies presented in this dissertation have been carried out at Stenden University of Applied Sciences where I had the opportunity to introduce problem-based learning at the Hotel Management School Leeuwarden. Through the years, my interest in education has evolved from educational management and curriculum development to educational theory and research.

Several people played an important role in the realization of this dissertation. I would like to thank my promoter Professor Wim Gijselaers for his guidance, confidence, and wisdom. His ideas, comments, and encouragement greatly helped me to accomplish the work on this dissertation. Professor Wynand Wijnen not only shaped my thinking about problem-based learning but he also inspired me to do research on problem-based learning and stimulated to start to work on this dissertation.

I would like to thank all students and colleagues at Stenden University of Applied Sciences for their cooperation and participation in the studies of this dissertation. In particular, I would like to mention the colleagues who were extremely helpful. I am profoundly indebted to my colleague Wichard Zwaal for his involvement in and contribution to research. His constructive and critical comments on this dissertation were invaluable. Other colleagues have supported me in various ways and did encourage me to finalize this dissertation. In particular, I would like to express my gratitude to Herman Bierma, Klaes Eringa, Joris Paulussen, and Aafke van der Wal for their sustained moral support. Also, I am thankful to Joop Bos for his constructivist design of the cover.

Finally, I would like to thank my wife Joyce, my son Guy Maurice, and my daughter Nadine and her friend Kris for their love, moral support, and patience. 
Introduction 


\section{Introduction}

"As part of the beginning tutor training for facilitating problem-based learning (PBL), we regularly observe tutor and student behavior in PBL-groups. A tutor manual, in which the main aspects of the theme and issues that come up for discussion are explained, is made available to the tutor. Some tutors take the manual to the PBL-sessions; other tutors leave the tutor manual behind in their room. We have observed that PBL-groups facilitated by a tutor, who did not use the manual in the $P B L$-session, intensively collaborate with one another, explore the problem thoroughly, try to find different ways to solve the problem, independently formulate learning goals, and tutor interventions pass off smoothly. The students are in control of their learning process and are capable of bringing up issues for discussion. The pattern of interaction in PBL-groups with a tutor, who uses his tutor manual during the PBL-session, is quite different. As soon as the tutor uses the manual for a comment or contribution with respect to content, the students' exploration of the problem eases off, conversations flag, and the focus of interaction shifts from the group to the tutor. In the discussion and formulation of their own learning goals, the students do not completely trust their own judgments, address the tutor as an expert, who apparently has all the right answers in his manual, and they try to get to those answers. It is remarkable how a relatively simple detail in tutor behavior affects what students want to know and how they learn."

How people learn and especially how people learn in project groups and work teams have been acknowledged in educational and organizational settings (Akkerman, Van den Bossche, Admiraal, Gijselaers, Segers, Simons, \& Kirschner, 2007). Learning is both an individual process of meaningful and conceptual understanding, and a collaborative engagement in knowledge construction, and production in dynamic organizational structures. The preparation of students for their future work field requires not only the mastery of a body of relevant knowledge and skills but also the articulation of the student's active involvement in gaining new knowledge and understandings, and the cultivation of independent judgment. Theories and ideas about knowledge and learning in higher education and in societal or organizational settings converge and shift towards a constructivist perspective (Simons \& Bolhuis, 2004). Constructivism is a perspective on the construction of knowledge and a way of thinking about the formation of knowledge that contributes to the educational debate by providing a view on what knowledge is and how students gain knowledge and understanding through dialogue and collaboration (Bereiter, 2002a). However, discussions on the relevance of constructivism for pedagogical practice are often obscured by misunderstandings of the underlying ontological and epistemological assumptions about human existence and knowledge. 
The ontological and epistemological positions of constructivism are rarely spelled out but are essential for understanding the relevance of constructivism for higher education. The case, illustrated at the beginning of this chapter, makes clear that even when students are working in a learning environment which is considered to be a prototype of constructivist education, still unforeseen learning effects may occur that are not line with the constructivist ideas underlying PBL. Students' beliefs about the nature of knowledge and the role of the teacher may be stronger than the intentions of the PBL course designer.

Discourses about constructivism have for a large part taken place in specialized fields like science and mathematics education, and the philosophy of education (Ernest, 1991; Kukla, 2000; Matthews, 1997; 1998; Rowlands, Graham, \& Berry, 2001). Constructivist discourses focused on theories of knowledge and knowing, and these discourses, apart from serving as a useful and relevant critique on traditional educational practices, have not had an important impact on shaping those educational practices (Davis \& Sumara, 2002; Gordon, 2009). Nevertheless, philosophical and epistemological questions contribute to understanding the value of constructivism for the educational debate as demonstrated in the PBL-case (Bickhard, 1993; 1997; Marlowe \& Page, 1998; Matthews, 1997; Morf, 1998; Phillips, 1995; 2000; Steffe \& Gale, 1995; Von Glasersfeld, 1995; Von Krogh \& Roos, 1995).

\section{Constructivism: ontological and epistemological assumptions}

Constructivism builds on the philosophical hypothesis that the world we know is a human construction and we cannot have knowledge of the world that exists independently of our minds. Our conceptions of reality can only be compared to other conceptions but not with reality itself. How can we know the real world? How can we know what we know? The ancient Greek philosophers already raised these fundamental questions about knowledge and knowing. What is knowledge? Plato (360BC), for instance, dealt with questions that belong to the domain of epistemology in his famous simile of the cave.

\footnotetext{
"And now, I said, let me show in a figure how far our nature is enlightened or unenlightened: -Behold! Human beings living in an underground den, which has a mouth open towards the light and reaching all along the den; here they have been from their childhood, and have their legs and necks chained so that they cannot move, and can only see before them, being prevented by the chains from turning round their heads. Above and behind them a fire is blazing at a distance, and between the fire and the prisoners there is a raised way; and you will see, if you look, a low wall built along the way, like the screen which marionette players have in front of them, over which they show the puppets.... And now look again, and see what will naturally follow it' the prisoners
} 
are released and disabused of their error. At first, when any of them is liberated and compelled suddenly to stand up and turn his neck round and walk and look towards the light, he will suffer sharp pains; the glare will distress him, and he will be unable to see the realities of which in his former state he had seen the shadows; and then conceive some one saying to him, that what he saw before was an illusion, but that now, when he is approaching nearer to being and his eye is turned towards more real existence, he has a clearer vision, -what will be his reply? And you may further imagine that his instructor is pointing to the objects as they pass and requiring him to name them, -will he not be perplexed? Will he not fancy that the shadows which he formerly saw are truer than the objects which are now shown to him?" (Plato, 360BC, Book VII)

How can we certainly know if an object really exists before we perceive it? How do we know that our perceptions, images or descriptions of reality are true? How does our picture of reality correspond with the objective reality? Is true knowledge an exact representation of the real world? How is the reality outside us represented in our heads? How do we know if the reality that we perceive is a true reality and not a fake? How real is real really? These questions can be placed in a long tradition that started with discussions initiated by the Greek philosophers. The "skeptics", for instance, formulated persuasive arguments against claims about the truth and questioned the certainty of knowledge. The skeptic tradition is reflected in the constructivist's view of the biological and psychological roots of understanding in which knowledge is not a representation of the world outside but a construction by human beings, who only know the cognitive reality (Von Glasersfeld, 2000). The tangible reality of our experiences, "die Wirklichkeit", is the constructed world in our minds from which we derive all knowledge (Lindemann \& Vossler, 1999; Peschl \& Riegler, 1999; Von Glasersfeld, 1998). The ontological reality or "Realität" exists independently of our observations and lies beyond all knowing. "Die Realität bringt die Wirklichkeit hervor, aber die Realität existiert nicht in der Wirklichkeit. Die Wirklichkeit ist das einzige, das für uns erfahrbar existiert" (Roth, 1992, p. 321). The ontological reality is not accessible for human beings. One can only speculate about it or consider it a matter of faith and religion (Jensen, 1999; Von Glasersfeld, 1992). This perspective on reality has important consequences for how reality and knowledge are perceived in organizations. An organization is a social system that, within the framework of its own dynamics, by a process of self-preservation and self-development constructs its own reality, and generates feasible and viable action perspectives (Hejl and Stahl, 2000). All knowledge that is produced by the organization, is based on the distinctions in observations and elaborated perceptions of the system itself. From a constructivist perspective, the center of attention of the organization is not externally oriented, but is directed to the internal dynamics of the organization and its interactions with the environment. The business environment is a social construct, a design of possible realities, that are produced by the organization itself taking into account the other actors in the external 
environment. The central question is: "How does the organization perceive and generate images of the business reality?" or "How does the organization know what it knows?" One of the main tasks of managers is to organize the processes that further the perception, construction, and interpretation of reality, the coming into being of "Wirklichkeit aus der Realität" (Hejl and Stahl, 2000).

Constructivism does not deny the existence of reality, and even accepts a correspondence between the cognitive and the objective reality, but is unable to pronounce upon the exact nature of that correspondence (Roth, 1992). The relationship between reality and knowledge is one of viability. Viability refers to the biological notion of the adaptation of an organism to a given condition of the environment. Knowledge cannot be true but can only be viable. The replacement of truth with viability places constructivism against objectivism. The absence of a reality check may lead to relativism or solipsism because direct verification of the constructed knowledge with the reality outside is not possible (Fleury, 1998; Von Glasersfeld, 1995; 2000). The utilitarian concept of viability refers to the inter-subjective consensus on practical value of knowledge.

Constructivism reintroduces the properties of the observer and its influence on his observations. Each reality is based on personal experiences and unique histories and, by consequence, differs from other individuals' realities. Objectivity is the illusion that

14 observations can be made without an observer (Von Glasersfeld \& Ackermann, 1997). Constructivism accepts different explanatory propositions as legitimate expressions of a domain of reality and does not claim the exclusive validity of explanations as an expression of how things really are in an objective reality (Maturana, 1988). Knowledge is neither a matter of anything goes nor an approximation to truth, it is a careful process of improving on existing knowledge (Bereiter, Cassells, \& Hewitt, 1997). Knowledge is justified when it proves to be useful in achieving goals rather than verified by its correspondence to reality (Colliver, 1999). Consequently, constructivism itself must be considered as a model, a useful working hypothesis, and not as the model. It is an unfinished product, which usefulness for and applications to practice are subject to discussion and improvement (Von Glasersfeld, 2000; 2001). The value of knowledge is dependent on its application to new problems, other situations, and practices.

Higher education requires both an adequate epistemology, ideas about what knowledge is, and a learning methodology, ideas how to facilitate teaching and learning. When knowledge is individually and socially constructed, and results in viable knowledge that cannot represent an objective reality, the question arises how learners are able to construct shared understandings and come to agreement on what kind of 
knowledge and knowing really counts. A constructivist approach to education confronts teachers and students with issues about the nature of knowledge and knowing (Fitzgerald \& Cunningham, 2002; Hofer \& Pintrich, 1997; How \& Berv, 2000; Petraglia, 1998; Phillips, 2000). If knowledge is not true but only viable, the questions arise about why, what, and how are we teaching and learning. What do teachers and students think knowledge really is and how certain can we be that we teach and learn the "right" knowledge? Why should students believe in the expertise of teachers and in their authority if knowledge is not true, but just a viable human construction? Research of the beliefs that teachers and students hold about the nature of knowledge and knowing may provide insight into what they believe knowledge is and how it is acquired.

\section{A constructivist view of education}

Higher education prepares students for participation in a dynamic and knowledge intensive society. The overwhelming amount of available information calls for well-developed competencies to select, evaluate, and use relevant information. The changing demands on tomorrow's workforce have necessary and logical consequences for teaching and learning in higher education. What really matters in educating a new generation of students for life is not the mere acquisition of facts and information but the gain of competencies of inquiry and argumentation to attain deeper levels of understanding (Kuhn, 2007). College graduates become employees "who can think creatively, adapt flexibly to new work demands, identify as well as solve problems, and create complex products in collaboration with others" (Windschitl, 2002, p.135). Higher education has gradually adopted a constructivist view of learning in which students' active knowledge acquisition and elaboration are endorsed through the provision of collaborative learning opportunities together with highly contextualized knowledge resources (Anderson, Greeno, Reder, \& Simon, 2000; Bereiter, 1994; Billett, 1996; De Corte, 1995; 2000; Dochy, Segers, Van den Bossche, \& Gijbels, 2003; Matthews, 1998; Phillips, 2000; Steffe \& Gale, 1995; Von Glasersfeld, 1995; 2005). Unfortunately, the relevance of constructivism for educational practice has been obscured by the fact that a wide range of different forms and interpretations of constructivism can be found under the label of constructivism (Howe \& Berv, 2000; Phillips, 2000). Most of the writings on constructivism have been theoretical in nature rather than empirical (Von Glasersfeld, 1993; 1995; 1998). Constructivism is frequently used as an umbrella term covering a diversity of interpretations reflecting issues that can be traced back to different sources. It is a multi-faceted concept and researchers often disagree about the distinctions between the various divisions and subdivisions of constructivism (Howe \& Berv, 2000; Phillips, 2000). Under the label of constructivism fall a wide range of different interpretations of constructivism, among others: educational or psychological 
constructivism, radical constructivism, trivial constructivism, social constructivism, social constructionism, information-processing constructivism, social psychological constructionism, pragmatic social constructivism, critical constructivism, cybernetic constructivism (Ernest, 1995; Geelan, 1997; Prawat, 1996; Steffe \& Gale, 1995). Regardless of the differences between the various forms of constructivism, several shared principles of constructivism can be recognized.

\section{Self-directed and constructive learning}

Knowing how to set and master learning goals, how to plan and monitor learning are important issues for students in higher education. Learning requires the active, constructive, and goal-oriented involvement of the student. Students are stimulated to gain ownership of the learning process to attain their own learning objectives. Students construct new knowledge on the basis of what they already understand. Previously unknown data and information are assimilated in the existing knowledge base. Learning is a purposeful knowledge construction process involving the whole person. Responsibility, interest, self-regulation, and motivation for learning are neither pre-given nor built-in in the learning environment (Järvelä \& Niemivirta, 1999). Individual affective, motivational, and cognitive differences of the students should be taken into account during the knowledge construction processes and the development of (meta)cognitive skills is important for monitoring the learning process. Learning as a self-regulated, self-conscious, self-motivated, and self-initiated activity presupposes

16 that students are able to take responsibility for their own learning. Constructivism emphasizes the active role of the learner, the self-initiated activity, the identification of the self with an idea through action, and the maintenance of a dynamic interrelation between the individual and the environment. Actively acquired knowledge that builds on well-structured prior knowledge is made manifest through collaborative learning activities that yield evident results. Learning is both a process of individual knowledge construction and a process of social interaction in dynamic social contexts. It is a dynamic balance between the student's effort and commitment to learning, the collaborative learning activities, and the contextual variables that trigger and sustain learning activities. Interest in learning is a motivational orientation that develops over time, tends to be relatively long lasting and stable, and is related to the increase of knowledge and positive feelings in a particular domain (Hidi \& Harackiewicz, 2000). The development of interest in learning is supported by environmental and contextual factors, challenging tasks and assignments, meaningful educational materials, and the discussions with other students during collaborative activities. Learning environments should be designed in such a way that they confront the students with intellectual questions that support and challenge student's thinking, and provide motivational and emotional challenges that further student's self-directed learning and active knowledge construction. 


\section{Learning from authentic tasks}

Self-regulated learning is supported by authentic learning contexts that are interesting and meaningful, provide diverse resources and learning materials, and offer ample opportunities for collaboration (De Corte, 1995; 2000). By exposing students to challenging learning environments and by engaging them in purposeful learning activities, considerable contributions can be made to the enhancement of the students' personal interest in and motivation for learning. Learning from authentic tasks and the application of knowledge to real-life situations makes learning meaningful for students. Authentic tasks reflect the complexity of the future work situation. Meaningful and holistic learning in real-world contexts from authentic and unstructured tasks can be achieved by using multiple perspectives in the problem-solving process. Students learn best when they participate in activities that they perceive as useful and relevant aspects of their future work (Lave \& Wenger, 1991; Savery \& Duffy, 1996; Vosniadou, 2001).

\section{Collaborative learning}

The social context in which learning activities take place is an integral part of the learning activity. Both what is learned and how it is learned in combination with the peculiarities of the specific situation are important. Learning is primarily a social activity and participation in social life is central for learning to occur. Collaborative learning in dialogue with other students enables students to share and discuss knowledge, and offers opportunities to articulate one's thinking. Authentic learning in collaboration with other students has become "the central pillar of constructivist orthodoxy and is the one on which practically every other principle is dependent to some extent" (Petraglia, 1998, p. 77). Collaborative learning is a process of active knowledge construction and personal understanding in dialogue and engagement with other students. Students are critically dependent on one another during the learning process and are jointly responsible and individually accountable for gaining results. Personal experience and knowledge are brought into the discussion to enhance mutual and deeper understanding, to improve the ability to work in teams, to enhance the ability to solve new problems, and to show the abilities to access and turn information into viable and useful knowledge (Salomon, 1998).

The shift of focus in learning theory from a conception of learning as a knowledge transmission process to a conception of learning as a self-organized, collaborative process of constructing new knowledge on the basis of prior knowledge has established constructivism as an accepted view of learning in higher education. On the one hand, opportunities have been created for researching constructivism in different learning environments. On the other hand, research of how students conceptualize knowledge, teaching, and learning may provide insight in how students experience these learning environments. 


\section{Overview of the studies}

The challenge for higher professional education is to facilitate innovative learning environments that enable students to master an integrated body of knowledge and to develop the necessary skills about learning how to learn and how to create knowledge. How students construct knowledge and how students learn are significant issues and research has provided evidence for constructivist approaches to education (Bostock, 1998; Hay \& Barab, 2001; Steffe \& Gale, 1995). Problem-based learning is commonly seen as a good example of a constructivist conception about teaching and learning (Savery \& Duffy, 1995; Taylor \& Miflin, 2008) and problem-based learning has been widely accepted as an approach to education and the curriculum (Hmelo-Silver, 2004; Neville \& Norman, 2007; Norman \& Schmidt, 2000; Taylor \& Miflin, 2008))

How students respond to the constructivist ideas about knowledge and learning and how they translate these ideas into their own conceptions of knowledge and learning is dealt with in the first line of research in this thesis (see figure 1). Students' epistemological beliefs and their conceptions about teaching and learning serve as a frame of reference from which students interpret the demands of the learning situation and these relatively stable and consistent conceptions guide students' learning activities (Entwistle \& Peterson, 2004; Lam \& Kember, 2006). What are the epistemological beliefs and conceptions of teaching and learning that students hold?

18 Do students express beliefs and conceptions that fit in a constructivist framework? Do students in the constructivist classroom endorse constructivist views about teaching and learning or do they still hold on to traditional ideas about teaching and learning?

The second line of research emerges from the criticism of constructivism on the transmissibility of knowledge. If knowledge cannot be transmitted from teacher to student what kind of worked-out alternatives are feasible? How do the abstract ideas of constructivism find expression in higher education? Which kind of learning environments can be characterized as constructivist and can we find evidence for constructivist pedagogy in these different learning environments? One of the main factors that drives student learning activities and motivation in learning environments like problem-based learning is the task. What are the characteristics of tasks and problems that function as the trigger for learning? 


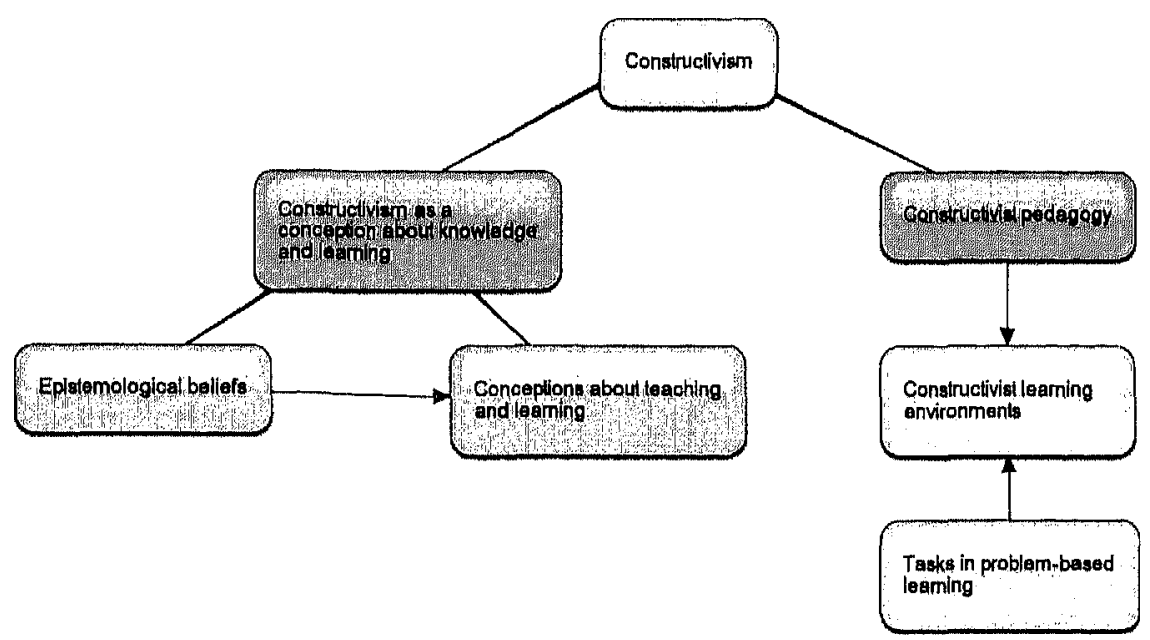

Figure 1: Context of the thesis

\section{Research on constructivism as a conception about knowledge and learning}

\section{Epistemological beliefs}

Epistemological beliefs are a psychological and educational construct and research has provided evidence for the conceptualization of epistemological beliefs as a multidimensional system of more or less independent beliefs (Schommer, 1993; 1994; Schommer-Aikins, 2002; 2004). Research by Chan and Elliott (2002; 2004) has yielded four dimensions of epistemological beliefs:

- The dimension innate/fixed ability that ranges from the belief in knowledge as inborn and fixed to the belief that knowledge is not inborn and changeable.

- The learning effort/process dimension ranges from the belief in learning by drill and practice to learning as a process of understanding and learning.

- The dimension authority/expert knowledge ranges from knowledge that is handed down by the teacher as an expert to knowledge that is created by personal experience.

- The certainty of knowledge dimension ranges from the belief that knowledge is unchangeable and certain to the beliefs that knowledge is changeable and uncertain.

Research of epistemological beliefs has acknowledged that the personal beliefs that students hold about knowledge and knowing influence self-directed learning and academic performance (Bråten \& Strømsø, 2004; 2005; Paulsen \& Feldman, 2005; 2007; Schommer, 1990; 1993; Schommer-Aikins \& Easter, 2006; Schraw \& Sinatra, 2004). 
Critical thinking and problem solving skills are essential for advancing knowledge construction in authentic, powerful learning environments (Cho, Schmelzer, \& McMahon, 2002; De Corte, 2000, Vosniadou, 2001, Wilson, 1996).

\section{Conceptions about teaching and learning}

By the time students enter higher education, they have experienced different teaching-learning environments through which they have developed a more or less coherent set of ideas about teaching and learning. Conceptions about teaching and learning are personal and generalized ways to describe students' ideas about good teaching and learning. Research of conceptions about teaching and learning has generated a division into two contrasting views: a traditional and a constructivist conception about teaching and learning (Samuelowicz \& Bain, 2001; 2002).

The traditional conception about teaching and learning is teacher-centered and content-oriented. The focus in the traditional conception is on knowledge transmission. Teaching is conceived as a unilateral process whereby knowledge is transmitted from the teacher to the students. The teacher is the expert who directs and controls student learning. The information transmission teacher-focused approach is generally associated with a surface approach to learning (Trigwell, Prosser, \& Waterhouse, 1999). The constructivist conception about teaching and learning is student-centered and learning-oriented. In the constructivist conception, emphasis is put on facilitation of learning and knowledge construction (Kember \& Gow, 1994). Students actively construct knowledge and are responsible for their own learning.

Chapter 2 examines the structural relationship between epistemological beliefs and conceptions about teaching and learning, and builds on prior research by Chan (2003), and Chan and Elliott (2002). Epistemological beliefs and conceptions of teaching and learning are important factors for learning and understanding. Constructivist learning environments like problem-based learning might advance epistemological development. A mismatch between the learning environment and students' beliefs and conceptions of knowledge and learning might have varied consequences for the quality of learning. Therefore, it is not only important to investigate which epistemological beliefs and conceptions of teaching and learning students hold, but also to investigate a possible structural relationships between these beliefs and conceptions.

First, the present study aims at contributing to the knowledge about epistemological beliefs and conceptions of teaching and learning by investigating if we can we find evidence for the multidimensionality of epistemological beliefs and to find out what epistemological beliefs students in higher education hold? The second research questions deals with students' conceptions about teaching and learning. Do students conceive teaching and learning from a constructivist perspective in which they engage 
in a self-regulated and collaborative process of knowledge construction or do students still conceptualize teaching and learning from a traditional point of view emphasizing the transmission of knowledge from the teacher to the students? How students' epistemological beliefs relate to their ideas or conceptions about teaching and learning may lead to better understanding of what and how students learn (Hofer, 2001). The third research question addresses the potential impact of students' epistemological beliefs on their conceptions about teaching and learning. How are the dimensions of epistemological beliefs related to conceptions about teaching and learning? Is it possible to establish structural relationships between dimensions of students' epistemological beliefs and their conceptions about teaching and learning?

In chapter 3, research of international hospitality management students' beliefs and conceptions may provide insight into two issues. First, the sample of international hotel management students, which is a part of the larger sample that was used for the analysis of the data in chapter two, is specifically useful for research into the cultural backgrounds of epistemological beliefs and the cross-cultural differences in epistemological beliefs. This study builds on prior research on cultural differences by Chan and Elliott (2002; 2004), and Qian and Pan (2002), and adds to our understanding of how international hospitality management students approach knowledge and learning issues. Second, the domain-specific nature of beliefs about knowledge and conceptions about teaching and learning has been an issue of research (Hofer, 2000; Muis, Bendixen, \& Haerle, 2006). In the study reported in chapter three, a sample of students from the field of hospitality will be used to investigate if domain generality or domain specificity is an issue in researching the relationship between epistemological beliefs and conceptions about teaching and learning.

\section{Constructivist pedagogy and problem-based learning}

\section{Chapter 4: Constructivist pedagogy in different learning environments} The principles of constructivism have got through to educational practices in higher education. One of the constructivist approaches to education that has widely gained recognition, especially in the fields of medicine and health sciences, is problem-based learning (Barrows \& Tamblyn, 1980; Hendry, Frommer, \& Walker, 1999; Savery \& Duffy, 1995). In its original conception, problem-based learning was designed for and introduced to the pre-clinical phase of the medical curriculum at McMaster University (Canada) almost forty years ago (Barrows \& Tamblyn, 1980). Since its introduction, many universities have introduced problem-based learning and various interpretations of PBL that deviate from the original whole curriculum concept have emerged (Taylor \& Miflin, 2008). 
Though problem-based learning is generally seen as an excellent example of constructivist pedagogy, other learning environments that use problems, cases, tasks or projects as stimuli for the learning process may also fit under the constructivist umbrella. Chapter 4 deals with the question if we can find evidence for constructivist pedagogy in four different learning environments? The research question will be approached from the student perspective and the perspective of instructional designers. The student perspective deals with the following research question: Is there a difference in the degree of constructivism as perceived by students between the four educational settings studied? Research from the instructional designer perspective focused on: Is there a difference in the degree of perceived implementation of constructivist principles between instructional designers involved in each of the four educational settings studied? The comparison between the student perspective and the instructional designer perspective leads to the final research question of this chapter. Is there a difference in the perceived degree of constructivism between students and instructional designers?

\section{Chapter 5: Tasks in problem-based learning}

Problem-based learning is an educational paradigm that is widely established in many academic fields and is recognized as a valuable approach to effective learning and competency development (Barrows \& Tamblyn, 1980; Schmidt, 1983). Problem-based learning as an integrated approach to the curriculum can be traced back to its origins

22 at McMaster University (Barrows \& Tamblyn, 1980; Taylor \& Miflin, 2008) and Maastricht University. Among the many institutions that have integrated problem-based learning in their curricula, Stenden University of Applied Sciences adopted the problem-based learning approach over twenty years ago. Problem-based learning was implemented in different fields of study from economics and business administration, and social studies to primary teacher education.

Effective constructivist learning environments are problem-based and involve active student engagement in the learning process by solving real-world problems (Merrill 2002). Problem-based learning revolves around learning from authentic, real-life tasks, situations and problems. In chapter 5 , the focus of research zooms in to one of the major elements of problem-based learning: the characteristics of the task. The starting point for the learning process is an authentic or real-life problem that is exemplary for a professional context (Jonassen, 2000). Tasks in PBL trigger, drive, and structure individual and collaborative learning. Students gain, apply, and evaluate knowledge by solving professional problems to gain insight in the broader problem field. Though descriptive studies on task characteristics and directions for finding and writing tasks are available, empirical studies on task characteristics are not widely available. 
Task analysis is one of the key factors of problem-based learning. The study that is reported in chapter 5 is exploratory in nature and aims the development of a questionnaire to identify factors that are characteristic for PBL-tasks. Moreover, the study might contribute to our knowledge about to the design and the evaluation of tasks in problem-based learning.

\section{Conclusions}

The present thesis consists of a series of empirical studies, which examine constructivism as a conception of knowledge, learning and teaching. Students' epistemological beliefs, conceptions of teaching and learning, and the relationship between beliefs and conceptions will be investigated in chapter 2 and 3 . Research of constructivist learning environments will focus on two issues. In the study in chapter 4, evidence will be searched for constructivist pedagogy in different learning environments. The study in chapter 5 investigates an important driver of student learning in constructivist learning environments: the characteristics of tasks. 


\section{References}

Akkerman, S., Van den Bossche, P., Admiraal, W., Gijselaers, W., Segers, M., Simons, R-J., \& Kirschner, P. (2007). Reconsidering group cognition: From conceptual confusion to a boundary area between cognitive and socio-cultural perspectives? Educational Research Review, 2(1), 39-63.

Anderson, J. R., Greeno, J. G., Reder, L. M., \& Simon, H. A. (2000). Perspectives on Learning, Thinking, and Activity. Educationa/ Researcher, 29(4), 11-13.

Bereiter, C. (2002a). Artifacts, canons, and the progress of pedagogy: A response to contributors. In B. Smith (Ed.), Liberal Education in a Knowledge Society (pp. 223-244). Chicago: Open Court Publishing Company.

Bereiter, C. (2002b). Education and Mind in the Knowledge Age. Mahwah: Lawrence Erlbaum Associates.

Bereiter, C., Cassells, C., \& Hewitt, J. (1997). Postmodernism, knowledge building, and elementary science. Elementary School Journal, 97, 329-340.

Bickhard, M. H. (1993). On why constructivism does not yieid relativism. Journal of Experimental and Theoretical Artificial Intelligence, 5, 275-284.

Bickhard, M. H. (1997). Constructivisms and relativisms: A shopper's guide. Science and Education, 6, 29-42.

Bereiter, C. (1994). Constructivism, Socioculturalism, and Popper's World 3. Educational Researcher, 23(7), 21-23.

24 Billett, 5. (1996). Situated learning: Bridging sociocultural and cognitive theorizing. Learning and Instruction, 6(3), 263-280.

Bostock, S. J. (1998). Constructivism in mass higher education: a case study. British Journal of Educational Technology، 29(3), 225-240.

Bråten, I., \& Strømsø, H. I. (2004). Epistemological beliefs and implicit theories of intelligence as predictors of achievement goals. Contemporary Educational Psychology, 29, 371-388.

Bråten، I.، \& Strømsø, H. I. (2005). The relationship between epistemological beliefs, implicit theories of intelligence, and self-regulated learning among Norwegian postsecondary students. British Journal of Educational Psychology, 75, 539-565.

Chan, K-W. (2003). Hong Kong teacher education students' epistemological beliefs and approaches to learning. Research in Education, 69(1), 36-50.

Chan, K-W., \& Elliott, R. G. (2002). Exploratory study of Hong Kong teacher education students' epistemological beliefs: cultural perspectives and implications on beliefs research. Contemporary Educational Psychology, 27, 392-414.

Chan, K-W., \& Elliott, R. G. (2004). Relational analysis of personal epistemology and conceptions about teaching and learning. Teaching and Teacher Education, 20, 817-831.

Cho, W., Schmelzer, C. D., \& McMahon, P. S. (2002). Preparing Hospitality Managers for the 21st century: education, critical thinking, and collaborative learning. Journal of Hospitality \& Tourism Research, 26(1), 23-37. 
Colliver, J. A. (1999) Constructivism with a dose of pragmatism: A Cure for What Ails Educational Research. Advances in Health Sciences Education, 4, 187-190.

Davis, B., \& Sumara, D. (2002). Constructivist discourses and the field of education: Problems and possibilities. Educational Theory, 52(4), 409-428.

De Corte, E. (1995). Fostering cognitive growth: A perspective from research on mathematics learning and instruction. Educational Psychologist, 30(1), 37-46.

De Corte, E. (2000). Marrying theory building and the improvement of school practice: a permanent challenge for instructional psychology. Learning and Instruction, 10(3), 249-266.

Dochy, F., Segers, M., Van den Bossche, P., \& Gijbels, D. (2003). Effects of problem-based learning: a metaanalysis. Learning and Instruction, 13, 533-568.

Eklund-Myrskog, G. (1998). Students' conceptions of learning in different educational contexts. Higher Education, 35, 299-316.

Entwistle, N. J., \& Peterson, E. R. (2004). Conceptions of learning and knowledge in higher education: Relationships with study behaviour and influences of learning environment. International Journal of Educational Research, 41(6), 407-428.

Ernest, P. (1991). The Philosophy of Mathematics Education. London: The Falmer Press.

Ernest, P. (1995). The one and the many. In L. P. Steffe \& J. Gale (Eds.), Constructivism in Education (pp. 459-486). Hillsdale: Lawrence Erlbaum Associates.

Fitzgerald, J., \& Cunningham, J. W. (2002) Mapping basic issues for identifying epistemological outlooks. In B. K. Hofer \& P. R. Pintrich (Eds.), Personal Epistemology: The Psychology of Beliefs about Knowledge and Knowing (pp. 209-228). Mahwah: Lawrence Erlbaum Associates

Fleury, S. C. (1998). Social studies, trivial constructivism, and the politics of social knowledge. In M. Larochelle, N. Bednarz \& J. Garrison (Eds.), Constructivism and Education (pp. 156-172). Cambridge: Cambridge University Press.

Freire, P. (1972). Pedagogy of the Oppressed. Harmondsworth: Penguin Books.

Geelan, D. R. (1997). Epistemological anarchy and the many forms of constructivism. Science \& Education, 6, 15-28.

Gordon, M. (2009). Toward a pragmatic discourse of constructivism: Reflections on lessons from practice. Educational Studies, 45(1), 39-58.

Hay, D., Kinchin, I., \& Lygo-Baker, 5. (2008). Making learning visible: the role of concept mapping in higher education. Studies in Higher Education, 33(3), 295-311.

Hay, K. E., \& Barab, S. A. (2001). Constructivism in practice: A comparison and contrast of apprenticeship and constructionist learning environments. The Journal of the Learning Sciences, $10(3), 281-322$.

Hejl, P. M., \& Stahl, H. K. (2000): Management und Wirklichkeit. Das Konstruieren von Unternehmen, Märkten und Zukünften. Heidelberg: Carl-Auer-Systeme Verlag.

Hendry, G. D., Frommer, M., \& Walker, R. A. (1999). Constructivism and problem-based learning. Journal of Further and Higher Education, 23(3), 359-371.

Hidi, S., \& Harackiewicz, J. M. (2000). Motivating the academically unmotivated: A critical issue for the 21st century. Review of Educational Research, 70(2), 151-179. 
Hmelo-Silver, C. (2004). Problem-based learning: What and how do students learn? Educational Psychology Review, 16(3), 235-266.

Hofer, B. K. (2000). Dimensionality and disciplinary differences in personal epistemology. Contemporary Educational Psychology, 25, 378-405.

Hofer, B. K. (2001). Personal epistemology research: Implications for learning and teaching. Journal of Educational Psychology Review, 13(4), 353-383.

Hofer, B. K., \& Pintrich, P. R. (1997). The development of epistemological theories: beliefs about knowledge and knowing and their relation to learning. Review of Educational Research, 67(1), 88-140.

Howe, K. R., \& Berv. J. (2000). Constructing constructivism, Epistemological and pedagogical. In D. C. Phillips (Ed.), Constructivism in Education. Opinions and Second Opinions on Controversial Issues. Ninety-ninth Yearbook of the National Society for the Study of Education. Part 1 (pp. 19-40) Chicago: The University of Chicago Press.

Järvelä, S., \& Niemivirta, M. (1999). The changes in learning theory and the topicality of the recent research on motivation. Research Dialogue in Learning and Instruction, 1(2), 57-65.

Jensen, 5. (1999). Erkenntnis - Konstruktivismus - Systemtheorie. Einführung in die Philosophie der Konstruktivistischen Wissenschaft. Opladen/Wiesbaden: Westdeutscher Verlag.

Jonassen, D. H. (2000). Toward a design theory of problem solving. Educational Technology Research and Development, 48(4), 63-85.

Kember, D., and Gow, L. (1994). Orientations to teaching and their effect on the quality of student learning. Journal of Higher Education, 65(1), 58-74.

26 Kuhn, D. (2007). is direct instruction the answer to the right question? Educational Psychologist, 42(2), 109-113.

Kukla, A. (2000). Social Constructivism and the Philosophy of Science. London \& New York: Routledge.

Lam, B-H., \& Kember, D. (2006). The relationship between conceptions of teaching and approaches to teaching. Teachers and Teaching: Theory and Practice, 12(6), 693-713.

Lave, J., \& Wenger, E. (1991). Situated Learning. Legitimate Peripheral Participation. Cambridge: Cambridge University Press.

Lindemann, H., \& Vossler, N. (1999). Die Behinderung liegt im Auge des Betrachters. Konstruktivistisches Denken für die pädagogische Praxis. Neuwied: Luchterhand Verlag.

Marlowe, B. A., \& Page, M. L. (1998). Creating and Sustaining the Constructivist Classroom. Thousand Oaks: Corwin Press.

Matthews, M. R. (1997). Introductory comments on philosophy and constructivism in science education. Science \& Education, 6, 5-14.

Matthews, M. R. (Ed.), (1998). Constructivism in Science Education. A Philosophical Examination. Dordrecht: Kluwer Academic Publishers.

Maturana, H. R. (1988). Reality: The search for objectivity or the quest for a compelling argument. The Irish Journal of Psychology, 9(1), 25-82.

Maturana, H. R., \& Varela, F. J. (1980). Autopoiesis and Cognition. The Realization of the Living. Dordrecht: Reidel. 
Maturana, H. R., \& Varela, F. J. (1987). The Tree of Knowledge. The Biological Roots of Human Understanding. Boston: New Science Library.

Merrill, M. D. (2002) First principles of instruction. Educational Technology, Research, and Development, 50(3), 43-59.

Morf, A. (1998). An epistemology for didactics: Speculations on situating a concept. In M. Larochelle, N. Bednarz \& J. Garrison (Eds.), Constructivism and Education. (pp. 29-42). Cambridge: Cambridge University Press.

Muis, K. R., Bendixen, L. D., \& Haerle, F. C. (2006). Domain-generality and domain-specificity in personal epistemology research: Philosophical and empirical questions in the development of a theoretical model. Educational Psychology Review, 18(1), 3-54.

Neville, A. J., \& Norman, G. R. (2007). PBL in the undergraduate MD program at McMaster University: Three iterations in three decades. Academic Medicine, 82(4), 370-374.

Norman, G. R., \& Schmidt, H. G. (2000). Effectiveness of problem-based learning curricula. Medical Education, 34, 721-728.

Paulsen, M. B., \& Feldman, K. A. (2005). The conditional and interaction effects of epistemological beliefs on the self-regulated learning of college students: Motivational strategies. Research in Higher Education, 46(7), 731-768.

Paulsen, M. B., \& Feldman, K. A. (2007). The conditional and interaction effects of epistemological beliefs on the self-regulated learning of college students: Cognitive and behavioral strategies. Research in Higher Education, 48(3), 353-401.

Peschl, M. F., \& Riegler, A. (1999). Does representation need reality? Rethinking epistemological issues in the light of recent developments and concepts in cognitive science. In A. Riegler, $M$. Peschl \& A. von Stein (Eds.), Understanding Representation in the Cognitive Sciences. Does Representation Need Reality? (pp. 9-17). New York: Kluwer Academic/ Plenum Publishers.

Petraglia, J. (1998). Reality by Design. The Rhetoric and Technology of Authenticity in Education. Mahwah: Lawrence Erlbaum Associates.

Phillips, D. C. (1995). The Good, the Bad, and the Ugly: The Many faces of Constructivism. Educational Researcher, 24(7), 5-12.

Phillips, D. C. (2000). An opinionated account of the constructivist landscape. In D. C. Phillips (Ed.), Constructivism in Education. Opinions and Second Opinions on Controversial Issues. Ninety-ninth Yearbook of the National Society for the Study of Education. Part 1 (pp. 1-16). Chicago: The University of Chicago Press.

Plato, (360 BC). The Republic. Retrieved May 21, 2009, from http://classics.mit.edu/Plato/republic.8.vii.html

Prawat, R. S. (1996). Constructivisms, modern and postmodern. Educational Psychologist, 31(3/4), 215-225.

Roth, G. (1992), Das konstruktive Gehirn: Neurobiologische Grundlagen von Wahrnehmung und Erkenntnis. In S. J. Schmidt (Hrsg.), Kognition und Gesellschaft. Der Diskurs des Radikalen Konstruktivismus 2 (pp. 68-75). Frankfurt am Main: Suhrkamp Verlag.

Rowlands, S., Graham, T., \& Berry, J. (2001) An Objectivist Critique of Relativism in Mathematics Education. Science \& Education, 10 (3), $215-241$. 
Salomon, G. (1998). Novel constructivist learning environments and novel technologies: some issues to be concerned with. Research Dialogue in Learning and Instruction, 1(1), 3-12.

Samuelowicz, K., \& Bain, J. D. (2001). Revisiting academic's beliefs about teaching and learning. Higher Education, 47, 299-325.

Samuelowicz, K., \& Bain, J. D. (2002). Identifying academics' orientations to assessment practice. Higher Education, 43, 173-201.

Savery, J. R., \& Duffy, T. M. (1995). Problem based learning: An instructional model and its constructivist framework. Educational Technology, September-October, 31-38.

Schmidt, H. G. (1983). Problem-based learning: rationale and description. Medical Education, 17, $11-16$.

Schommer, M. (1990). Effects of beliefs about the nature of knowledge on comprehension. Journal of Educational Psychology, 82(3), 498-504.

Schommer, M. (1993). Epistemological development and academic performance among secondary students. Journal of Educational Psychology, 85(3), 406-411.

Schommer, M. (1994). Synthesizing epistemological belief research: Tentative understandings and provocative confusions. Educational Psychology Review, 6(4), 293*319.

Schommer-Aikins, M. (2002). An evolving theoretical framework for an epistemological belief system. In B. K. Hofer \& P. R. Pintrich (Eds.), Personal epistemology: The psychology of beliefs about knowledge and knowing (pp. 103-118). Mahwah, NJ: Lawrence Erlbaum Associates. Schommer-Aikins, M. (2004). Explaining the epistemological belief system: Introducing the embedded systemic model and coordinated research approach. Educational Psychologist, 39(1), 19-29.

Schommer-Aikins, M., \& Easter, M. (2006). Ways of knowing and epistemological beliefs: Combined effect on academic performance. Educational Psychology, 26(3), 411-423.

Schraw, G., \& Sinatra, G. M. (2004). Epistemological development and its impact on cognition in academic domains. Contemporary Educational Psychology, 29, 95-102.

Simons, R-J., \& Bolhuis, S. (2004). Constructivist learning theories and complex learning environments. In R. H. Mulder \& P. F. E. Sloane (Eds.), New approaches to vocational education in Europe: The construction of complex learning-teaching arrangements (pp. 13-25). Oxford: Symposium Books.

Steffe, L. P., \& Gale J. (Eds.), (1995). Constructivism in Education. Hillsdale: Lawrence Erlbaum Associates.

Taylor, D., \& Miflin, B. (2008). Problem-based learning: Where are we now? Medical Teacher, $30(8)$, 742-763.

Trigwell, K., Prosser, M., \& Waterhouse, F. (1999). Relations between teachers' approaches to teaching and students' approaches to learning. Higher Education, 37, 57-70.

Vosniadou, S. (2001). How children learn. Brussels/Geneva: International Academy of Education/International Bureau of Education.

Von Glasersfeld, E. (1992). Konstruktion der Wirklichkeit und des Begriffs der Objektivität. In H. Gumin \& H. Meier, (Hrsg.), Einführung in den Konstruktivismus (pp. 9-39). München: Piper Verlag. 
Von Glasersfeld, E. (1993). Learning and adaptation in the theory of constructivism.

Communication \& Cognition, 26(3/4), 393-402.

Von Glasersfeld, E. (1995). Radical Constructivism: A way of Knowing and Learning. London: The Falmer Press.

Von Glasersfeld, E. (1998). Why constructivism must be radical, In M. Larochelle, N. Bednarz \& J. Garrison (Eds.), Constructivism in education (pp. 23-28). Cambridge, UK: Cambridge University Press.

Von Glasersfeld, E. (2000). Problems of constructivism. In L. P. Steffe \& P. W. Thompson (Eds.), Radical Constructivism in Action. Building on the Pioneering Work of Ernst von Glasersfeld (pp. 3-9). London: Routledge Falmer.

Von Glasersfeld, E. (2001). Universalien als Konstruktion. In P. M. Hejl (Hrsg.), Universalien und Kon struktivismus (pp. 68-75). Frankfurt am Main: Suhrkamp Verlag.

Von Glasersfeld, E. (2005). Thirty years of radical constructivism. Constructivist Foundations, $1(1)$, 9-18.

Von Glasersfeld, E., \& Ackermann, E. (1997). Dialoge - Heinz von Foerster, zum 85. Geburtstag. In A. Müller, K. H. Müller \& F. Stadier (Hrsg.), Konstruktivismus und Kognitionswissenschaft. Kulturelle Wurzeln und Ergebnisse. Heinz von Foerster gewidmet (pp. 43-55). Wien/New York: Springer Verlag.

Von Krogh, G., \& Roos, J. (1995). Organizational Epistemology. New York: St. Martin's Press.

Windschitl, M. (2002). Framing constructivism in practice as the negotiation of dilemmas: An analysis of the conceptual, pedagogical, cultural, and political challenges facing teachers. Review of Educational Research, 72(2), 131-175.

Wilson, B. G. (Ed.), (1996). Constructivist Learning Environments. Case Studies in Instructional Design. Englewood Cliffs: Educational Technology Publications. 


\section{The structural relationship between students" epistemological beliefs and conceptions of teaching and learning}

Otting, H., Zwaal, W., Tempelaar, D., \& Gijselaers, W. The structural relationship between students' epistemological beliefs

and conceptions of teaching and learning Accepted for publication (2010) in: Studies in Higher Education 


\begin{abstract}
The aim of the present study was to explore the relationship between students' epistemological beliefs and conceptions of teaching and learning. The results showed that the epistemological beliefs dimension learning effort/process was positively related to the constructivist conception of teaching and learning and was negatively related to the traditional conception of teaching and learning. The relationships that we established between the learning effort/process, expert knowledge, and certainty of knowledge dimensions of epistemological beliefs and the conceptions about teaching and learning are in line with our university's constructivist philosophy of education. Students seem to recognize the importance of self-directed and collaborative learning by solving authentic tasks in a problem-based learning environment. Consequently, students who do not believe in teachers as a main source of expertise tend to have constructivist conceptions of teaching and learning.
\end{abstract}

Keywords: epistemological beliefs, conceptions of teaching and learning, constructivism, problem-based learning. 


\section{Introduction}

Technological, economical, and organizational innovations have led to rapid and profound change in today's global society. Innovation is of vital importance for successful competition in a global environment and continuous change has become the constant value in the workplace. The competency of employees to acquire and apply relevant knowledge in the workplace is becoming more and more important as a major factor contributing to business success. It is not only in the company's interest to develop and use the human talent to increase business performance, but also in the employee's interest to develop competencies that increase their expertise and employability (Thijssen \& Vernooij, 2004). Today's professional work demands continuous development of expertise in a process of lifelong learning (Tynjälä, 1999). Lifelong learning has become an essential competency for the personal and professional advancement in a knowledge society. The challenge for higher education is to facilitate learning processes that enable students to construct and reconstruct knowledge, and to master an integrated body of knowledge and skills that is relevant to the professional workplace. However, higher education's contribution to a knowledge-intensive society surpasses the mere transfer of professional knowledge and skills, and aims at the continuous creation of new knowledge and the application of knowledge to professional practice. How students construct knowledge, how students learn, and the beliefs that students hold about what kind of knowledge and knowing really counts are becoming major issues for higher education.

Research of the beliefs that students hold about the nature of knowledge and knowing and how these epistemological beliefs relate to their ideas of teaching and learning may lead to better understanding of how to further students' intellectual development and learning (Hofer, 2001). In a comprehensive review of research on epistemological theories, Hofer and Pintrich (1997) proposed a framework that restricts personal epistemology to two general areas of epistemological theories: the nature of knowledge and the nature of knowing.

1. The nature of knowledge concerns the beliefs an individual has about what knowledge is. In this area fall two dimensions: certainty of knowledge and simplicity of knowledge. Certainty of knowledge ranges from the belief that knowledge is fixed and absolute to the belief that knowledge is more fluid and evolving. Simplicity of knowledge covers a view of knowledge as a continuum from isolated facts to interrelated concepts.

2. The nature of knowing concerns the beliefs a person has about how people acquire knowledge. This area of knowing is divided into two dimensions: source of knowledge and justification of knowledge. The source of knowledge ranges from 
knowledge as a transmission process to knowledge as a process of active construction of meaning. Justification of knowledge deals with the evaluation of knowledge claims, the use of evidence and the role of experts and authority.

Research on epistemological beliefs has yielded better understanding of students' ideas about knowledge and knowing (Hofer \& Pintrich, 1997; 2002). Epistemological beliefs predict numerous aspects of students' academic performance including comprehension, cognition in different academic domains, motivation, and self-regulated learning (Bråten \& Strømsø, 2004; 2005; Paulsen \& Feldman, 2005; 2007; Schommer, Crouse, \& Rhodes, 1992; Schommer-Aikins \& Easter, 2006; Schraw \& Sinatra, 2004). Research in the field of educational psychology recognizes that academic contexts influence the gradual development of students' epistemological beliefs from more naìve to more sophisticated (Schommer, 1990; 1993). For example, Vermunt and Verschaffel (2000) demonstrated that it is important that students participate in teaching-learning environments that foster active knowledge construction by collaborative problem solving to further the development of students' beliefs about knowledge. How students deal with new information, how they learn and gain understanding of curriculum content depends greatly on their beliefs about knowledge and knowing. For example, students, who view knowledge and knowing as an active construction process, experience learning environments and approach learning tasks differently than students, who believe that knowledge is certain and handed down by authorities (Muis,

34 Bendixen, \& Haerle, 2006). It is generally recognized that higher education contributes to the development of epistemological beliefs and affects various aspects of student learning (Perry, 1970; Schommer-Aikins \& Easter, 2006). However, the majority of studies into epistemological beliefs took place in traditional learning environments in which teachers as subject experts select relevant educational contents, teach and instruct students, and steer their learning towards predetermined goals. Research of epistemological beliefs in a constructivist learning context is not widely available (Stathopoulou \& Vosniadou, 2007).

The present study aims at contributing to the knowledge about the relationship between epistemological beliefs and conceptions of teaching and learning in a constructivist educational context. Problem-based learning (PBL) is generally considered as one of the best examples of constructivist education (Savery, 2006; Savery \& Duffy, 1996). PBL not only contributes to the improvement of students' problem solving skills and leads to more profound understanding of subject matter but may also positively influence the development of students' epistemological beliefs. What are the epistemological beliefs that students hold and how do these beliefs relate to their conceptions of teaching and learning? Are students' epistemological beliefs and conceptions of teaching and learning in line with the constructivist principles that underlie problem-based learning? 


\section{Conceptual framework}

\section{Epistemological beliefs}

Perry (1970) was one of the first to address the issue of the development of epistemological beliefs. Epistemological beliefs are a core set of beliefs about knowledge and knowing. Perry's research focused on how students' epistemological beliefs develop during the years in higher education. He found that students' beliefs about knowledge develop from simple and certain to complex and relativistic. Students with naïve epistemological beliefs are more likely to hold beliefs that knowledge is simple and unchanging, whereas students with a more sophisticated personal epistemology believe that knowledge is uncertain and complex. Building on Perry's work, two main clusters of research on epistemological beliefs can be distinguished. The first cluster concerns a group of researchers that supports a one-dimensional, developmental approach to epistemological beliefs and pre-supposes a hierarchically organized system of epistemological beliefs. Students' personal beliefs systematically develop from less to more sophisticated beliefs. Students move from an objectivist position, an unquestioned view of truth as right or wrong, through a relativistic position allowing for uncertainty and diversity, to a more balanced position recognizing intellectual and ethical commitment to diversity and uncertainty (Hofer, 2002; Moore, 2002; Pintrich, 2002). The second group of researchers conceptualizes personal epistemology as a system of multidimensional epistemological beliefs that are more or less independent from one another and may develop asynchronously. The multidimensional conception of epistemological beliefs includes both beliefs about knowledge and beliefs about learning (Schommer, 1990; 1993; 1994; Schommer-Aikins, 2002; 2004; Schommer-Aikins \& Easter, 2006). Both the developmental model and the multidimensional model contribute to a better understanding of personal epistemology. In the present study, we take Schommer's approach to personal epistemology as a system of independent beliefs as a point of departure for research.

Schommer (1990) developed a questionnaire that fits the theoretical framework for measuring the multidimensionality of epistemological beliefs and contains 12 subsets of in total 63 items measuring students' preferences to statements about knowledge and learning. Research with Schommer's questionnaire for measuring epistemological beliefs supports the multidimensionality of epistemological beliefs but could not confirm the initially hypothesized five factor structure (Schommer, 1990; 1993). Inconsistent findings were reported about the exact number and nature of the dimensions of epistemological beliefs. Moreover, criticism arose about the methodological soundness of the instrument and its applicability in different cultural and educational contexts (Chan \& Elliott, 2004b; Clarebout, Elen, Luyten and Bamps, 
2001; Hofer, 2000). For instance, Chan's (2000) analysis of Schommer's epistemological beliefs questionnaire casted doubt on the validity and reliability of the scale and also showed that the 12 subsets of items did not load on the proposed subscales. He found insufficient support for the applicability of Schommer's questionnaire in the context of teacher education in Hong Kong. Validation of the epistemological beliefs questionnaire in different cultural and educational contexts is still an issue for further research. Notwithstanding the criticism on Schommer's questionnaire, the development of a paper-and-pencil instrument measuring epistemological beliefs has enabled research into the relation between epistemological beliefs and learning approaches (Hofer, 2001; Rodriguez \& Cano, 2006; 2007).

Quantitative research on epistemological beliefs confirmed the multidimensionality of epistemological beliefs but no consensus could be established on the number and the labels of the hypothesized dimensions (Brăten \& Strømsø, 2005; Cano, 2005; Hofer, 2000; Jehng, Johnson, \& Anderson, 1993; Schraw, Bendixen, \& Dunkle, 2002; Strømsø \& Bråten, 2003). Several researchers adapted and revised the epistemological beliefs questionnaire (Qian \& Alvermann, 1995; Wood \& Kardash, 2002). For instance, Chan (2000) modified and refined Schommer's instrument for measuring epistemological beliefs by exploratory and confirmatory factor analysis, which resulted in the identification of a 30-item questionnaire. He distinguished four dimensions of epistemological beliefs:

36 1. The dimension innate/fixed ability ranges from the belief in knowledge as inborn and fixed to the belief that knowledge is not inborn and changeable.

2. Learning effort/process dimension refers to the belief in learning by drill and practice at one end or learning as a process of understanding and learning how to learn at the other.

3. The dimension authority/expert knowledge ranges from knowledge being handed down by experts to knowledge being created from personal experience and justification.

4. The certainty of knowledge dimension refers to the belief that knowledge is unchangeable and certain at one end or knowledge as changeable and uncertain at the other.

Successful validation of the Epistemological Beliefs Questionnaire (EBQ), confirmation of the same four factor structure and consistent findings of research show the applicability of the instrument in the Hong Kong context (Chan, 2003; 2008). However, research with the EBQ in other cultural and educational contexts is unavailable. This calls for research with the EBQ in other contexts. In this study, we will examine students' epistemological beliefs in a Western cultural context and a problem-based learning environment. 


\section{Conceptions of teaching and learning}

The conceptions that students hold about what constitutes good teaching and learning influence how they approach learning tasks (Brownlee, Purdie, \& Boulton-Lewis, 2003). Students' conceptions of teaching and learning have implications for how students conceive the learning process and influence the quality of the learning outcomes (Lonka, Joram, \& Bryson, 1996; Trigwell \& Ashwin, 2006). Studies on conceptions of teaching and learning usually assume a hierarchical structure of the teaching and learning conceptions. For instance, Van Rossum and Hamer (2006) describe six qualitatively different learning and teaching conceptions that build on studies by Kember (1997), Samuelowicz and Bain (2001), and Van Rossum, Deijkers, and Hamer (1985). The teaching and learning conceptions that are described in table 1 clearly show the hierarchical and relational structure between conceptions of learning and conceptions of teaching.

Table 1: Learning and teaching conceptions based on Van Rossum and Hamer (2006)

\begin{tabular}{lll}
\hline & Conception of learning & Conception of teaching \\
\hline Conception 1 & Increase of knowledge & Well-structured lectures \\
Conception 2 & Memorizing & Lectures with opportunities for questions \\
Conception 3 & Memorizing and application & Interactive lectures \\
Conception 4 & Understanding subject matter & Coaching and facilitation \\
Conception 5 & Understanding reality & Dialogue \\
Conception 6 & Self-realization & Inspiration \\
\hline
\end{tabular}

The boundaries between Van Rossum and Hamer's (2006) teaching-centered conceptions 1, 2, and 3 and learning-centered conceptions 4, 5, and 6 are relatively hard whereas the boundaries within the two groups are relatively soft, which indicates the existence of two broad but quite distinct conceptions: a student-centered approach focusing on knowledge construction processes and a teacher-focused, content-oriented knowledge transmission approach. For example, Samuelowicz and Bain (2001; 2002) clearly distinguish two contrasting groups - teaching-centered and learning-centered and consider the boundary between these two groups as hard. Conversely, Kember (1997) stressed the need to experiment with co-operative forms of teaching and learning as an in-between position to bridge the gap between the two conceptions. However, Samuelowicz and Bain $(2001 ; 2002)$ could not find evidence for the teacher-student interaction position as a hybrid position between the two opposing categories, which was proposed in their previous five-level classification of teaching and learning orientations (Samuelowicz \& Bain, 1992). The traditional, teacher-centered and the constructivist, student-centered conceptions are often portrayed as opposite 
poles on a continuum and are often considered as incompatible. However, it has been questioned if both conceptions really represent conflicting positions. Elen, Clarebout, Léonard, and Lowyck (2007) argued that the student-centered and teacher-centered conceptions emphasize fundamental different tasks and responsibilities of teachers and students in the learning process, which implies that there is no continuum between student-centeredness and teacher-centeredness. Both conceptions concentrate on different aspects of the teaching-learning environment and must be seen as complementary rather than as oppositional (Cronjé, 2006). Consequently, the question arises if students can be consistently classified on the dichotomy of traditional-constructivist conceptions of teaching and learning or is it conceivable that students have mixed conceptions of teaching and learning?

Many learning environments in higher professional education focus on authentic tasks and problems to stimulate students to engage in active and cooperative learning activities. The development of these learning environments has been inspired by the rise of constructivism as a perspective on knowledge and learning with clear implications for a student-directed focus on education. Constructivist learning environments are more or less an umbrella for a variety of case-, project-, or problem-based learning environments that have several common characteristics. In constructivist learning environments, students are confronted with descriptions of real-life situations requiring thorough analysis and problem solving skills. Students

38 explore the problem context or project space and make a representation of the problem. They search for multiple solution paths, test and reflect on relevant solutions for the problem situation (Jonassen, Hernandez-Serrano, \& Choi, 2000). Constructivist learning environments are comprehensive frameworks in which students collaborate with other students, use meaningful tasks and authentic materials, and are encouraged to become active learners. These learning environments promote constructive, cumulative, goal-oriented, and self-regulated learning processes (De Corte, 1995; 2000; Vosniadou, 2001). However, constructivist learning environments place great demands on students' competencies for self-directed and collaborative learning, and the success of educational innovations like problem-based learning depends on how students perceive education. Their conceptions of teaching and learning are built up through the years of experience in education and their exposure to different learning situations. If students' conceptions of teaching and learning remain unchanged by the exposure to constructivist learning environments it can be questioned if educational innovations, which build on constructivist ideas about education, may bring about the desired effects on student learning processes and outcomes. Even if the basic concepts correspond with the current Zeitgeist in educational psychology, which is constructivist in nature, the success of innovations will be impeded if conceptions of teaching and learning of both teachers and students remain untouched (Lonka, Joram, \& Bryson, 1996). 
Research on conceptions of teaching and learning mainly focused on the teacher (Kember, 1997; Samuelowicz \& Bain, 1992; Trigwell, Prosser, \& Waterhouse, 1999) or the student teacher (Chan, 2001; 2004; Chan, Tan, \& Khoo, 2007). However, students' conceptions of teaching and learning seem be influenced by cultural context and academic practices. For instance, research of pre-service teachers' conceptions of teaching and learning in different cultural and educational contexts reflected possible influences of the different contexts on students' conceptions. Chan (2001) found that student teachers in the Hong Kong context are generally more inclined to a traditional than a constructivist conception. Contrary, research with the same instrument in a Singapore cultural and educational context showed that teacher education students mainly endorse a constructivist conception. A possible explanation might be that the change of the education system in Singapore from a teacher-focused to a student-centered pedagogy is reflected in the teachers' education students' inclination towards a constructivist conception of teaching and learning. It is conceivable that research in a problem-based learning environment might reveal the influence of the underlying constructivist learning principles on students' conceptions of teaching and learning.

Research on epistemological beliefs, conceptions of teaching and learning, and the teaching-learning environment

One of the central issues in the study of epistemological beliefs is the potential impact of students' epistemological beliefs on their conceptions of teaching and learning. Epistemological issues regarding the nature and justification of human knowledge find their relevance in confrontation with educational practice. Students' epistemological beliefs and conceptions of teaching and learning develop by participating in educational practices. Research offers insight in the relation between students' epistemological beliefs and their preferences toward certain learning environments. For instance, Tsai (2000), and Tsai and Chuang (2005) found that students with constructivist beliefs about knowledge and learning showed preference toward learning environments where they could apply prior knowledge to open-ended tasks. Students with constructivist beliefs like group work and inquiry learning. Therefore, it is interesting to establish if agreement exists between a constructivist learning environment and students' epistemological beliefs and conceptions of teaching and learning.

The alignment between teaching-learning environment and students' epistemological beliefs and conceptions of teaching and learning seems to be an important factor for successful learning and understanding of subject matter (Eklund-Myrskog, 1998; Trigwell \& Ashwin, 2006). Explicit exposure to and discussion of the constructivist 
principles of problem-based learning might advance epistemological development. For instance, Conley, Pintrich, Vekiri, and Harrison (2004) reported that learners in a constructivist classroom developed more sophisticated epistemological beliefs than learners in a traditional classroom. Students' ideas about education and previous learning experiences do not always fit the demands of the learning environment. Therefore, it is important to investigate if students' epistemological beliefs and conceptions of teaching and learning are consistent with the demands of the learning environment. A mismatch between the teaching-learning environment and the students' conceptions of knowledge and learning might have a negative impact on the quality of student learning (Kinchin, 2004; Mamede, Schmidt, \& Geoffrey, 2006). If the teaching-learning environment does not correspond with the students' beliefs and conceptions, students may experience varied consequences for the quality of learning and in-depth understanding of subject matter. However, there is a gap at present in our understanding of how students' epistemological beliefs relate to and interact with their conceptions of teaching and learning and therefore research on the relationship between epistemological beliefs and conceptions of teaching and learning is needed.

Chan (2004), and Chan and Elliott (2004a) explored the structural relationships between students' beliefs of knowledge and their conceptions of teaching and learning in the context of teacher education. Significant paths were established between students' epistemological belief in learning effort/process and the constructivist conception of

40 teaching and learning, and between the epistemological beliefs, innate/fixed ability, authority/expert knowledge, certainty of knowledge, and the traditional conception of teaching and learning. Chan and Elliott (2002, 2004a) assume that the educational and cultural contexts influence the development of epistemological beliefs. However, research on the relation between epistemological beliefs and conceptions of teaching and learning in a Western cultural and educational context still needs exploration. The educational context in the present study is a problem-based learning environment. Problem-based learning requires students to manage their own learning process and to attain self-determined learning goals by actively constructing knowledge. The present study aims at establishing the structural relationship between students' epistemological beliefs and conceptions of teaching and learning in a problem-based learning environment. The first research question regards the students' epistemological beliefs and conceptions of teaching and learning. What are the epistemological beliefs and conceptions of teaching and learning held by the students in our sample? The second research question tries to establish the relationship between students' epistemological beliefs and conceptions of teaching and learning. How are the dimensions of epistemological beliefs related to conceptions of teaching and learning? 


\section{Research method}

\section{Participants}

The participants in the study were 617 students from nine different bachelor programs of a middle-sized University of Applied Sciences in the North of the Netherlands. The majority of the students in this study were from the Netherlands $(85 \%)$. The international students (15\%) were from a variety of countries in Europe, Americas, Africa, and Asia and most of the foreign students (75.6\%) studied International Hospitality Management. The 85\%-15\% national-international proportion in the sample is a good reflection of the overall student population at the university. The sample included $1^{\text {st }}$ year students $(54.7 \%), 2^{\text {nd }}$ year students $(26 \%), 3^{\text {rd }}$ year students $(14.6 \%)$, and $4^{\text {th }}$ year and up (4.7\%). For the majority of the students English is not their first language but their command of English is more than adequate. Preliminary investigation of the instruments with a pilot group of students resulted in minor adjustments of two items to enhance understanding.

\section{Context}

Problem-based learning is a learner-centered instructional and curricular approach that is organized around ill-structured, authentic problems that can be studied from multiple perspectives. Students in PBL-groups are confronted with learning tasks and problems that appeal to meaningful and self-directed learning (Barrows \& Tamblyn, 1980; Poikela \& Poikela, 2005; Savery, 2006; Savery \& Duffy, 1996).

Since the introduction of the first PBL-curriculum in medical education at McMaster University in 1968, PBL has received wide-spread attention and recognition, and consequently many medical schools have followed McMaster's example by introducing PBL to their curriculum (Moore, 1991; Moust, Van Berkel, \& Schmidt, 2005; Neville \& Norman, 2007; Taylor \& Miflin, 2008). In the course of time PBL has been applied to many different areas, among others, teacher education (Goodnough, 2006;

Murray-Harvey, Curtis, Cattley, \& Slee, 2005), technology education (Williams, Iglesias, \& Barak, 2008), health sciences education (Van den Hurk, Dolmans, Wolfhagen, \& Van der Vleuten, 2001), social work education (Plowright \& Watkins, 2004), physiotherapy, computer engineering, and psychology (Abrandt Dahlgren \& Dahlgren, 2002), and economics and business education (Borghans, Gijselaers, Milter, \& Stinson, 2000; McCuddy, Van den Bosch, Martz, Matveev, \& Morse, 2007; Smith, 2005).

Under the heading of PBL fall a variety of approaches ranging from single module or single course approaches to integrated and complex approaches, and from hybrid or blended PBL with a mixture of lectures and tutorials to full PBL (Mennin, Gordan, 
Majoor, \& Osman, 2003; Savin-Baden, 2004; Tan, 2004). However, there seems to be consensus about common characteristics of PBL:

- $\mathrm{PBL}$ is a pedagogical method that is grounded in the principles of constructivism (Kumar \& Natarajan, 2007; Savery \& Duffy, 1996).

- The learning process in PBL starts with the presentation of a professional problem or the description of authentic phenomena that need explanation and exploration. (Barrows, 2002; Barrows \& Tamblyn, 1980). The students are confronted with ill-structured and complex real-life problems (Jonassen, 2000).

- Collaboration in the PBL-group drives student learning, motivates students to explore new knowledge domains, and furthers professional development (Hammar Chiriac, 2008; Lehtinen, 2002).

- PBL is learner-centered and self-directed. Students are encouraged to take responsibility for their own learning. Self-regulated learning implies careful planning of study activities and monitoring of the learning process to achieve study results (Barrows, 2002; Hmelo-Silver, 2004; Van den Hurk, 2006).

- The students use a specific and systematic approach to support in-depth analysis and problem solving in the PBL-group. The so-called 'seven step' or 'seven jump' method, developed at Maastricht University, is a widely applied problem-based learning cycle (Schmidt, 1983).

- Students study for understanding. Knowledge elaboration takes place through individual study followed by in-depth reporting, explanation, and discussion in the PBL-group. Students discuss literature and information collected from a variety of resources to gain understanding of subject matter, and to integrate and apply knowledge (Van den Hurk et al., 2001; Visschers-Pleijers, Dolmans, De Grave, Wolfhagen, Jacobs, \& Van der Vleuten, 2006).

- Tutors must have sufficient pedagogical content knowledge to facilitate self-directed and collaborative learning in the PBL-group (Williams, Iglesias, and Barak, 2008). Tutors stimulate and sustain students' active learning by focusing on exploratory questioning, effective discussions, and constructive feedback (Silén, 2006; Van Berkel \& Dolmans, 2006).

- Assessment methods should match with the curriculum objectives and the objectives set by the students. Self-responsible learning in a problem-based environment calls for assessment methods that do justice to the students' achievements (Oberski, Matthews-Smith, Gray, \& Carter, 2004; Savin-Baden, 2004; Segers \& Dochy, 2001; Segers, Martens, \& Van den Bossche, 2008).

Experiences with PBL in different fields of study diverge and research into the effectiveness of PBL has produced inconclusive evidence, because both benefits of and difficulties with PBL have been reported (Gijbels, Dochy, Van den Bossche, \& Segers, 
2005; Kirschner, Sweller, \& Clark, 2006; Moust, Van Berkel, \& Schmidt, 2005; Norman \& Schmidt, 2000). Nevertheless, an increasing number of universities have introduced PBL to their curricula (Hussain, Mamat, Salleh, Saat, \& Harland, 2007).

\section{Instruments}

The first section of the questionnaire supplied five questions on demographic data: age, program, study year, gender, and nationality.

The second section of the questionnaire measured statements on epistemological beliefs. Chan (2000) developed an instrument for measuring epistemological beliefs the Epistemological Beliefs Questionnaire (EBQ). A review of the literature on epistemological beliefs and the evaluation of Schommer's questionnaire laid the foundation for the EBQ. In the EBQ, 12 of the 30 questions can be directly traced back to Schommer's questionnaire. Factor analysis of the EBQ extracted four factors: fixed/innate ability, authority/expert knowledge, certainty of knowledge, and learning effort/process. The reliability coefficients were considered as satisfactory (Cronbach's alpha ranged from $=.69$ to $=.58$ ). The validation of the instrument by confirmatory factor analysis resulted in satisfactory goodness of fit indices $G F I=.93, A G F I=.90$, RMSEA $=.058$, and $R M R=.064$. A pilot study with the $E B Q$ showed that the wording of a few items needed minor adjustments. For instance, the item 'Some children are ...' was changed in 'Some people are...' to improve consistency.

The third section of the questionnaire aimed at measuring students' conceptions of teaching and learning. The 30-item Teaching and Learning Conceptions Questionnaire (TLCQ), which was developed by Chan (2001), explored if dimensions of teaching and learning could be identified. The Cronbach's alpha values of the whole scale (.86), the constructivist conception subscale (.84), and the traditional subscale (.84) were good. Confirmatory factor analysis showed satisfactory goodness-of-fit indices ( $\mathrm{GFI}=.93$, AGFI=.90, RMSEA $=.05, \mathrm{RMR}=.05$ ).

\section{Procedure}

Students filled out the questionnaire in one of the PBL-sessions in the beginning of the academic year 2005 - 2006. The questionnaire was administered and collected by research assistants who were well informed about the theoretical and practical aspects of the research and were able to answer the students' questions about the questionnaire. The students participated on a voluntary basis and received no compensation for their participation. Instruction on how to fill out the questionnaire was given by research assistants. It took the students about 20 to 30 minutes to fill out 
the questionnaire. They rated their preferences on the EBQ and TLCQ on a five-point Likert scale, from strongly disagree (1) to, strongly agree (5).

\section{Data Analysis}

For the statistical analysis of the data, the software programs SPSS 14.0 and EQS 6.1 were used. To estimate and test the interrelationships between the variables, linear structural equation modeling with EQS was used throughout the analyses. EQS provides a variety of goodness-of-fit indices. The assessment of model fit is a controversial issue in structural equation modeling and a single index or two-index strategy may lead to incorrect conclusions. Therefore, Fan and Sivo (2005) propose the use of multiple fit indices. In this study, we report five absolute fit indices: Goodness of Fit (GFI), Adjusted Goodness of fit (AGFI), Root Mean squared Residual (RMR), Standardized RMR (SRMR), and Root Mean Square Approximation (RMSEA). In a well-fitting model, values for the GFI and the AGFl are greater than .90. Values of .05 or less on the RMSEA generally indicate a close fit of the hypothesized model and the observed data, values of .08 or less indicate a reasonable fit and values of .10 or larger indicate bad fit (Bentler, 2006). EQS reports a $90 \%$ confidence interval of the RMSEA. A narrow confidence interval around the RMSEA reflects good precision of the model fit (Byrne, 2006). Hancock \& Mueller (2005) propose joint criteria of SRMR .09 or less and RMSEA .06 or less as target values to retain a model.

\section{Results}

\section{Epistemological Beliefs Questionnaire (EBQ)}

To ensure the appropriateness of the EBQ to our sample, confirmatory factor analysis of the instrument with EQS 6.1 was performed. As Mardia's normalized estimate value (13.90) indicated some non-normality in the data, the ROBUST option in EQS was used. The Lagrange Multiplier test $(L M)$ indicated that two error covariances and one cross loading contributed to misspecification of the model. Based on the LM recommendations and the theoretical relevance two error terms that showed considerable theoretical overlap were freely specified. Items in each dimension with factor loading under .30 were deleted. The validation of the instrument showed satisfactory goodness of fit indices: GFI=.94, AGFI $=92$, RMSEA $=.045(90 \% \mathrm{Cl} .039-.051)$, $S R M R=.056$ and $R M R=.051$. These results fit the criteria and are in line with prior research by Chan and Elliott (2002; 2004a), which confirms the applicability of the instrument to our sample. 
Cronbach's alpha of the four dimensions, ranging from .51 to .64 , reflects moderate internal consistency. Students in the sample scored above the midpoint (3) on learning effort $(M=3.64)$ and certainty of knowledge $(M=3.15)$ scales and below the midpoint on the other two dimensions of epistemological beliefs, innate ability $(M=2.98)$ and expert knowledge $(M=2.64)$.

Table 2: Cronbach's alpha, mean, standard deviation, and correlation coefficients of the EBQ dimensions

\begin{tabular}{|c|c|c|c|c|c|c|c|}
\hline & \multirow{2}{*}{$\begin{array}{l}\text { Cronbach's } \\
\text { alpha }\end{array}$} & \multirow[t]{2}{*}{ Mean } & \multirow{2}{*}{$\begin{array}{l}\text { Standard } \\
\text { deviation }\end{array}$} & \multicolumn{4}{|c|}{ Correlation } \\
\hline & & & & 1 & 2 & 3 & 4 \\
\hline 1. Innate/fixed ability ( 8 items) & .64 & 2.98 & .53 & & - & & \\
\hline 2. Learning effort/process (6 items) & .59 & 3.64 & .52 & -.050 & - & & \\
\hline 3. Expert knowledge ( 3 items) & .51 & 2.64 & .65 & $.315^{\star \star}$ & -.008 & - & \\
\hline 4. Certainty of knowledge ( 3 items) & .52 & 3.15 & .69 & $.082^{*}$ & $.162^{\star \star}$ & $.226 * *$ & - \\
\hline
\end{tabular}

** Correlation is significant at 0.01 level

* Correlation is significant at 0.05 level

To identify any patterns in de data, Pearson correlations were calculated. Results indicate that the certainty of knowledge dimension of the EBQ shows low, but significant correlations with innate ability ( $r=.082)$, learning effort $(r=.162)$, and expert knowledge ( $r=.226)$. A moderate significant correlation ( $r=.315)$ exists between innate ability and expert knowledge.

\section{Teaching and Learning Conceptions Questionnaire (TLCQ)}

Of the initial 30 items of the TLCQ, 25 items were retained in the final version that was used for further analysis. Five items with factor loading below 30 were deleted. LM-tests and inspection of the items showed three error terms with considerable overlap in item content. Confirmatory factor analysis resulted in satisfactory goodness of fit indices: GFI=.90, AGFI $=.88$, RMSEA $=.049(90 \% \mathrm{Cl} .044-.053)$, SRMR $=.061$ and $\mathrm{RMR}=.054$. The two-factor structure of the TLCQ with a traditional and a constructivist conception of teaching and learning corresponds with the factor structure that Chan (2001), Chan and Elliott (2004a), and Chan et al. (2007) reported. Factor analysis of the TLCQ showed the appropriateness of the instrument for this study. 
Table 3: Cronbach's alpha, mean, standard deviation, and correlation coefficient of the TLCQ dimensions

\begin{tabular}{lcccc} 
& Cronbach's alpha & Mean & Standard deviation & Correlation \\
\hline & .79 & 3.80 & .50 & 1 \\
\hline $\begin{array}{l}\text { 1. Constructivist conception } \\
\text { of teaching and learning }\end{array}$ & .81 & 2.73 & .53 & -.241 ** \\
$\begin{array}{l}\text { 2. Traditional conception } \\
\text { of teaching and learning }\end{array}$ & & &
\end{tabular}

** Correlation is significant at 0.01 level

The Cronbach's alpha reliabilities of the constructivist and traditional conception of teaching and learning dimensions reflected good internal consistency. The mean score of the students in our sample on the constructivist conception of teaching and learning subscale $(M=3.8)$ is well above the midpoint indicating that the students endorse a constructivist viewpoint. The negative correlation between the constructivist and the traditional conception of teaching and learning implies that the conceptions cannot be seen as fully independent of one another.

Relationship between epistemological beliefs and conceptions of teaching and learning

Results in table 4 show the correlations between the dimensions of the EBQ and the dimensions of the TLCQ. The epistemological beliefs dimensions innate ability $(r=.294)$, expert knowledge $(r=.465)$, and certainty of knowledge $(r=.297)$ are significantly related to the traditional conception of teaching and learning. Thus, students who believe that the ability to learn is innate and fixed at birth are likely to hold traditional conceptions of education. In addition, the belief in the teacher as an expert who exerts authority and the assumption that knowledge is certain are positively related to a traditional conception of teaching and learning.

Table 4: Correlation coefficients of the dimensions of the EBQ and TLCQ

\begin{tabular}{lll}
\hline & TLCQ (traditional) & TLCQ (constructivist) \\
\hline 1. Innate/fixed ability & $.294^{* *}$ & $-.171^{* *}$ \\
2. Learning effort/process & -.054 & $.423^{* *}$ \\
3. Expert knowledge & $.465^{* *}$ & $-.156^{* *}$ \\
4. Certainty of knowledge & $.297^{* *}$ & .059 \\
\hline
\end{tabular}

** Correlation is significant at 0.01 level 
The dimensions learning effort/process ( $r=.423$ ), innate/fixed ability $(r=-.171)$, and expert knowledge $(r=-156)$ are significantly related to the constructivist conception of teaching and learning. Students who attribute study success to their own learning efforts and do not believe in the innateness and certainty of knowledge are likely to hold a constructivist conception of teaching and learning.

Correlation analysis of the relation between the dimensions of epistemological beliefs and conceptions of teaching and learning suggests a structural relationship. Therefore, structural equation modeling (SEM) using EQS 6.1 was applied to test the relationship between epistemological beliefs and conceptions of teaching and learning. The full model (four dimensions of the EBQ affect two dimensions of the TLCQ) resulted in $\mathrm{GFI}=.85, \mathrm{AGFl}=.83, \mathrm{RMR}=.058, \mathrm{SRMR}=.065$ and $\mathrm{RMSEA}=.049$. Analysis showed that three paths were non-significant (the paths from innate ability and certainty of knowledge to the constructivist conception and the path from innate ability to the traditional conception of teaching and learning). After deletion of the non-significant paths the adapted model was re-tested. The goodness-of-fit results of the adapted model with absolute fit indices $\mathrm{GFI}=.86$ and $\mathrm{AGFI}=.85$ show a moderately fitting model. The values for the GFI and the AGFI approximate the satisfactory level of .90. The RMR $=057$, $S R M R=.064$, and RMSEA $=.042$ indicate a relatively good fit of the model and the narrow confidence interval $(90 \% \mathrm{Cl} .039-.044)$ of the RMSEA points at a good degree of precision. The results meet Hancock and Mueller's (2005) joint criteria of SRMR .09 or less and RMSEA .06 or less to retain the model. The model proposed in this study shows a fairly good fit and can be used to explore the structural relationships.

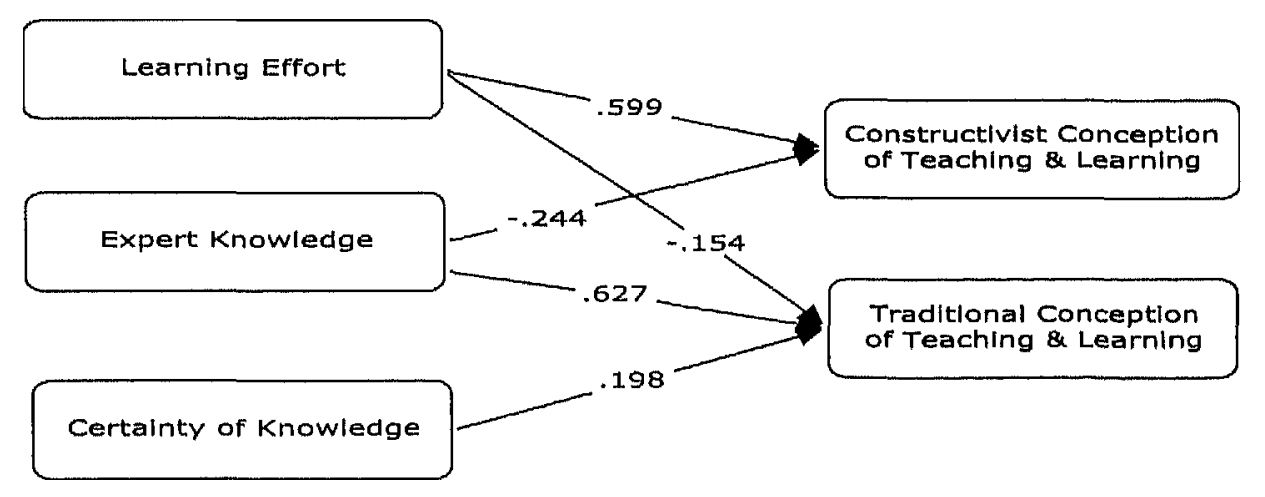

Figure 1: Model of the structural relations between students' epistemological beliefs and conceptions of teaching and learning.

The model of the structural relations between students' epistemological beliefs and conceptions of teaching and learning (Figure 1) shows that students' epistemological 
belief dimension learning effort/process is positively related to the constructivist conception and negatively related to the traditional conception of teaching and learning. Students, who value the role of the teacher as an expert in the teaching-learning situation and believe that knowledge is certain, hold traditional conceptions of teaching and learning. Contrary, students who do not believe in the teacher as the main source of knowledge and expertise tend to have a constructivist conception of education.

\section{Discussion}

\section{Epistemological beliefs}

This study provides evidence for the multidimensionality of epistemological beliefs and a coherent set of epistemological belief dimensions. Confirmatory factor analysis indicated that four dimensions of epistemological beliefs - innate /fixed ability, learning effort/process, expert knowledge, and certainty of knowledge - could be distinguished. The sample in our study was heterogeneous and included students from a variety of academic domains. Results on the learning effort/process dimension of the EBQ show that students predominantly view learning as a process of understanding ( $M=3.64)$. The subscale means of the students on the dimension learning effort/process of the EBQ are well above the midpoint of the scale indicating a strong tendency to believe that knowledge and understanding is acquired through self-directed learning activities. The students mean score on the certainty of knowledge dimension of the EBQ is above the midpoint ( $M=3.15)$, which indicates that many students believe that knowledge is certain and does not change. On the other subscales, innate/fixed ability $(M=2.98)$ and expert knowledge $(M=2.64)$ students scored below the midpoint of the scales. Our empirical findings support Schommer's (1990) characterization of personal epistemology as a system of more or less independent dimensions. It is remarkable that the four factor structure distinguished by Chan $(2000 ; 2003 ; 2008)$, could be confirmed in a different cultural context with a sample of students from several academic domains. The EBQ in our research showed moderate internal consistency with Cronbach's alpha ranging from .51 to .64 on the four subscales, which corresponds to Chan's (2000) findings that range from .58 to .69 . If we compare our findings on the four dimensions with Chan's findings, the main difference on the mean scores of the dimensions is found on the dimension certainty of knowledge placing the students in our sample ( $M=3.15)$ more toward the fixed and certain end of the subscale than Chan's students $(M=2.62)$ who tend to believe that knowledge is more relative and uncertain.

Chan (2000; 2004), and Chan and Elliott (2002; 2004a; 2004b) emphasize the role of the cultural value system and the Confucian philosophy in explaining the relatively high 
score of the Chinese students on the learning effort/process dimension (ranging in the different studies from $M=3.81$ to $M=3.92$ ). However, the students in our sample also demonstrate the belief in learning for understanding $(M=3.64)$. It seems unlikely that the cultural factor, especially the philosophy of Confucianism, fully explains the differences in the mean scores on the dimension learning effort/process that was found. We suggest taking educational factors into account. Students' exposure to constructivist learning environments and problem-based learning might provide a more likely explanation for the relatively high scores in the learning effort/process dimension. In the study of epistemological beliefs, the cultural and pedagogical contexts are often used as an explanation for the inconclusive results on the dimensional structure of epistemological beliefs (Chan \& Elliott, 2004b; Clarebout et al., 2001). Additional research is necessary to establish the potential impact of cultural and educational contexts on the various dimensions of epistemological beliefs.

Several studies underline the need for greater understanding of the philosophical discussions and theoretical underpinnings of constructivist theories and epistemological beliefs (Muis et al., 2006; Schraw, 2001; Tsai, 1999). Psychological research of epistemological beliefs tends to neglect philosophical issues and debates, especially on ontology and epistemology. Is knowledge a reflection of the external reality? Is there an external reality and how do we know that reality? Is knowledge socially constructed? Understanding the ontological and epistemological issues is essential to further psychological studies of knowledge and knowing (Alexander, 2006). The key constructs underlying epistemological beliefs and the constructivist way of thinking about reality and knowledge have to be aligned. Constructivism is first and for all an educational philosophy, which raises ontological and epistemological questions. The discussion of constructivism as an epistemology has to be reflected in the study of personal epistemology. The present version of the epistemological beliefs questionnaire could be improved by including items that represent the constructivist position on ontology and epistemology.

\section{Conceptions of teaching and learning}

The clear distinction between the traditional and constructivist conception of teaching and learning is very helpful and our results show that the majority of the students hold a constructivist conception of teaching and learning. The two-factor structure of the TLCQ in our study was similar to the factor structure that was reported by Chan (2001), Chan and Elliott (2004a), and Chan et al. (2007). The mean score of the students $(M=3.80)$ in our sample on the constructivist conception of teaching and learning is in agreement with Chan et al. (2007) who reported a mean score $(M=4.17)$ on the constructivist dimension. Both the Singapore students in the sample of Chan et al. 
(2007) and the students in our sample are educated in a constructivist learning environment and show a constructivist conception of teaching and learning. The relatively high mean score on the constructivist conception clearly indicates that students who are educated in an educational system, which is based on constructivist principles, have conceptions of education that well match with the learning environment. It seems plausible to conclude that problem-based learning is consistent with students' constructivist conceptions of education. However, the mean score $(M=2.73)$ of the students on the traditional conception of teaching and learning seems to indicate that students are hesitant to leave the traditional conception of teaching and learning behind. From an educational point of view, the underlying correspondence of the university's educational philosophy, which is based on constructivism and problem-based learning, with the constructivist conception of teaching and learning, can be seen as an indication of the presence of a constructive alignment between the goals of education and the students' learning activities.

The structural relationship between epistemological beliefs and conception of teaching and learning

This study explored the structural relationships between students' epistemological beliefs and conceptions of teaching and learning. The significant relationships that we found in our structural model between the dimensions of epistemological beliefs and

50 the traditional and constructivist conception of teaching and learning are in agreement with the principles of constructivism. Constructivism promotes student's self-regulated learning processes in challenging learning environments that offer ample opportunities for collaboration. The findings represent an important step in understanding the structural model.

In our model, two significant paths were established from expert knowledge to conceptions of teaching and learning. Expert knowledge has a strong positive relationship with the traditional conception of teaching and learning and is negatively related to the constructivist conception. On the one hand, this study gives evidence for the fact that students, who don't depend on teacher' expertise, show a constructivist conception of teaching and learning. On the other hand, students recognizing the expert role of the teacher endorse a traditional conception of education.

The positive significant path from certainty of knowledge to the traditional conception of teaching and learning shows that students who believe in knowledge as certain and unchangeable mainly have a traditional conception. No significant path could be established between certainty of knowledge and the constructivist conception of teaching and learning. 
The learning process/effort dimension of the EBQ is positively related to the constructivist conception of teaching and learning and is negatively related to the traditional conception of teaching and learning. It is generally presumed that there ought to be a constructive alignment between the constructivist learning environment with an emphasis on problem-solving, interaction and collaboration, the learning-oriented conception of teaching and learning, and the belief that knowledge and understanding can be attained by self-directed learning efforts.

Contrary to the significant correlations between the EBQ dimension innate/fixed ability and both dimensions of the TLCQ no significant relationships could be established with structural equation modeling.

Several interesting topics come up when we compare our model with Chan and Elliott's (2004a) model. Our study demonstrates a possible causal relationship of three dimensions of epistemological beliefs (learning effort, expert knowledge, and certainty of knowledge) on the conceptions of teaching and learning. Results suggest that students, who value their own learning efforts positively, and who are less dependent on the expertise of the teacher, have constructivist conceptions of teaching and learning. Students, who believe in the certainty of knowledge and the expertise of the teacher, tend to have traditional conceptions of teaching and learning. Chan and Elliott (2004a) linked epistemological beliefs with conceptions of teaching and learning, and found significant paths between de EBQ factors fixed/innate ability, authority/expert knowledge, and certainty of knowledge with the traditional conception of teaching and learning, and a path between the EBQ factor learning effort/process with the constructivist conception of teaching and learning. When we compare the structural model in this study more in detail with Chan and Elliott's (2004a) model several topics can be brought up for discussion.

In our structural model, a significant positive path was established between the EBQ dimension learning effort/process and the constructivist conception of teaching and learning, and a significant negative path was found from learning effort/process to the traditional conception of teaching and learning. Our findings differ substantially from Chan and Elliott (2004a) who found a significant negative path (-.55) from learning effort/process to the constructivist conception of teaching and learning indicating that the students' belief in their own learning effort/process are at odds with a constructivist conception of teaching and learning. How can this remarkable difference be explained? The significant relationships that we established between the learning effort/process dimension of the EBQ and the constructivist conception of teaching and learning are in line with our university's constructivist philosophy of education. Students seem to recognize and sustain the great importance that our university attaches to self-directed 
and collaborative learning by solving authentic tasks in a problem-based learning environment.

Students in both samples acknowledge that studying in higher education requires considerable learning effort and skills. Chan and Elliott (2004a) argue that the Chinese cultural value system with an explicit emphasis on the high value of education, and the focus on effort, perseverance and hard work could be a possible explanation for the relatively high mean score on the dimension learning effort/process. If we compare the scores on the EBQ and TLCQ dimensions of the 22 Chinese students in our sample with all other students no significant differences could be found on any dimension of the $E B Q$. The only significant difference was found on the traditional conception of teaching and learning scale $(t=2.75, D F=615, p=.006)$ indicating that Chinese students have a more traditional conception of teaching and learning.

Besides the positive significant path that Chan and Elliott (2004a) could establish from expert knowledge to the traditional conception of teaching and learning, our research also shows a negative significant path from expert knowledge to the constructivist conception of teaching and learning, which is in line with the expectations. Students who don't believe in the authority of the teacher are inclined to constructivist conceptions of teaching and learning and students who believe in the teacher as an expert and a source of knowledge adhere to traditional conceptions of teaching and

Contrary to Chan and Elliott's findings, who demonstrated a significant path between innate ability and the traditional conception of teaching and learning, we could not establish significant paths from innate ability to neither the traditional nor the constructivist conception of teaching and learning. However, the significant correlations that we found between innate ability and the conceptions of teaching and learning - a positive correlation with the traditional dimension and a negative correlation with the constructivist dimension - point in the right direction.

Chan and Elliott's (2004a) and this study established a positive significant path from certainty of knowledge to the traditional conception of teaching and learning. No significant path could be established between certainty of knowledge and the constructivist conception of teaching and learning. Notwithstanding the relativist epistemological constructivist philosophy of education and the emphasis on the students' active construction of knowledge, student's belief in knowledge as certain and unchangeable seems to persist.

Epistemological beliefs are often defined as personal beliefs about the nature of 
knowledge and the nature of knowing. Beliefs about what knowledge is are intimately related to beliefs about learning (Hofer \& Pintrich, 1997). For instance, Chan and Elliott (2004a) and Schommer-Aikins and Easter (2006) include beliefs about knowledge and learning in the study of epistemological beliefs. Besides, conceptions of teaching and learning are often presented as logically locked together, as a kind of one-to-one relationship. The way that students are taught influences what and how students learn, but teaching does not fully determine student learning. Teaching and learning are two different aspects of the learning process. On the one hand, knowledge and knowing/learning was measured with the EBQ, and on the other hand, teaching and learning was measured with the TLCQ, and structural relationships between epistemological beliefs and conceptions of teaching and learning could be established. Bearing in mind Hofer and Pintrich's (1997) claim that the conceptualization of epistemological beliefs should be restricted to the nature of knowledge and knowing. a clear distinction between beliefs of knowledge and knowing on the one hand and conceptions of teaching, and conceptions of learning on the other hand might improve the focus of both the EBQ and the TLCQ. Further research may contribute to gaining a clear understanding of the relations of the beliefs and conceptions with academic performance and other outcome variables like motivation, self-regulation, and study approaches. Beliefs about knowledge and knowing may directly or indirectly via a mediating role of conceptions of teaching and learning influence the quality of students' academic or cognitive performance.

\section{Educational implications}

We have demonstrated significant relationships between dimensions of personal epistemology and conceptions of teaching and learning. Students' epistemological beliefs and conceptions of teaching and learning have important implications for educational practice. Reviewing our main research question regarding the investigation of students' epistemological beliefs and conceptions of teaching and learning we come to the following main conclusion. This study shows that an educational philosophy grounded in social constructivism and exemplified by problem-based learning is reflected in the epistemological beliefs and constructivist conceptions of teaching and learning of the majority of the students. Core concepts from constructivism and problem-based learning seem to go hand in hand with the constructivist conceptions of teaching and learning that the majority of the students hold. Students, who still adhere to traditional beliefs of knowledge and traditional conceptions of teaching and learning, could benefit from teacher help and facilitation in adjusting to problem-based learning. 
learning. Key questions are: What is knowledge and how do students learn? From a constructivist perspective, knowledge is not passively absorbed by the student but actively constructed. The teacher does not simply transfer knowledge to the students but facilitates students' active knowledge construction processes to gain understanding of subject matter. Learning always builds on what the students already know. The prior knowledge, skills and experiences of life that the students have gained are the foundation on which new learning can be build. One of the major tasks of the teacher is to design challenging learning environments that motivate students to deal with problems that ask for unknown or multiple solutions. In cooperation with one another, students try to make sense of the problem context to reach viable and shared solutions.

The demands of the learning environment impact students' learning activities.

Students' experiences with problem-based learning may influence their epistemological beliefs and conceptions of teaching and learning. However, some students are unaware of the incompatibility of their epistemological beliefs with the demands of the learning environment. Epistemological beliefs are often not articulated and students tend to hold on to them (Schommer-Aikins, 2004). Teachers' awareness of the influence of epistemological beliefs on student learning and their commitment to classroom discussions of epistemological issues may contribute to the development of students' thinking about knowledge and knowing. Addressing students' epistemological beliefs may further in-depth understanding of the constructive alignment of students' beliefs

54 and conceptions about education with the demands of the actual learning environment (Brownlee, 2004).

It is frequently taken for granted that students possess the necessary communication and problem solving skills that are essential for successful participation in higher education and PBL. If students lack the necessary skills to successfully participate in constructivist forms of higher education, development of problem-solving skills, research skills and communication skills is needed to advance academic thinking. The facilitation of students' professional development must be consistent with the constructivist approach and aim at developing sophisticated epistemological beliefs to advance assimilation to the demands of higher education (Kaartinen-Koutaniemi \& Lindblom-Ylänne, 2008; Kember, 2001).

The students' prior beliefs and conceptions should be taken into account with the introduction to PBL. Students, who believe in expert knowledge and certainty of knowledge, and hold traditional conceptions of teaching and learning, may not immediately appreciate self-directed learning and working in groups. In the initial phase of the curriculum, careful guidance by PBL experts is necessary to systematically initiate students with traditional conceptions into the basics of PBL. 
The confrontation with unstructured and authentic tasks right from the start of the curriculum poses students for quite a challenge. Unstructured, authentic tasks are open to multiple solutions and students find it difficult to find appropriate solutions to the problem, do not know what and how to learn, and ask for guidance and direction. The high level of cognitive complexity involved in solving unstructured tasks may cause cognitive overload. Given the conceptions of teaching and learning, and the study skills that students bring into the learning situation, instructional designers should pay attention to the level of structuredness and complexity of the tasks in PBL. 


\section{References}

Abrandt Dahlgren, M., \& Dahlgren, L، O. (2002). Portraits of PBL: students' experiences of the characteristics of problem-based learning in physiotherapy, computer engineering and psychology. Instructional Science, 30, 111-127.

Alexander, P. A. (2006). What would Dewey say? Channeling Dewey on the issue of specificity of epistemic beliefs: A response to Muis, Bendixen, and Haerle (2006). Educational Psychology Review, 18 (1), 55-65.

Barrows, H. S. (2002). Is it truly possible to have such a thing as dPBL. Distance Education, 23(1), 119-122.

Barrows, H. S., \& Tamblyn, R. M. (1980). Problem-based learning: An approach to medical education. New York: Springer.

Bentler, P. M. (2006). EQS 6 Structural equations program manual. Encino, CA: Multivariate Software Inc.

Borghans, L., Gijselaers, W. H., Milter, R. G., \& Stinson, J. E. (Eds.), (2000). Business education for the changing workplace. Dordrecht: Kluwer Academic Publishers.

Bråten, 1., \& Strømsø, H. I. (2004). Epistemological beliefs and implicit theories of intelligence as predictors of achievement goals. Contemporary Educational Psychology, 29, 371-388.

Bråten, I., \& Strømsø, H. I. (2005). The relationship between epistemological beliefs, implicit theories of intelligence, and self-regulated learning among Norwegian postsecondary students. British Journal of Educational Psychology, 75, 539-565.

56 Brownlee, J. (2004). Teacher education students' epistemological beliefs. Developing a relational model of teaching. Research in Education, 72, 1-17.

Brownlee, J., Purdie, N., \& Boulton-Lewis, G. (2003). An investigation of student teachers' knowledge about their own learning. Higher Education, 45, 109-125.

Byrne, B. M. (2006). Structural equation modeling with EQS. Basic concepts, applications, and programming. Mahwah, NJ: Lawrence Erlbaum Associates.

Cano, F. (2005). Epistemological beliefs and approaches to learning: Their change through secondary school and their influence on academic performance. British Journal of Educational Psychology, 75, 203-221.

Chan, K-W. (2000). Teacher education students' epistemological beliefs: A cultural perspective on learning and teaching. Sydney: Paper presented at the Australian Association for Research in Education conference.

Chan, K-W. (2001). Validation of a measure of personal theories about teaching and learning. Perth: Paper presented at the Australian Association for Research in Education conference.

Chan, K-W. (2003). Hong Kong teacher education students' epistemological beliefs and approaches to learning. Research in Education, 69(1), 36-50.

Chan, K-W. (2004). Pre-service teachers' epistemological beliefs and conceptions about teaching and learning: cultural implications for research in teacher education. Australian Journal of Teacher Education, 29(1), 1-13. 
Chan, K-W. (2008). Hong Kong teacher education students' epistemological beliefs and their relations with conceptions of learning and learning strategies. The Asia Pacific Education Researcher, 16(2), 199-214.

Chan, K-W., \& Elliott, R. G. (2002). Exploratory study of Hong Kong teacher education students' epistemological beliefs: cultural perspectives and implications on beliefs research. Contemporary Educational Psychology, 27, 392-414.

Chan, K-W., \& Elliott, R. G. (2004a). Relational analysis of personal epistemology and conceptions about teaching and learning. Teaching and Teacher Education, 20, 817-831.

Chan, K-W., \& Elliott, R. G. (2004b). Epistemological beliefs across cultures: Critique and analysis of beliefs structure studies. Educational Psychology, 24(2), 123-142.

Chan, K-W., Tan, J., \& Khoo, A. (2007). Pre-service teachers' conceptions about teaching and learning: A closer look at Singapore cultural context. Asia-Pacific Journal of Teacher Education, 35(2), 181-195.

Clarebout, G., Elen, J., Luyten, L., \& Bamps, H. (2001). Assessing epistemological beliefs: Schommer's questionnaire revisited. Educational Research and Evaluation, 7(1), 53-77.

Cronjé, J. (2006). Paradigms regained: toward integrating objectivism and constructivism in instructional design and the learning sciences. Educational Technology Research \& Development, 54(4), 387-416.

De Corte, E. (1995). Fostering cognitive growth: A perspective from research on mathematics learning and instruction. Educational Psychologist, 30(1), 37-46.

De Corte, E. (2000). Marrying theory building and the improvement of school practice: a permanent challenge for instructional psychology. Learning and instruction, 10(3), 249-66.

Eklund-Myrskog, G. (1998). Students' conceptions of learning in different educational contexts. Higher Education, 35, 299-316.

Elen, J., Clarebout, G., Léonard, R., \& Lowyck, J. (2007). Student-centred and teacher-centred learning environments: what students think. Teaching in Higher Education, 12(1)، 105-117.

Fan, X., \& Sivo, S. A. (2005). Sensitivity of fit indexes to misspecified structural or measurement model components: Rationale of two-index strategy revisited. Structural Equation Modeling: A Multidisciplinary Journal, 12(3), 343-367.

Gijbels, D., Dochy, F, Van den Bossche, P., \& Segers, M. (2005). Effects of problem-based learning: a meta-analysis from the angle of assessment. Review of Educational Research, 75(1), 27-61.

Goodnough, K. 2006. Enhancing pedagogical content knowledge through self-study: an exploration of problem-based learning. Teaching in Higher Education, 11(3), 301-318.

Hammar Chiriac, E. (2008). A scheme for understanding group processes in problem-based learning. Higher Education, 55(5), 505-518.

Hancock, G. R., \& Mueller, R. O. (2005). Structural equation modeling. A first course. Rotterdam: Erasmus University Medical Center.

Hmelo-Silver, C. (2004). Problem-based learning: What and how do students learn? Educational Psychology Review, 16(3), 235-266. 
Hofer, B. K. (2000). Dimensionality and disciplinary differences in personal epistemology. Contemporary Educational Psychology, 25, 378-405.

Hofer, B. K. (2001). Personal epistemology research: Implications for learning and teaching. Journal of Educational Psychology Review, 13(4), 353-383.

Hofer, B. K. (2002). Personal epistemology as a psychological and educational construct: An introduction. In B. K. Hofer \& P. R. Pintrich (Eds.), Personal epistemology: The psychology of beliefs about knowledge and knowing (pp. 389-414). Mahwah, NJ: Lawrence Erlbaum Associates.

Hofer, B. K., \& Pintrich, P. R. (1997). The development of epistemological theories: beliefs about knowledge and knowing and their relation to learning. Review of Educational Research, $67(1)$, 88-140.

Hofer, B. K., \& Pintrich, P. R. (2002). Personal epistemology: The psychology of beliefs about knowledge and knowing. Mahwah, NJ: Lawrence Erlbaum Associates.

Hussain, R. M. R., Mamat, W. H. W., Salleh, N., Saat, R. M., \& Harland, T. (2007). Problem-based learning in Asian universities. Studies in Higher Education, 32(6), 761-772.

Jehng, J. J., Johnson, S. D., \& Anderson, R. C. (1993). Schooling and students' epistemological beliefs about learning. Contemporary Educational Psychology, 18, 23-35.

Jonassen, D. H. (2000). Toward a design theory of problem solving. Educational Technology Research and Development, 48(4), 63-85.

Jonassen, D. H., Hernandez-Serrano, J., \& Choi, I. (2000). Integrating constructivism and learning technologies. In J. M. Spector and T. M. Anderson (Eds.), Integrated and holistic perspectives on

58 learning, instruction and technology. Understanding complexity (pp. 103-127). Dordrecht: Kluwer Academic Publishers.

Kaartinen-Koutaniemi, M., \& Lindblom-Ylänne, S. (2008). Personal epistemology of psychology, theology and pharmacy students: a comparative study. Studies in Higher Education, 33(2), 179-191.

Kember, D. (1997). A reconceptualisation of the research into university academics' conceptions of teaching. Learning and Instruction, 7, 255-275.

Kember, D. (2001). Beliefs about knowledge and the process of teaching and learning as a factor in adjusting to study in higher education. Studies in Higher Education, 26(2), 205-221.

Kinchin, I. M. (2004). Investigating students' beliefs about their preferred role as learners. Educational Research, 46(3), 301-312.

Kirschner, P., Sweller, J., \& Clark, R. (2006). Why minimal guidance during instruction does not work: An analysis of the failure of constructivist, discovery, problem-based, experiential and inquiry-based teaching. Educational Psychologist, 41, 75-86.

Kumar, M., \& Natarajan, U. (2007). A problem-based learning model: showcasing an educational paradigm shift. Curriculum Journal, 18(1), 89-102.

Lehtinen, E. (2002). Developing models for distributed problem-based learning: theoretical and methodological reflection. Distance Education, 23(1), 109-117. 
Lonka, K., Joram, E., \& Bryson, M. (1996). Conceptions of learning and knowledge: does training make a difference? Contemporary Educational Psychology, 21, 240-260.

Mamede, S., Schmidt, H. G., \& Geoffrey, R. (2006). Innovations in problem-based learning: What can we learn from recent studies? Advances in Health Sciences Education, 11, 403-422.

McCuddy, M. K., Van den Bosch, H., Martz, Wm. B., Matveev, A. V., \& Morse, K. O. (Eds.), (2007). The challenges of educating people to lead in a challenging world. Dordrecht: Springer.

Mennin, S., Gordan, P., Majoor, G., \& Osman, H. A. S. (2003). Position paper on problem-based learning. Education for Health, 16(1), 98-113.

Moore, G. T. (1991). Initiating problem-based learning at Harvard Medical School. In D. Boud \& G. Feletti (Eds.), The challenge of problem-based learning (pp. 80-87). London: Kogan Page.

Moore, W. 5. (2002). Understanding learning in a postmodern world: Reconsidering the Perry scheme of ethical and intellectual development. In B. K. Hofer \& P. R. Pintrich (Eds.), Personal epistemology: The psychology of beliefs about knowledge and knowing (pp. 17-36). Mahwah, NJ: Lawrence Erlbaum Associates.

Moust, J. H. C., van Berkel, H. J. M., \& Schmidt, H. G. (2005). Signs of erosion: reflections on three decades of problem-based learning at Maastricht University. Higher Education, 50, 665-683.

Muis, K. R., Bendixen, L. D., \& Haerle, F. C. (2006). Domain-generality and domain-specificity in personal epistemology research: Philosophical and empirical questions in the development of a theoretical model. Educational Psychology Review, 18(1), 3-54.

Murray-Harvey, R., Curtis, D. D., Cattley, G., \& Slee, P. T. (2005). Enhancing teacher education students' generic skills through problem-based learning. Teaching Education, 16(3), 257-273.

Neville, A. J., \& Norman, G. R. (2007). PBL in the undergraduate MD program at MCMaster University: Three iterations in three decades. Academic Medicine, 82(4), 370-374.

Norman, G. R., \& Schmidt, H. G. (2000). Effectiveness of problem-based learning curricula. Medical Education, 34, 721-728.

Oberski, I. M., Matthews-Smith, G., Gray, M., \& Carter, D. E. (2004). Assessing problem-based learning with practice portfolios: one innovation too many? Innovations in Education and Teaching International, 41(2), 207-221.

Paulsen, M. B., \& Feldman, K. A. (2005). The conditional and interaction effects of epistemological beliefs on the self-regulated learning of college students: Motivational strategies. Research in Higher Education, 46(7), 731-768.

Paulsen, M. B., \& Feldman, K. A. (2007). The conditional and interaction effects of epistemological beliefs on the self-regulated learning of college students: Cognitive and behavioral strategies. Research in Higher Education, 48(3)، 353-401.

Perry, W. G. (1970). Forms of intellectual and ethical development in the college years: A scheme. New York: Holt, Rinehart, and Winston.

Pintrich, P. R. (2002). Future challenges and directions for theory and research on personal epistemology, In B. K. Hofer \& P. R. Pintrich (Eds.), Personal epistemology: The psychology of beliefs about knowledge and knowing (pp. 389-414). Mahwah, NJ: Lawrence Erlbaum Associates. 
Plowright, D., \& Watkins, M. (2004). There are no problems to be solved, only inquiries to be made, in social work education. Innovations in Education and Teaching International, 41(2), 185-206.

Poikela, E., \& Poikela, S. (2005). The strategic points of problem-based learning. In E. Poikela \& 5. Poikela, (Eds.), PBL in context - Bridging work and education (pp. 7-22). Tampere: Tampere University Press.

Qian, G., \& Alvermann, D. (1995). Role of epistemological beliefs and learned helplessness in secondary school students' learning science concepts from text. Journal of Educational Psychology, 87(2), 282-292.

Rodriguez, L., \& Cano, F. (2006). The epistemological beliefs, learning approaches and study orchestrations of university students. Studies in Higher Education, 31(5), 617-636.

Rodriguez, L., \& Cano, F. (2007). The learning approaches and epistemological beliefs of university students: a cross-sectional and longitudinal study. Studies in Higher Education, 32(5), 647-667.

Samuelowicz, K., \& Bain, J. D. (1992). Conceptions of teaching held by academic teachers. Higher Education, 24, 93-111.

Samuelowicz, K., \& Bain, J. D. (2001). Revisiting academic's beliefs about teaching and learning. Higher Education, 41, 299-325.

Samuelowicz, K., \& Bain, J. D. (2002). Identifying academics' orientations to assessment practice. Higher Education, 43, 173-201.

Savery, J. R. (2006). Overview of problem-based learning: Definitions and distinctions. The interdisciplinary journal of problem-based learning, 1(1), 9-20.

60 Savery, J. R., \& Duffy, T. M. (1996). Problem based learning: An instructional model and its constructivist framework. In B. G. Wilson (Eds.), Constructivist learning environments: Case studies in instructional design (pp. 35-48). Englewood Cliffs, NJ: Educational Technology Publications.

Savin-Baden, M. (2004). Understanding the impact of assessment on students in problem-based learning. Innovations in Education and Teaching International, 41(2), 221-233.

5chmidt, H. G. (1983). Problem-based learning: Rationale and description. Medical Education, 17, 11-16.

Schommer, M. (1990). Effects of beliefs about the nature of knowledge on comprehension. Journal of Educational Psychology, 82(3), 498-504.

Schommer, M. (1993). Epistemological development and academic performance among secondary students. Journal of Educational Psychology, 85(3), 406-411.

Schommer, M. (1994). Synthesizing epistemological belief research: tentative understandings and provocative confusions. Educational Psychology Review, 6(4), 293-319.

Schommer-Aikins, M. (2002). An evolving theoretical framework for an epistemological belief system. In B. K. Hofer \& P. R. Pintrich (Eds.), Personal epistemology: The psychology of beliefs about knowledge and knowing (pp. 103-118). Mahwah, NJ: Lawrence Erlbaum Associates.

Schommer-Aikins, M. (2004). Explaining the epistemological belief system: introducing the embedded systemic model and coordinated research approach. Educational Psychologist, 39(1), $19-29$. 
Schommer, M., Crouse, A., \& Rhodes, N. (1992). Epistemological beliefs and mathematical text comprehension: believing it is simple does not make it so. Journal of Educational Psychology, $84(4), 435-443$.

Schommer-Aikins, M., \& Easter, M. (2006). Ways of knowing and epistemological beliefs: combined effect on academic performance. Educational Psychology, 26(3), 411-423.

Schraw, G. (2001). Current themes and future directions in epistemological research: A commentary. Educational Psychology Review, 13(4), 451-464.

Schraw, G., Bendixen, L. G., \& Dunkle, M. E. (2002). Development and validation of the Epistemic Beliefs Inventory (EBI). In B. K. Hofer \& P. R. Pintrich (Eds.), Personal epistemology: The psychology of beliefs about knowledge and knowing (pp. 261-275). Mahwah, NJ: Lawrence Erlbaum Associates.

Schraw, G., \& Sinatra, G. M. (2004). Epistemological development and its impact on cognition in academic domains. Contemporary Educational Psychology, 29, 95-102.

Segers, M., \& Dochy, F. (2001). New assessment forms in Problem-based learning: the value-added of the students' perspective. Studies in Higher Education, 26(3), 327-343.

Segers, M., Martens, R., \& Van den Bossche, P. (2008). Understanding how a case-based assessment instrument influences student teachers' learning approaches. Teaching and Teacher Education, 24(7), $1751-1764$.

Silén, C. (2006). The tutor's approach to base groups (PBL). Higher Education, 51, 373-385.

5mith, G. F. (2005). Problem-based learning: can it improve managerial thinking? Journal of Management Education, 29(2), 357-378.

Stathopoulou, C., \& Vosniadou, S. (2007). Exploring the relationship between physics-related epistemological beliefs and physics understanding. Contemporary Educational Psychology, $32(3), 255-281$.

Strømsø, H. 1., \& Bråten, I. (2003). Epistemological beliefs and implicit theories of intelligence among Norwegian post-secondary students. Padova, Italy: Paper presented at the $10^{\text {th }}$ European Conference for Research on Learning and Instruction.

Tan, O. 5. (2004). Students' experiences in problem-based learning: three blind mice episode or educational innovation? Innovations in Education and Teaching International, 41(2), 169-184.

Taylor, D., \& Miflin, B. (2008). Problem-based learning: Where are we now? Medical Teacher, 30(8), 742-763.

Thijssen, T. J. P., \& Vernooij, F. T. J. (2004). Breaking the boundaries between academic degrees and life-long learning. In R. Milter, V. S. Perotti and M. S. R. Segers (Eds.), Breaking boundaries for global learning (pp. 137-156). Dordrecht: Springer.

Trigwell, K., \& Ashwin, P. (2006). An exploratory study of situated conceptions of learning and learning environments. Higher Education, 51, 243-258.

Trigwell, K., Prosser, M., \& Waterhouse, F. (1999). Relations between teachers' approaches to teaching and students' approaches to learning. Higher Education, 37, 57-70.

Tsai, C. C. (1999). "Laboratory exercises help me memorize the scientific truths": A study of eighth graders views and learning in laboratory activities. Science Education, 83(6), 654-674. 
Tsai, C. C. (2000). Relationships between student scientific epistemological beliefs and perceptions of constructivist learning environments. Educational Research, 42(2), 193-202.

Tsai, C. C., \& Chuang, S. C. (2005). The correlation between epistemological beliefs and preferences toward Internet-based learning environments. British Journal of Educational Technology, 36(1), 97-100.

Tynjälä, P. (1999). Toward expert knowledge? A comparison between a constructivist and a traditional learning environment in the university. International Journal of Educational Research, 31, 357-442.

Van Berkel, H. J. M., \& Dolmans, D. H. J. M. (2006). The influence of tutoring competencies on problems, group functioning and student achievement in problem-based learning. Medical Education, 40, 730-736.

Van den Hurk, M. M., Dolmans, D. H. J. M., Wolfhagen, I. H. A. P., \& Van der Vleuten, C. P. M. (2001). Testing a causal model for learning in a problem-based curriculum. Advances in Health Sciences Education, 6, 141-149.

Van den Hurk, M. M. (2006). The relation between self-regulated strategies and individual study time, prepared participation and achievement in a problem-based curriculum. Active Learning in Higher Education, 7(2), 155-169.

Van Rossum, E. J., Deijkers, R., \& Hamer, R. (1985). Students' learning conceptions and their interpretation of significant educational concepts. Higher Education, 14, 617-641.

Van Rossum, E. J., \& Hamer, R. (2006). Learning and teaching: A model of linked continua of conceptions. Thessaloniki: Paper presented at the $24^{\text {th }}$ European Council on Hotel, Restaurant \&

62 Institutional Education Conference.

Vermunt, J., \& Verschaffel, L. (2000). Process-oriented teaching. In R-J. Simons, J. van der Linden \& T. Duffy (Eds.), New Learning (pp. 209-226). Dordrecht: Kluwer Academic Publishers.

Visschers-Pleijers, A. J. S. F., Dolmans, D. H. J. M., de Grave, W. S., Wolfhagen, I. H. A. P., Jacobs, J. A., \& Van der Vleuten, C. P. M. (2006). Student perceptions about the characteristics of an effective discussion during the reporting phase in problem-based learning. Medical Education, 40, 924-931.

Vosniadou, S. (2001). How children learn. Brussels/Geneva: International Academy of Education/International Bureau of Education.

Williams, P., Iglesias, J. J., \& Barak. M. (2008). Problem based learning: application to technology education in three countries. International Journal of Technology and Design Education, 4, 319-335.

Wood, P., \& Kardash, C. M. (2002). Critical elements in the design and analysis of critical thinking studies. In B. K. Hofer \& P. R. Pintrich (Eds.), Personal epistemology: The psychology of beliefs about knowledge and knowing (pp. 231-260). Mahwah, NJ: Lawrence Erlbaum Associates. 


\section{International hospitality management students" epistemological beliefs and conceptions of teaching and learning}

Otting, H, Zwaal, W., \& Gijselaers, W. International hospitality management students' epistemological beliefs and conceptions of teaching and learning Accepted for publication (2009) in: Journal of Hospitality and Tourism Education 


\section{Abstract}

The aim of this study is to investigate international hospitality management students' beliefs about knowledge and their conceptions of teaching and learning in a problem-based learning environment. Structural Equation Modeling (SEM) was used to investigate the relation between epistemological beliefs and conceptions of teaching and learning. Results show structural relations between three dimensions of epistemological beliefs and constructivist or traditional conceptions of teaching and learning. Congruency exists between the constructivist nature of the problem-based learning environment, the students' constructivist conceptions of teaching and learning, and the students' beliefs in learning effort/process. Our findings indicate that hospitality management students' epistemological beliefs and their conceptions of teaching and learning are in alignment with the demands of problem-based hospitality education. Moreover, students from different cultural backgrounds may benefit from their learning experiences in a problem-based environment.

Keywords: problem-based learning, constructivism, epistemological beliefs, conceptions of teaching and learning. 


\section{Introduction}

Today's society can be characterized by a trend towards globalization. The hospitality industry as one of the largest and most internationalized industries in the service sector is exemplary for this trend. International hotel chains have gained broad geographic presence in the major markets and are continuing their worldwide expansion plans (Straus, 2007). International hotels provide their international customers with standardized facilities, and high quality services (Whitla, Walters, \& Davies, 2007). Successful globalization not only depends on standardization of products and services but also depends on how the local culture and environment are integrated in the hospitality service products (Roper, Brookes, \& Hampton, 1997). Global quality standards combined with a distinct local flavor are essential to provide optimal services to meet the diverse needs and expectations of both national and international guests. The provision of high-quality services by competent employees not only leads to more satisfied guests but also drives customer loyalty and business success. The knowledge, skills, and commitment of the employees are among the most valuable company's assets. An employee's career in the hospitality industry depends upon his commitment to work and learning. Continuous improvement of knowledge and skills are a prerequisite for successful adaptation to the changing conditions in the hospitality business (Akrivos, Ladkin, \& Reklitis, 2007).

Alongside innovations and technological advancement, traditional practices have survived. For instance, many kitchens are traditional workplaces with a division of labor that not only finds expression in a vertical division of labor characterized by a strict hierarchy that has its origin in Escoffier's late 1800s kitchen brigade system but also in a horizontal division of labor in specialized, highly organized, and structured workplace sections in which the chef supervises, synchronizes, and coordinates the workflow of the sections to deliver a meal to the customer at the right time and quality (James, 2006). However, customer needs change rapidly and because of the fierce competition, the hospitality industry implements technological innovations and delivers new service products to satisfy the needs of the customers. Ottenbacher, Gnoth, and Jones (2006), for instance, identified five success factors that contribute to the successful development of new high-contact service products: market attractiveness, market responsiveness, marketing synergy, employee involvement, and employee commitment. Though empowerment and commitment of employees can make the difference between the success and failure of high-contact service innovations, very low levels of employee participation and empowerment are also reported (Connolly \& McGing, 2007). The hospitality industry does not always recognize the importance of effective human resource management. The high mobility of the workforce, the high labor turnover, the low pay, the poor working conditions, and the increasing portion of the 
workforce, especially women, which is temporary employed, illustrate that human resource management still has a long way to go in the hospitality industry (Baum, 2007).

It seems evident that the potential shortage of qualified and competent employees and the changing business environment not only affect the hospitality industry but also hospitality management education. The question arises if hospitality management education sufficiently provides the industry with employees and managers that have the right competencies? The primary goal of hospitality management education is to facilitate student learning and understanding in the field of hospitality. Students have to demonstrate that they have acquired a body of knowledge and they must be competent to apply their knowledge and skills to the hospitality industry. The mixture of tradition and innovation that characterizes the hospitality industry can, for instance, be found in the dual nature of hospitality education at Stenden University. On the one hand, students are involved in the day-to-day operations of Stenden University's hotel, restaurants, and conference facilities. The production of food and the provision of services are used to gain overall knowledge of and an insight into operations management. Technical skills of food production and services are subordinate to the managerial and conceptual perspective on hospitality operations. On the other hand, the hospitality management curriculum is firmly embedded in the domain of business administration and all universities offering a degree in business administration,

66 irrespective of specialization, have to satisfy the uniform requirements of the national standard for the body of knowledge and skills. Though the necessity of gaining factual and general knowledge is recognized, the primary focus in the teaching-learning situation lies in the acquisition and application of knowledge and skills in the context of the hospitality industry. Contrary to the traditional model of education, which essentially regards education as the transmission of knowledge from teacher to students stressing the acquisition and storing of information, emphasis is put on learning as a personal knowledge construction process that is integrated in and inseparable from social and cultural practice (Lave \& Wenger, 1991; Petraglia, 1998; Phillips, 2000; Terhart, 2003). The practice of hospitality management calls for an integrated perspective on knowledge and learning. Management competencies like leadership, team work, collaboration, intercultural sensitivity, ethical decision making, and problem solving are essential for the global hospitality industry and not only affect what students have to learn but also how they learn (Gijbels, Van de Watering, Dochy, \& Van den Bossche, 2006; McCuddy, Van den Bosch, Martz, Matveev, \& Morse, 2007). How do we educate students to effectively and efficiently lead hospitality organizations in a rapidly changing and increasingly complex world? Hospitality management schools teach new subjects and educational contents in response to the needs of the industry. However, the development of students' competencies cannot 
sufficiently be brought about by traditional approaches to education that focus on reproduction of knowledge and the adaptation of students to the existing situation. New conceptions of teaching and learning are needed to satisfy the hospitality industry's demand for competent practitioners that not only combine action and reflection but are also able to contribute to the creation of new knowledge and knowing (Tribe, 2002). These conceptions of teaching and learning are predominantly constructivist in nature and emphasize the students' active role in the knowledge construction process. Constructivists believe that critical thinking and problem solving skills are essential for advancing knowledge construction (Cho, Schmelzer, \& McMahon, 2002). Constructivist learning environments can be characterized as powerful and authentic learning environments in which students are encouraged to become active learners (De Corte, 2000; Vosniadou, 2001; Wilson, 1996). Students engage in collaborative problem-solving and use a variety of tools and information resources. They are self-responsible and self-directed learners who personally and socially construct knowledge. In authentic learning environments, students focus on the meaningful and functional development of the competencies that are required in today's workplace: problem solving, learning to learn, creative thinking, leadership, and technical and business literacy (Meister, 1998; Simons, Van der Linden, \& Duffy, 2000). Competency development bears upon a personal and social (re)construction process in interaction with a continuously changing environment. The emphasis on the active role of the student in the learning process calls for awareness of what knowledge is and why knowledge is of major importance for further intellectual development.

\section{Epistemological beliefs}

Knowledge and learning are of vital importance both to hospitality industry and hospitality education. Therefore, more fundamental questions about knowledge and learning need to be addressed. The scientific discussion of these crucial questions about knowledge and knowing belongs to the domain of epistemology. The beliefs a person holds about the nature of knowledge and knowing are called personal epistemology or epistemological beliefs. Epistemological beliefs influence our judgments about the credibility of knowledge claims. Epistemological beliefs are psychological and educational constructs that are used to explain the personal beliefs about knowledge and knowing. In this study, we follow Schommer's (1990) conceptualization of personal epistemology. Schommer proposed an epistemological belief system of more or less independent dimensions of beliefs. Schommer's conceptual framework has become a prominent line of research and the multidimensionality of epistemological beliefs has been confirmed (Bråten \& Strømsø, 2005; Chan \& Elliott, 2002; Karabenick \& Moosa, 2005; Schommer, 1993; 1994). The influences of students' epistemological beliefs on academic performance in different fields of study, on motivation, and on self-regulated 
learning have been acknowledged in many empirical studies (Brăten \& Strømsø, 2004; 2005; Paulsen \& Feldman, 2005; 2007; Schommer, 1990; 1993; Schommer-Aikins \& Easter, 2006; Schraw \& Sinatra, 2004). For instance, research by Bråten and Strømsø (2005) showed that the dimensions of epistemological beliefs were consistently related to aspects of self-regulated learning and plays an important role in self-regulated learning. Their findings indicate that the relation between epistemological beliefs and self-regulated learning may vary between fields of study. Students' epistemological beliefs differ across fields of study and academic domains. The domain-specific context may influence the development of epistemological beliefs. For instance, students in ill-structured domains (e.g. history or psychology) may develop more constructivist ideas about knowledge and learning than students in more structured domains like medicine and mathematics (Lonka \& Lindblom-Ylänne, 1996; Muis, Bendixen, \& Haerle, 2006). However, research of students' epistemological beliefs and conceptions of education in the domain of hospitality is not widely available (Zwaal \& Otting, 2007). Research of students' epistemological beliefs in the field of hospitality may provide insight in the relation between their beliefs about knowledge and their conceptions of teaching and learning.

Epistemological beliefs influence how students approach learning tasks, acquire information, and gain understanding. Several researchers expressed the need for further research into the cultural and educational backgrounds of epistemological

68 beliefs (Chan \& Elliott, 2002; 2004; Youn, Yang, \& Choi, 2001). For instance, Qian and Pan (2002) studied differences in epistemological beliefs of students with American and Chinese backgrounds and found that Chinese students more strongly than American students believe in simple and certain knowledge, and have stronger beliefs that the ability to learn is innate. Investigating cross-cultural differences in epistemological beliefs may increase our understanding of how students approach knowledge and learning issues. There is also no consensus on the issue of gender in the research of epistemological beliefs (Hofer \& Pintrich, 1997; Pintrich, 2002). Research into gender issues has suggested differences in the way men and women experience and justify knowledge and knowing. For instance, the Women's Ways of Knowing collective addressed the issue of how women perceive themselves and their worlds as a central theme for the study of personal epistemology (Belenky, Clinchy, Goldberger, \& Tarule, 1986). The Women's Ways of Knowing has given insight in the epistemological development and position of women and has brought issues of gender into the study of epistemological beliefs (Clinchy, 2002).

\section{Conceptions of teaching and learning}

Critical thinking, learning to learn, self-management, communication and collaboration 
are among the competencies that students in hospitality management education have to acquire. Students' experiences with the teaching-learning environment fundamentally influence their ideas about what good teaching and learning is or ought to be. The acquisition of hospitality management competencies requires active student involvement in the learning process and therefore calls for a shift from a traditional and teacher-centered conception focusing on knowledge transmission toward a constructivist and student-centered conception of teaching and learning emphasizing students' active knowledge construction processes (Chan \& Elliott, 2004; Samuelowicz \& Bain, 2001; Trigwell, Prosser, \& Waterhouse, 1999).

\section{Research questions}

Studies of epistemological beliefs show important interrelations between students' epistemological beliefs, the learning environment and conceptions of and approaches to learning (Chan, 2003; 2008; Chan \& Elliott, 2004). However, studies of the interrelations between epistemological beliefs and conceptions of teaching and learning in the field of hospitality and tourism are not available. The main purpose of this paper is to investigate hospitality management students' epistemological beliefs, their conceptions of teaching and learning, and the relationship between these beliefs and conceptions.

1. What are the epistemological beliefs of hospitality management students?

2. What are the conceptions of teaching and learning that hospitality management students hold?

3. How do hospitality management students' epistemological beliefs relate to their conceptions of teaching and learning?

\section{Method}

\section{Participants}

The participants in this study were 347 students' ( $44.1 \%$ male and $55.9 \%$ female) from a four-year undergraduate International Hospitality Management Program. The age of the students ranged from 17 to $27(M=20.4, S D=2.17)$. The majority of the students in this study were from the Netherlands $(80.9 \%)$. The international students $(19.1 \%)$ were from a variety of countries in Europe, North and South America, Africa, and Asia.

1 The International Hospitality Management students that participated in this study are a section of the sample of the study reported in the previous chapter. 


\section{Educational context: Problem-based learning}

Problem-based learning (PBL) is a well-known example of the constructivist conception of education (Gijbels et al., 2006; Hendry, Frommer, \& Walker, 1999; Savery \& Duffy, 1996). Right from the start in 1987 of the International Hospitality Management Program studied, problem-based learning was introduced as an integrative approach to the curriculum. The main educational objectives of PBL focus on the acquisition of an integrated body of knowledge related to the domain of hospitality management and the development of the students' problem solving and learning skills (Barrows \& Tamblyn, 1980). Realistic problems, usually descriptions of real-life situations or events derived from the hospitality industry, are analyzed by a group of \pm 12 students under guidance of a tutor. The PBL-group uses a systematic procedure, the seven step approach, to define and analyze the problem, and to structure student learning in-and outside the PBL-group.

The study of problem-based learning has become a prominent line of research in the medical and health sciences and has yielded important insights in various aspects of student learning (Gijbels, Dochy, Van den Bossche, \& Segers, 2005; Segers, Van den Bossche, \& Teunissen, 2003; Vernon \& Blake, 1993). Implementation and research of problem-based learning in economics and business education is much less prevalent (Walker, Bridges, \& Chan, 1996) and only recently research of problem-based learning in

70 hospitality education has surfaced (Huang, 2005; Kivela \& Kivela, 2005; Martin, West, \& Bill, 2008; Zwaal \& Otting, 2007). Problem-based learning aims to stimulate knowledge building, application of knowledge, and understanding of subject matter. However, more systematic research is needed to confirm the role of problem-based learning in encouraging the development of more sophisticated epistemological beliefs and conceptions of teaching and learning. It is expected that students' conceptions of teaching and learning become more constructivist by participating in problem-based learning.

\section{Instruments}

Chan and Elliott's (2002) Epistemological Beliefs Questionnaire (EBQ) that builds on Schommer's multidimensional framework best fitted our purposes because of the explicit attention to the cultural context in the development of the instrument. By way of illustration an item of every factor is given below.

1. Innate/fixed ability. Item: "Some people are born good learners; others are just stuck with limited ability". 
2. Learning effort/process.

Item: "Knowing how to learn is more important than the acquired facts".

3. Authority/expert knowledge.

Item: "I still believe in what experts say even though it differs from what I

know".

4. Certainty of knowledge.

Item: "If scientists try hard enough, they can find the truth to almost

anything".

Students' conceptions of teaching and learning were measured with the Teaching and Learning Conceptions Questionnaire (TLCQ). The TLCQ is a 30-item questionnaire that measures a traditional and a constructivist conception of teaching and learning. An exemplary item for the traditional conception of teaching and learning is: "Learning means remembering what the teacher has taught". An example of an item on the constructivist subscale is: "Instruction should be flexible enough to accommodate individual differences among students". Chan (2001) validated the questionnaire by confirmatory factor analysis and established satisfactory goodness of fit indices.

\section{Data analysis}

Structural Equation Modeling (SEM) with EQS 6.1 (Bentler, 2006) was used to investigate the structure and validity of the EBQ and TLCQ, and the structural relationship between EBQ and TLCQ. In this study, we report the following absolute fit indexes: Root Mean square Residual (RMR), Standardized RMR (SRMR), and Root Mean Square Error of Approximation (RMSEA). In a well-fitting model, values of 05 or less on the RMSEA indicate a close fit and values of .08 or less indicate a reasonable fit of the hypothesized model and the observed data (Bentler, 2006). Moreover, a narrow confidence interval of the RMSEA reflects a good precision of the model fit (Byrne, 2006). Hancock and Mueller (2005) proposed target values for SRMR of .09 or less and RMSEA of .06 or less for a well-fitting model. SPSS 14.0 was used to test differences in epistemological beliefs and conceptions of teaching and learning between students. As the participants in this study do not make up a homogeneous sample, differences with regard to gender, age, study year, and nationality in students' epistemological beliefs and conceptions of teaching and learning will be analyzed.

\section{Results}

\section{Epistemological beliefs}

Confirmatory factor analysis of the EBQ with EQS 6.1 (ROBUST option) was performed. The Lagrange Multiplier test (LM) indicated that some error covariances contributed to 
misspecification of the model. Consequently, four error terms with considerable overlap in content were set as free parameters. Items with a factor loading $<.30$ were deleted. The validation of the instrument showed satisfactory goodness of fit indexes with RMSEA $=.055$ (Cl: $90 \% .045-.060)$, RMR $=.063$ and SRMR $=.066$, which confirms the applicability of the instrument to the cultural and educational context of this study. Cronbach's alpha, mean scores and standard deviations of the four EBQ dimensions are shown in Table 1 and reflect moderate internal consistency. The mean score on the dimension 'learning effort' is well above the midpoint of the five-point rating scale, which indicates that hospitality management students' believe in investing time and energy for gaining study success. Hospitality management students generally tend not to believe that knowledge can be transferred from a teacher to a student, because their score on the dimension 'Authority/expert knowledge' is below the midpoint of the scale. The mean score $(M=3.01)$ of the students on the EBQ dimension 'innate ability' is at the midpoint of the scale. However, the students' mean score on the dimension 'certainty of knowledge' ( $M=3.27)$ indicates that hospitality management students tend to believe that knowledge is certain.

Pearson correlations (table 1) were calculated to identify patterns in the data. Results show that certainty of knowledge significantly correlates with learning effort and expert knowledge. Another significant correlation exists between innate ability and expert knowledge. Although evidence has been provided for the multidimensionality of epistemological beliefs, significant correlations between several factors indicate that the epistemological dimensions are not independent.

Table 1: Cronbach's alpha, means, standard deviations and inter-correlations of the dimensions of the EBQ and TLCQ

\begin{tabular}{|c|c|c|c|c|c|c|c|c|c|}
\hline & $\begin{array}{l}\text { Cronbach's } \\
\text { alpha }\end{array}$ & Mean & SD & 1 & 2 & 3 & 4 & 5 & 6 \\
\hline 1. Innate/fixed ability & .64 & 3.01 & .5 & - & & & & & \\
\hline 2. Learning effort/process & .59 & 3.55 & .51 & -.030 & - & & & & \\
\hline 3. Authority/expert knowledge & e .45 & 2.75 & .64 & $.372^{* *}$ & .023 & $\cdot$ & & & \\
\hline 4. Certainty of knowledge & .51 & 3.27 & .70 & $.120^{\star}$ & $.178^{* *}$ & $.200^{\star *}$ & - & & \\
\hline 5. TLCQ (traditional) & .78 & 2,86 & .52 & $.338 * *$ & -.080 & $.412^{\star \star}$ & $.285^{\star \star}$ & - & \\
\hline 6. TLCQ (constructivist) & .77 & 3.73 & .51 & $-.169 * *$ & $440 * *$ & $-.114^{*}$ & .100 & $-.216 * *$ & - \\
\hline
\end{tabular}

* Correlation is significant at 0.05 level

** Correlation is significant at 0.01 level

\section{Conceptions of Teaching and Learning}

The two-factor structure of the Teaching and Learning Conceptions Questionnaire 
(TLCQ) with a constructivist and a traditional conception of teaching and learning is consistent with prior research (Chan \& Elliott, 2004; Chan, Tan, \& Khoo, 2007). Analysis showed that 25 items with factor loadings higher than .30 could be retained in the final version of the instrument. Confirmatory factor analysis resulted in satisfactory goodness of fit indexes, RMSEA =.057 ( $\mathrm{Cl}: 90 \% .050-.063), \mathrm{RMR}=.069$ and SRMR=.073 that meet Hancock and Mueller's (2005) target values and confirms the validity and applicability of the TLCQ for this study.

Cronbach's alpha, mean scores, and standard deviations of the TLCQ dimensions are given in Table 1. Cronbach's alpha of the constructivist $(a=.77)$ and traditional $(a=.78)$ conception of teaching and learning reflect good internal consistency. Moreover, a significant negative correlation exists between the traditional and constructivist dimension of the TLCQ $(r=-.216, p=.00)$. The mean scores on the constructivist $(M=3.73)$ and the traditional $(M=2.86)$ conception of teaching and learning in our study show that international hospitality management students tend to hold more constructivist than traditional conceptions of teaching and learning.

Students in our sample do not consistently score above the midpoint of the scale on the constructivist conception and below midpoint on the traditional conception or vice versa. Results show that 201 students can be considered as 'constructivists' with scores on the midpoint and above on the constructivist conception and lower than 3 on the traditional conception of teaching and learning. Only 16 students can be considered as 'traditionalists', scoring 3 or above on the traditional and lower than 3 on the constructivist conception of teaching and learning. A considerable amount of students can be considered as incongruent: 113 students score 3 or above on both conceptions and 17 students score below the midpoint on both conceptions. Though $62.5 \%$ of the students show a congruent conception of teaching and learning, $37.5 \%$ of the students hold an incongruent orientation. The relatively high percentage of students with a score above the midpoint on the constructivist conception of teaching and learning is an indication that students ${ }^{\prime}$ conceptions are well attuned to the problem-based learning environment. However, the traditional conception of teaching and learning still plays an important role in the minds of the students. The traditional and the constructivist conception of teaching and learning co-exist.

\section{Relationship between epistemological beliefs and conceptions of teaching and} learning

The results in Table 1 show several significant correlations between dimensions of the EBQ and dimensions of the TLCQ. The epistemological beliefs dimensions innate ability, expert knowledge, and certainty of knowledge are significantly related to the 
traditional conception of teaching and learning. These results indicate that students, who believe that the ability to learn is inborn, regard the teacher as an expert, and assume that knowledge is certain, more likely hold traditional conceptions of teaching and learning.

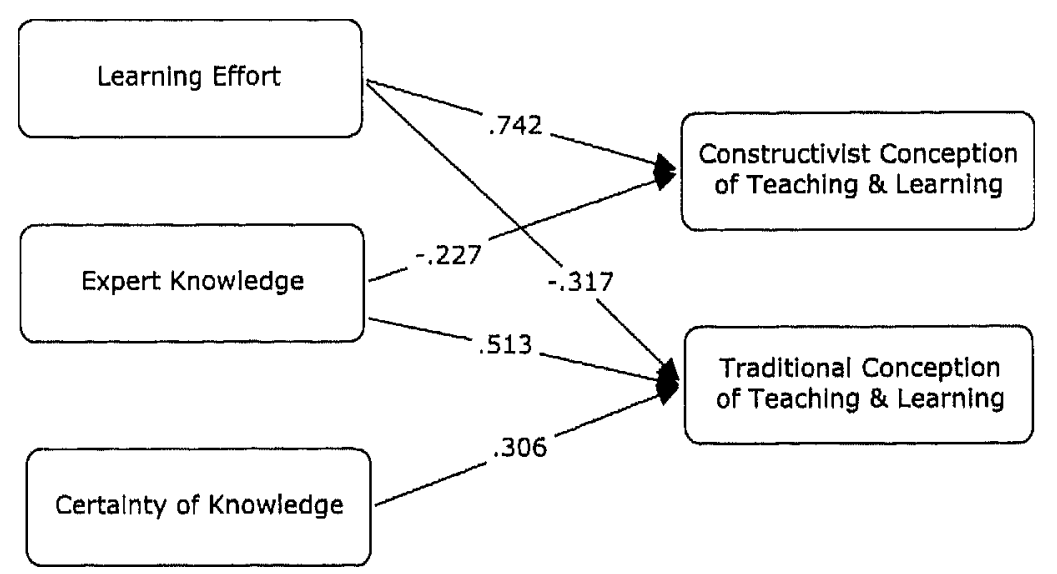

Figure 1. Structural relation between epistemological beliefs and conceptions of teaching and learning

The EBQ dimension learning effort/process is significantly and positively related to a constructivist conception of teaching and learning. Students with a constructivist conception of teaching and learning generally do not agree with statements that the learning ability is fixed at birth and limits what students can learn. Moreover, they tend not to believe in the teacher's authority and expertise.

Structural relations between the dimensions of the EBQ and the TLCQ (Fig. 1) were identified by Structural Equation Modeling (SEM) with EQS 6.1. Analysis showed that five paths of the full model were significant and elimination of the three non-significant paths led to a revised model with satisfactory goodness of fit indexes: RMSEA $=.048$ ( $\mathrm{Cl}: 90 \% .044-.052), \mathrm{RMR}=.067$ and $\mathrm{SRMR}=.070$. The RMSEA value .048 indicates a close fit of the model (Bentler, 2006). The SRMR and RMSEA values are within the range that Hancock \& Mueller (2005) proposed as joined target values for the SRMR (.09 or less) and the RMSEA (.06 or less) indicating a well-fitting model.

Results show that the EBQ dimension learning effort/process is positively related to the constructivist conception of teaching and learning and the EBQ dimension expert knowledge is negatively related to the constructivist dimension.

The EBQ dimension learning effort/process is negatively related to the traditional conception of teaching and learning and a positive relation was established between 
the EBQ dimensions authority/expert knowledge and certainty of knowledge and the traditional conception of the TLCQ. These three dimensions of epistemological beliefs are significantly related to the traditional conception of teaching and learning.

\section{Gender}

Gender issues are important in education. What is taught and how teaching takes place might be differently interpreted by female or male students and, by consequence, influence the learning process. T-tests show significant differences between male and female students. On the dimension authority/expert knowledge, male and female students differ significantly $(t=2.61, D F=343, p=.010)$. Male students $(M=2.85)$ more likely believe in the lecturer as an expert and source of expertise than the female students ( $M=2.67)$. Moreover, male students $(M=3.39)$ consider knowledge as less relative and more absolute than female students $(M=3.18, t=2.69, D F=343, p=.008)$. Results show non-significant differences for gender on the constructivist conception of teaching and learning, and on the learning effort/process dimension of epistemological beliefs. The male students have a significantly more traditional conception of teaching and learning than their female counterparts $(t=2.59, D F=343, p=.010)$. Male students $(M=2.93)$ more likely agree with the traditional dimension of the TLCQ than female students ( $M=2.79$ ). Female hospitality management students in this study have lower scores than male hospitality students on the epistemological dimensions expert knowledge, innate ability, and certainty of knowledge, and they don't support traditional viewpoints on teaching and learning.

\section{Junior and senior students}

The t-test shows that $1^{\text {st }}$ year students have significantly higher mean scores on the authority/expert knowledge dimension $(M=2.83, t=3.09, D F=345, p=.002)$ than senior students ( $2^{\text {nd }}$ year and up) have on authority/expert knowledge dimension ( $M=2.62$ ). Junior students have lower mean scores $(M=3.51)$ on the learning effort/process dimension of the $E B Q(t=-1.97, D F=345, p=.050)$ than senior students $(M=3.62)$. Moreover, junior students score significantly lower $(t=-4.21, D F=331.5, p=.000)$ on the constructivist dimension ( $M=3.64$ ) and significantly higher ( $t=3.39, D F=240.9, p=.001)$ on the traditional dimension of the TLCQ $(M=2.94)$ than senior students who have a mean score of 3.86 on the constructivist dimension and a mean score of 2.74 on the traditional dimension. These results demonstrate that senior students' beliefs of knowledge and conceptions of teaching and learning are more in line with constructivist views of education. Junior students tend to hold more traditional views on knowledge and learning and they look upon the teacher as the source of expertise and the provider of knowledge. 
Results show significant differences between younger and older students. Younger students $(<21)$ have significant $(t=2.84, D F=345, p=.005)$ higher scores on the dimension authority/expert knowledge $(M=2.84)$ than students of 21 years or older $(M=2.64)$. Contrary, older students score significantly higher $(t=-2.96, D F=345, p=.003)$ on the learning effort/process dimension of the $E B Q(M=3.64)$ than younger students $(M=3.48)$. Significant differences $(t=-2.95, D F=345, p=.003)$ were also found on the constructivist dimension of the TLCQ between older students $(M=3.82)$ and younger students $(M=3.65)$. Students of 21 years and older generally endorse the constructivist principles that underlie problem-based learning and attribute their learning results more to their own efforts than younger students do.

Seniority both in age and in years in education shows a consistent pattern. Younger students' epistemological beliefs and conceptions of teaching and learning are more traditional and less constructivist. Experience of life and involvement in problem-based learning positively influence the development of epistemological beliefs and support a constructivist conception of teaching and learning.

\section{Nationality}

76 Do international hospitality management students from four different continents (Africa, America, Asia, and Europe) have different epistemological beliefs and conceptions of teaching and learning? ANOVA indicates significant differences between international student groups on the traditional and the constructivist dimensions of the TLCQ, and on the innate ability dimension of the EBQ of the Asian students. A post hoc Bonferroni analysis shows that African students $(M=2.25$ ) significantly less believe in the learning ability as inborn compared to the students from America ( $M=3.56)$, Asia $(M=3.28)$ or Europe $(M=3.26)$. Besides, American students $(M=3.26)$ have significantly less constructivist conceptions of teaching and learning than students from Europe $(M=3.73)$ and Africa $(M=4.06)$.

\section{Discussion and conclusion}

The present study shows that epistemological beliefs held by international hospitality students are multidimensional. Validation of the EBQ confirmed four dimensions of epistemological beliefs: innate/fixed ability, learning effort/process, authority/expert knowledge, and certainty of knowledge. Our results are in line with prior research with the EBQ (Chan, 2008; Chan \& Elliott, 2002; 2004). The high mean score on the dimension learning effort/process and the low mean score on the dimension authority/expert knowledge indicate that hospitality management students tend to 
believe in constructivist views of knowledge and knowing. Moreover, the high mean scores on the constructivist conception of teaching and learning and the below average mean score on the traditional conception clearly demonstrate that hospitality management students generally subscribe to constructivist views. The present research shows that epistemological beliefs are related to conceptions of teaching and learning. The dimension learning effort/process of the EBQ shows a positive relationship with the constructivist conception of teaching and learning and the dimension expert knowledge of the EBQ is negatively related to the constructivist dimension of teaching and learning. Three dimensions of the EBQ are related to the traditional conception of teaching and learning. Learning effort/process is negatively related to the traditional conception. The dimensions authority/expert knowledge and certainty of knowledge are positively related to the traditional conception of the TLCQ. These relationships indicate a link between more traditional epistemological beliefs and traditional conceptions of teaching and learning. Confirmatory factor analysis showed a structural relation between epistemological beliefs and conceptions of teaching and learning. The majority of the students in our sample attribute study success to their own learning efforts and active engagement in self-directed learning. These students are not exclusively dependent on their lecturers for information and generally have constructivist conceptions of teaching and learning.

Our findings show the multidimensionality of epistemological beliefs and are in agreement with prior research by Chan and Elliott (2004). However, a closer inspection of the EBQ reveals that both knowledge and learning issues are addressed in the questionnaire on epistemology. The instrument could be improved by focusing on knowledge only instead of both knowledge and learning. The common ground between the study of epistemological beliefs and the study of constructivism can be found in epistemological issues. Therefore, a questionnaire on epistemological beliefs should focus on questions about what knowledge is and should include questions from both the constructivist and traditional perspectives on knowledge. In connection with a change of focus in the epistemological beliefs questionnaire, the TLCQ should distinguish between teaching and learning issues because theories of teaching and learning may address similar issues but do not necessarily coincide. Therefore, we would suggest the separate development of three conceptions: conceptions of knowledge, conceptions of learning, and conceptions of teaching. This suggestion is in line with research by Kember (2001), who suggested two contrasting belief sets, a didacticreproductive and a facilitative/transformative belief set. Both belief sets were characterized by three components: knowledge, teaching, and learning.

A minority of the students doesn't attribute their learning to their own efforts, depend on the teacher as the source of knowledge, believe in the certainty of knowledge, and consequently endorse a traditional view on teaching and learning. Moreover, there are 
students with mixed orientations, which is an indication that students do not always show a consistent pattern on the dimensions of the EBQ and the TLCQ. For the most part, students in a problem-based learning environment have acquired a constructivist conception of teaching and learning but that does not imply that their traditional conception has decreased at the same time.

This study has several implications for educational practice. First, successful introduction of problem-based learning not only depends on careful guidance of students by qualified lecturers during the PBL-sessions but must also be supported by paying attention to the development of epistemological beliefs and conceptions of education that students hold. Discussions about the basic features of constructivist education are essential to bring about a clearer understanding of problem-based learning and its underlying educational principles. Second, unstructured and authentic tasks in problem-based learning may lead to different problem definitions and multiple solution paths. The multitude of ideas and possibilities in problem-based learning creates a constructive friction that stimulates learning but may also cause feelings of uncertainty for students who are searching for the right solution and are confronted with inconsistent or contradictory results. Third, students who are not used to self-directed learning find it difficult to formulate their own learning goals and to monitor their own learning process. Fourth, students that are accustomed to the traditional teacher-centered lecture method often lack the necessary communication and problem solving skills and experience difficulties to efficiently work together in problem-based learning. Attention should be paid to the prior knowledge and learning skills that students bring into the PBL-setting and how their beliefs about knowledge and their conceptions of teaching and learning influence the way they approach learning tasks. Fifth, the relatively low score of the students on the EBQ dimension authority/expert knowledge indicates that teachers facilitate learning processes in problem-based learning and encourage students to self-directed learning. Sixth, the well above the midpoint mean scores on the learning effort/process dimension of the $E B Q$ and the constructivist dimension of the TLCQ, and the positive relation between both dimensions correspond with the basic assumptions of problem-based learning. However, further research is needed to establish structural relations between epistemological beliefs, conceptions of teaching and learning, and problem-based learning.

Does problem-based learning fit with international students' epistemological beliefs and conceptions of teaching and learning? International students, who are educated in the traditional classroom, may experience difficulties with problem-based learning and other constructivist learning environments. In a traditional educational system with a focus on individual knowledge acquisition, students are not used to work with 
participative approaches to learning. It has often been argued that Asian students in general and Chinese students in particular, not always experience education in the Western world positively (Zhang \& Brunton, 2007). Therefore, the transferability of problem-based learning and Western hospitality management education to non-Western settings can be questioned. This research established significant differences between students from different nationalities on the constructivist and the traditional conceptions of teaching and learning. However, the size of several groups was small, which complicates the extrapolation of the findings. By way of precaution, we would nevertheless recommend a comprehensive introduction of international students to cope with the problem-based learning environment.

The main conclusion of this study is that the hospitality management students in our study have more constructivist than traditional conceptions of teaching and learning. The educational philosophy of our university is explicitly based on constructivist principles of education and problem-based learning is firmly integrated in the curriculum. Problem-based learning seems to influence the development of more constructivist beliefs and conceptions. Both the hospitality industry and higher education stress the importance of integrating knowing and doing, critical reflection and debate, individual and cooperative learning, and critical inquiry and independent thinking in providing students with the competencies that the industry really needs. This study shows that international hospitality management students from different cultural and educational backgrounds have conceptions of teaching and learning that enable them to positively experience problem-based learning. Hence, we can conclude that problem-based learning can be used effectively with students from different cultural backgrounds. 


\section{References}

Akrivos, C., Ladkin, A., \& Reklitis, P. (2007). Hotel manager's career strategies for success. International Journal of Contemporary Hospitality Management, 19(2), 107-119.

Baum, T. (2007). Human resources in tourism: Still waiting for change. Tourism Management, 28(6), 1383-1399.

Barrows, H. S., \& Tamblyn, R. M. (1980). Problem-based learning. New York: Springer.

Belenky, M., Clinchy, B., Goldberger, N. R., \& Tarule, J. (1986). Women's ways of knowing: The development of self, mind, and voice. New York: Basic Books.

Bentler, P. M. (2006). EQS 6 Structural equations program manual. Encino, CA: Multivariate Software Inc.

Brăten, I., \& Strømsø, H. I. (2004). Epistemological beliefs and implicit theories of intelligence as predictors of achievement goals. Contemporary Educational Psychology, 29, 371-388.

Bråten, I., \& Strømsø, H. I. (2005). The relationship between epistemological beliefs, implicit theories of intelligence, and self-regulated learning among Norwegian postsecondary students. British Journal of Educational Psychology, 75, 539-565.

Byrne, B. M. (2006). Structural equation modeling with EQS. Basic concepts, applications, and programming. Mahwah, NJ: Lawrence Erlbaum Associates.

Chan, K-W. (2001). Validation of a measure of personal theories about teaching and learning. Paper presented at the AARE 2001 conference, Fremantle, Australia.

Chan, K-W. (2003). Hong Kong teacher education students' epistemological beliefs and approaches

80 to learning. Research in Education, 69(1), 36-50.

Chan, K-W. (2008). Hong Kong teacher education students' epistemological beliefs and their relations with conceptions of learning and learning strategies. The Asia Pacific Education Researcher, 16(2), 199-214.

Chan, K-W., \& Elliott, R. G. (2002). Exploratory study of Hong Kong teacher education students' epistemological beliefs: cultural perspectives and implications on beliefs research. Contemporary Educational Psychology, 27, 392-414.

Chan, K-W., \& Elliott, R. G. (2004). Relational analysis of personal epistemology and conceptions about teaching and learning. Teaching and Teacher Education, 20,817-831.

Chan, K-W., Tan, J., \& Khoo, A. (2007). Pre-service teacher's conceptions about teaching and learning: a closer look at Singapore cultural context. Asia-Pacific Journal of Teacher Education, 35(2), 181-195.

Cho, W., Schmelzer, C. D., \& McMahon, P. S. (2002). Preparing Hospitality Managers for the 21st century: education, critical thinking, and collaborative learning. Journal of Hospitality \& Tourism Research, 26(1), 23-37.

Clinchy, B. (2002). Revisiting Women's ways of knowing. In B. K. Hofer and P. R. Pintrich (Eds.), Personal epistemology: The psychology of beliefs about knowledge and knowing (pp. 63-88). Mahwah, NJ: Lawrence Erlbaum Associates. 
Connolly, P., \& MCGing, G. (2007). High performance work practices and competitive advantage in the Irish hospitality sector. Internationa/ Journal of Contemporary Hospitality Management, 19(3), 201-210.

De Corte, E. (2000). Marrying theory building and the improvement of school practice: a permanent challenge for instructional psychology. Learning and Instruction, 10(3), 249-266.

Gijbels, D., Dochy, F., Van den Bossche, P., \& Segers, M. (2005). Effects of problem-based learning: A meta-analysis from the angle of assessment. Review of Educational Research, 75(1), 27-61.

Gijbels, D., Van de Watering, G., Dochy, F., \& Van den Bossche, P. (2006). New learning environments and constructivism: The students' perspective. Instructional Science, 34, 213-226.

Hancock, G. R., \& Mueller, R. O. (2005). Structural equation modeling. A first course. Rotterdam: Erasmus University Medical Center.

Hendry, G. D., Frommer, M., \& Walker, R. A. (1999). Constructivism and problem-based learning. Journal of Further and Higher Education, 23(3), 359-371.

Hofer, B. K., \& Pintrich, P. R. (1997). The development of epistemological theories: beliefs about knowledge and knowing and their relation to learning. Review of Educational Research, 67(1), 88-140.

Huang, R. (2005). Chinese international students' perceptions of the problem-based learning experience. Journal of Hospitality, Leisure, 5port and Tourism Education, 4(2), 36-43.

James, S. (2006). Learning to cook: Production learning environment in kitchens. Learning Environments Research, 9(1), 1-22.

Karabenick, S. A., \& Moosa, S. (2005). Culture and personal epistemology: US and Middle Eastern students' beliefs about scientific knowledge and knowing. Social Psychology of Education, 8 , 375-393.

Kember, D. (2001). Beliefs about knowledge and the process of teaching and learning as a factor in adjusting to study in higher education. Studies in Higher Education, 26(2), 205-221.

Kivela, J., \& Kivela, R. J. (2005). Student perceptions of an embedded problem-based learning instructional approach in a hospitality undergraduate programme. International Journal of Hospitality Management, 24(3), 437-464.

Lave, J., \& Wenger, E. (1991). Situated learning. Legitimate peripheral practice. Cambridge: Cambridge University Press.

Lonka, K., \& Lindblom-Ylänne, S. (1996). Epistemologies, conceptions of learning, and study practices in medicine and psychology. Higher Education, 31, 5-24.

Martin, L., West, J., \& Bill, K. (2008). Incorporating problem-based learning strategies to develop learner autonomy and employability in sports science undergraduates. Journal of Hospitality, Leisure, Sport \& Tourism Education. 7(1), 18-30.

McCuddy, M. K. (2007). The challenges of educating people to lead in a challenging world, In M. K. Mc Cuddy, H. van den Bosch, Wm. B. Martz, A. V. Matveev \& K. O. Morse (Eds.), The challenges of educating people to lead in a challenging world (pp. 3-30). Dordrecht: Springer.

Meister, J. C. (1998). Corporate universities. Lessons in building a world-class work force. New York: McGraw-Hill. 
Muis, K. R., Bendixen, L. D., \& Haerle, F. C. (2006). Domain-generality and domain-specificity in personal epistemology research: Philosophical and empirical questions in the development of a theoretical model. Educational Psychology Review 78(1), 3-54.

Ottenbacher, M., Gnoth, J., \& Jones, P. (2006). Identifying determinants of success in development of new high-contact services. Insights from the hospitality industry. International Journal of Service Industry Management, 17(4), 344-363.

Paulsen, M. B., \& Feldman, K. A. (2005). The conditional and interaction effects of epistemological beliefs on the self-regulated learning of college students: Motivational strategies. Research in Higher Education, 46(7), 731-768.

Paulsen, M. B., \& Feldman, K. A. (2007). The conditional and interaction effects of epistemological beliefs on the self-regulated learning of college students: Cognitive and behavioral strategies. Research in Higher Education, 48(3), 353-401.

Petraglia, J. (1998). Reality by Design. The rhetoric and technology of authenticity in education. Mahwah, NJ: Lawrence Erlbaum Associates,

Phillips, D. C. (Ed.), (2000). Constructivism in education. Opinions and second opinions on controversial issues. Ninety-ninth Yearbook of the National Society for the Study of Education. Part 1. Chicago, Il: The University of Chicago Press.

Pintrich, P. R. (2002). Future challenges and directions for theory and research on personal epistemology. In B. K. Hofer \& P. R. Pintrich (Eds.), Personal epistemology: The psychology of beliefs about knowledge and knowing (pp. 389-414). Mahwah, NJ: Lawrence Erlbaum Associates.

82 Qian, G., \& Pan, J. (2002). A comparison of epistemological beliefs and learning from science text between American and Chinese high school students. In B. K. Hofer \& P. R. Pintrich (Eds.), Personal epistemology: The psychology of beliefs about knowledge and knowing (pp. 365-385). Mahwah, NJ: Lawrence Erlbaum Associates.

Roper, A., Brookes, M., \& Hampton, A. (1997). The multi-cultural management of international hotel groups. International Journal of Hospitality Management, 16(2), 147-159.

Samuelowicz, K., \& Bain, J. D. (2001). Revisiting academic's beliefs about teaching and learning. Higher Education, 41, 299-325.

Savery, J. R., \& Duffy, T. M. (1996). Problem based learning: An instructional model and its constructivist framework. In B. G. Wilson (Ed.), Constructivist learning environments: Case studies in instructional design (pp. 135-148). Englewood Cliffs, NJ: Educational Technology Publications.

Schommer, M. (1990). Effects of beliefs about the nature of knowledge on comprehension. Journal of Educational Psychology, 82(3), 498-504.

Schommer, M. (1993). Epistemological development and academic performance among secondary students. Journal of Educational Psychology, 85(3), 406-411.

Schommer, M. (1994). Synthesizing epistemological belief research: tentative understandings and provocative confusions. Educational Psychology Review, 6(4), 293-319.

Schommer-Aikins, M., \& Easter, M. (2006). Ways of knowing and epistemological beliefs: combined effect on academic performance. Educational Psychology, 26(3), 411-423. 
Schraw, G., \& Sinatra, G. M. (2004). Epistemological development and its impact on cognition in academic domains. Contemporary Educational Psychology, 29, 95-102.

Segers, M., Van den Bossche, P., and Teunissen, E. (2003). Evaluating the effects of redesigning a problem-based learning environment. Studies in Educational Evaluation, 29, 315-334.

Simons, R. J., Van der Linden, J., \& Duffy, T. (2000). New learning: three ways to learn in a new balance. In R. J. Simons, J. van der Linden \& T. Duffy (Eds.), New Learning (pp. 1-10). Dordrecht: Kluwer Academic Publishers.

Straus, K. (2007). Hotels' 325. Hotels. The magazine of the worldwide hotel industry,41(7), 36-50.

Terhart, E. (2003). Constructivism and teaching: a new paradigm in general didactics. Curriculum Studies, 35(1), 25-44.

Tribe, J. (2002). The philosophic practitioner. Annals of Tourism Research, 29(2), 338-357.

Trigwell, K., Prosser, M., \& Waterhouse, F. (1999). Relations between teachers' approaches to teaching and students' approaches to learning. Higher Education, 37, 57-70.

Vernon, D. T., \& Blake, R. L. (1993). Does problem-based learning work? A meta-analysis of evaluative research. Academic Medicine, 68, 550-563.

Vosniadou, S. (2001). How children learn. Brussels/Geneva: International Academy of Education/International Bureau of Education.

Walker, A., Bridges, E., \& Chan, B. (1996). Wisdom gained, wisdom given: instituting PBL in a Chinese culture. Journal of Educational Administration, 34(5), 12-31.

Whitla, P., Walters, P. G. P., \& Davies, H. (2007). Global strategies in the international hotel industry. International Journal of Hospitality Management, 26(4), 777-792.

Wilson, B. G. (Ed.), (1996). Constructivist learning environments: Case studies in instructional design. Englewood Cliffs, NJ: Educational Technology Publications.

Youn, I., Yang, K-M., \& Choi, I-J. (2001). An analysis of the nature of epistemological beliefs: Investigating factors affecting the epistemological development of South Korean high school students. Asia Pacific Education Review, 2(1), 10-21.

Zhang, Z., \& Brunton, M. (2007). Differences in living and learning: Chinese International students. Journal of Studies in International Education, 11(2), 124-140.

Zwaal, W., \& Otting, H. (2007). Hospitality management students' conceptions of education. Tourism and Hospitality Research, 7(3/4), 256-268. 


\title{
The identification of constructivist pedagogy in different learning environments
}

\author{
Published as: \\ Otting, H. \& Zwaal, W. (2007) \\ The Identification of Constructivist Pedagogy in different Learning Environments \\ In M. K. McCuddy, H. van den Bosch, Wm. B. Martz, A. V. \\ Matveev, \& K. O. Morse (Eds.), \\ The Challenges of Educating People to Lead in a Challenging World (pp. 171-196). \\ Dordrecht: Springer.
}




\begin{abstract}
The present study aims at contributing to empirical research on constructivist learning environments and tries to identify major elements of constructivist pedagogy in four learning environments. The different learning environments that fit in a constructivist framework are: problem-based learning, action learning, project work, and workplace learning. The problem statement that was investigated in the present study is: Can we find evidence for constructivist pedagogy in four different learning environments? The research question was approached from both the student and the instructional designer perspective. Moreover, we were interested if there is a difference in the perceived degree of constructivism between students and instructional designers. To identify constructivist pedagogy, a constructivism survey developed by Tenenbaum, Naidu, Jegede, and Austin (2001), was used.

Results show that students assign the highest overall mean score to the problem-based learning condition and further analysis shows that five of the seven factors show significant differences. No significant differences could be established between the four conditions for instructional designers. Compared with students, instructional designers rate problem-based learning as significantly more conforming to constructivism. The present study shows that problem-based learning was perceived as most complying to constructivist principles.
\end{abstract}

86 Keywords: constructivist pedagogy, problem-based learning, project work, workplace learning, action learning. 


\section{Introduction}

The present society is often considered as a knowledge or learning society in which the continuous advancement of the level of knowledge has become an important political and economic issue (Dijstelbloem \& Schuijt, 2002; WRR, 2002). Increasing global competition and technological advancement have a decisive impact on the rate of product innovation in organizations and, by consequence, influence the work environment, the task complexity, and the expected performance of every individual employee. Knowledge and learning, rather than capital, are becoming the main resources of the new global economy in which the use and creation of knowledge are considered as the most important factors for sustained economic growth. Therefore, companies in the global knowledge economy focus on the improvement of their knowledge base and highly value lifelong learning activities. Successful companies are the ones that learn effectively, because they understand that knowledge is becoming their most valuable asset and therefore focus on knowledge creation and knowledge sharing for sustainable economic success (Choo, 1998; Davis \& Botkin, 1994a; 1994b; De Geus, 1997; Drucker, 1999; Nonaka, 1991; Nonaka \& Takeuchi, 1995). The business sector has discovered the value of knowledge and their interest in knowledge and learning is growing. In a knowledge society, learning is the key factor for the production and diffusion of knowledge. A knowledge economy requires continuous learning, because the shelf life of knowledge is getting shorter and knowledge rapidly becomes obsolete. Therefore, the new workplace competencies companies require focus on learning to learn, communication and collaboration, creative thinking and problem solving, technological literacy, global business literacy, leadership development, and career self-management (Meister, 1998). These requirements form a tremendous challenge to higher education for developing the competencies that students really need.

The contours for new ideas about knowledge and learning in higher education as a consequence of the aforementioned shift to a knowledge society are beginning to take shape. Graduates should not only possess a wide range of competencies, but must also be able to apply their knowledge and skills to a wide range of problem situations. The new workplace competencies, which are required by the growing knowledge intensity in today's society, demand a review of the perspective from which education, knowledge and learning should be approached. The teaching environment, with its emphasis on giving information, is gradually developing into a powerful learning environment that supports constructive knowledge acquisition processes (De Corte, 1995; 2000; Dochy, Segers, Van den Bossche, \& Gijbels, 2003). The focus of education should shift from transmission of information and knowledge to a conception of learning as a self-organized and continuous process of constructing and reconstructing new knowledge on the basis of prior knowledge. 
A constructivist conception of education not only emphasizes the cognitive aspects of learning, but also takes the development of the whole person of the learner in his social and cultural environment into consideration (Anderson, Greeno, Reder, \& Simon, 2000; Bereiter, 1994; Billett, 1996; Von Glasersfeld, 1999). In constructivism, learning can be seen as an active search for meaning that takes place in interaction with the environment. Thus, constructivism is a viewpoint of knowledge and learning, which is founded on the premise that individuals construct their own understanding of the world. Constructivism is first and foremost a way of thinking about the formation of knowledge. Knowledge is a human creation that is dependent on the learner as the source of all explanations of reality. Constructivist views of learning emphasize learning processes in which students actively construct knowledge for themselves in interaction with rich and authentic learning environments. Therefore, pedagogical practices like project work, workplace learning, and action learning, which stress active and collaborative learning activities, might also fit in a constructivist framework. However, little research has focused on the characteristics of constructivist pedagogy in connection with different learning environments.

Research on innovations in economics and business education and the effects of problem-based learning on student performance is well-documented (Bentzen-Bilkvist, Gijselaers, \& Milter, 2002; Borghans, Gijselaers, Milter, \& Stinson, 2000; Dolmans, Gijselaers, Moust, De Grave, Wolfhagen, \& Van der Vleuten, 2002; Milter, Stinson, \& Gijselaers, 1998). However, empirical research that places problem-based learning and related educational innovations in a constructivist framework is considerably less available (Hay \& Barab, 2001). Therefore, this study intends to contribute to the empirical research on problem-based learning in a constructivist framework and tries to identify the major elements of constructivist pedagogy in different learning environments.

\section{Conceptual framework}

\section{The constructivist perspective}

Constructivism is a perspective on knowledge that is based on the assumption that knowledge is not a representation of the world outside the human mind. "It holds that knowledge is under all circumstances constructed by individual thinkers as an adaptation to their subjective experience" (Von Glasersfeld, 2000, p. 4). Knowledge does not simply transfer from a knowledgeable person to someone who lacks knowledge. Knowledge cannot be simply given to another individual. Constructivism challenges the view that education is a process that can be characterized as 'filling the empty heads of students.' Learning is an active knowledge construction process. The 
principle of active knowledge construction has fundamental consequences for pedagogical practice and the role of the lecturer. The lecturer is not the person who possesses true knowledge, who has all the right answers, and persuades the students to see things his way. On the contrary, the lecturer must be considered as a person who is genuinely concerned with the student's beliefs and thinking processes, functions as a facilitator of the student's learning process, and encourages students to take responsibility for their own learning. Students are invited to contribute to dialogues, are given opportunities to express their specific interests, and to specify their own learning goals.

A constructivist view of learning emphasizes a learning process in which students actively construct knowledge for themselves. Learning can be seen as an active search for meaning that takes place in interaction with the environment. "Learning in constructivist terms is:

- both the process and the result of questioning, interpreting, and analyzing information;

- using this information and thinking process to develop, build, and alter our meaning and understanding of concepts and ideas; and

- integrating current experiences with our past experiences and what we already know about a given subject" (Marlowe and Page, 1998, p. 10).

Constructivism is not a unified concept and different interpretations of constructivism can be found (Ernest, 1995; Geelan, 1997; Otting, 2000; Phillips, 1995; 2000; Prawat, 1996; Steffe \& Gale, 1995). Although the interpretations of constructivism differ from one another, common beliefs like the focus on authentic tasks, the embeddedness of tasks in a challenging and complex task environment, are shared (Savery \& Duffy, 1996).

\section{Different learning environments}

In this section of the chapter, we describe and discuss four different learning environments that fit in a constructivist framework: problem-based learning, action learning, project work, and workplace learning.

\section{Problem-based learning}

Problem-based learning (PBL) was first introduced in medical education at McMaster University (Canada) in the late 1960s (Barrows \& Tamblyn, 1980). Soon after, other medical schools (University of Newcastle, University of New Mexico, and Maastricht University) adopted problem-based learning. In the Netherlands, Maastricht University was the first to integrate problem-based learning in the medical curriculum. Since then, 
several higher education institutions introduced problem-based learning as an alternative to the more traditional forms of teaching.

Dochy, Heylen, and Van de Mosselaer (2000) describe learning in a problem-based learning environment as an active, cumulative, constructive, context-bound, self-regulated, purposeful, and meaningful process. Moreover, they consider a cognitive conflict as the stimulus for learning, emphasize knowledge development in a social context, and stress the need for rehearsal and training for the development of expertise.

Problem-based learning is an educational philosophy for designing curricula and an instructional method that uses problems as a context for students to acquire and apply knowledge (Gijselaers, 1995). Problem-based learning is characterized by a modular, thematic, interdisciplinary approach (Bouhuijs, 1993). It is an integrated system for student learning in which students are confronted with real-life problems that need to be discussed and solved. Acquisition of an integrated body of knowledge related to the problem and the development and application of problem solving skills are the main educational objectives of problem-based learning (Barrows \& Tamblyn, 1980). The problems that form the basis of the study activities are usually descriptions of real-life situations or events, which have to be analyzed by a small group of students under supervision of a tutor. The learning process starts with the activation of the students'

90 prior knowledge. Students use a systematic procedure to analyze the problem, to formulate learning objectives, to collect additional information, and to acquire new and relevant knowledge.

The role of the tutor is essential for the progress of learning in the PBL tutorials. Tutors stimulate the learning processes and allow discussions to proceed. They promote a relaxed atmosphere and encourage the cooperation among students. They observe the group activities, ask stimulating questions, and intervene if the group functioning is impeded. The interventions of the tutor can make the difference in the success or failure of the PBL tutorial (Hendry, Frommer, \& Walker, 1999; Moust, Bouhuijs, \& Schmidt, 1997).

In PBL, the quality of student learning is largely dependent on the quality of the problems. If a problem is too simple, it will not stimulate the learning process. If the problem is too complex and unstructured, students will have difficulties to solve the problem on their own and will need help from an expert tutor. PBL-tasks should match the student's level of prior knowledge (Dochy, 1992; Jacobs, Dolmans, Wolfhagen, \& Scherpbier, 2003; Schmidt \& Gijselaers, 1990). PBL tasks have to lead to problem-solving activities and should stimulate a positive learning climate. Otting and Peeters (1986) distinguish between the objective and subjective characteristics of problems. The 
objective characteristics of a problem relate to the educational aims and contents of the problem. It should not pass unnoted that there might be a discrepancy between the responsibility of the instructional designers who have to take responsibility for the quality of the curriculum and the basic aim of problem-based learning: students take responsibility for their own learning. The design of a problem-based curriculum should neither fully prescribe what all the students should know nor give the student complete freedom. The development of self-directed learning skills and subject matter coverage are not necessarily incompatible goals in a problem-based curriculum (Dolmans, 1994). However, one should not overestimate the degrees of freedom for students in a problem-based curriculum. The subjective characteristics of a problem concern the motivational, attitudinal, and personal aspects. A problem should be attractive to students; it should stimulate a variety of learning activities, not only cognitive learning, but also social learning. It is essential that instructional designers take both the subjective and objective characteristics of the problem into account.

Problem-based learning requires a lot of knowledge, experience, creativity, and insight in the student's learning process. It is not enough for the student to master theory; it is of eminent importance to apply the knowledge in practice. Knowledge in problem-based learning is of both theoretical and practical relevance. Problem-based learning tries to bridge the gap between theory and practice. Schmidt (2001) considers problem-based learning as emblematic of a constructivist approach to education.

From two often-cited reviews of problem-based learning (Albanese \& Mitchell, 1993; Vernon \& Blake, 1993), it can be concluded that the effects of problem-based learning are difficult to measure because of the lack of methodologically reliable research. The reviews suggest that problem-based learning in medical education has a positive effect on clinical performance and skills. Recently, Dochy et al. (2003, p. 533) performed a meta-analysis on the effects of problem-based learning and came to the same conclusion: "the review reveals that there is a robust positive effect from PBL on the skills of students." Moreover, they report a remarkable finding. "Students in PBL gained slightly less knowledge, but remember more of the acquired knowledge" (Dochy et al., 2003, p. 533). This finding is in line with Capon and Kuhn's study (2004, p. 74), which concluded that the benefit of problem-based learning does not lie in superior acquisition of new concepts, but that "the answer to what's good about problem-based learning is that it promotes sense making."

\section{Action learning}

Action learning was developed in the 1970 s by Reg Revans $(1971 ; 1991 ; 1998)$ as a different approach to management education and as an alternative for the more traditional approaches to education in British business schools. Action learning 
recognizes the learning potential of the learner and uses prior experience as an important source for learning. Pedler (1991, p.XXII) defines action learning as "an approach to the development of people in organizations which takes the task as the vehicle for learning. It is based on the premise that there is no learning without action and no sober and deliberate action without learning." The emphasis in the learning process in not on the acquisition of facts, not on book learning and intellectualizing, but rather on a process of restructuring existing knowledge and past experience. Action learning is widely used and acknowledged as a practical and effective approach to leadership and organizational development (Donnenberg, 1999; Dotlich \& Noel, 1998; Gasparski \& Botham, 1998; Marquardt, 1999; McGill \& Beaty, 1995; Revans, 1971; 1991; Weinstein, 1999).

The recognition of ignorance is the key to action learning. In a condition of ignorance, risk, and confusion, the main task of the learner is to pose questions. Learning $(\mathrm{L})$ is the sum of programmed knowledge $(P)$ and questioning insight $(Q)$ : the learning equation is $L=P+Q$ (Revans, 1997). Programmed knowledge, the already existing knowledge and the knowledge of solutions to problems in the past, can be found in great quantities. In a static environment, this programmed knowledge provides solutions for well-known problems. However, in a society that is characterized by rapid and constant change, yesterday's solutions do not work and can even create an entirely wrong mental set. To solve new problems, to become aware of ignorance, and the ability to

92 ask penetrating questions are essential (Reid, 1997). Action learning is a cooperative and social process in which people learn with and from one another. In the regular meetings of the group (the action learning set), the students discuss their individual projects. Students learn more effectively by working together on similar problems as 'comrades in adversity' (Mumford, 1997). Learning is a process in which learners acquire the ability to behave and to function as community members. They are becoming practitioners that learn about the significance of knowledge in the context of the community. The attention is drawn away from abstract knowledge and cranial learning about practice to learning in a communal context. Working, learning and innovating are closely related (Brown \& Duguid, 1991).

Three main components of action learning can be distinguished:

Learning and action.

Students or participants accept responsibility for acting on a particular issue or problem and work together on a specific company project. The emphasis in action learning is on learning, not just on the taking of action. This emphasis on learning distinguishes the action-learning project from other projects. By giving the participant in the action learning program the opportunity to manage a project in an organization, two aims 
are targeted: the enhancement of the development of the company and the improvement of the learning capacity of the individual person, the team, and the organization.

Action in the real world.

The specific nature of the problem or task requires that action must be undertaken in the real world. Students are given authority to take action on the problem. In the process of finding, selecting, describing, and defining the action learning project the relevance of the project for educational and business goals must be discussed. The optimization of action learning goals and processes is demonstrated by the mutual relation of educational and business goals, and the interrelationship of learning and action. In the project, a balance must be maintained between the practical use of the project for the company and the learning opportunities for the individual student. In the action learning process, learning and action are closely interrelated. There is no learning without action and no action without learning. The opportunities to learn and the concern for practical benefits must be in balance. The integration of work with learning in the project minimizes the problem of transfer of learning.

The action learning set.

An action learning set is a learning situation in which a group of people work together and support each other. The set is the home base of its members. The action learning set consists of six to eight people who meet on a regular basis. The set members have the task to help one another in an unthreatening and supportive way. They learn from one another's experiences. "Action learning is a continuous essay in understanding and explaining one's actions, in a community of fellow learners" (Morris, 1994, p. 536). The group members are concerned with learning and with work. They are involved in a constant effort to balance the commitment to action (the focus on the progress of the project and the orientation on results) and to learning (the acquisition and evaluation of new information).

Action learning emphasizes that the main objective of working together as a team is to learn and work as a team. The success of the team's learning activities depends on the individual learning of all team members. Every group member learns individually and socially. Sharing the right answers is not enough; essential concepts and ideas must be explained to the other team members. According to Slavin (1991) three concepts are central to team learning: team rewards, individual accountability, and equal opportunities for success.

In order to bridge the gap between theory and practice and to improve on the practical management competencies of students, action learning is widely used. In a university context, most of the educational programs can be characterized as work-based and 
therefore, specific attention has to be given to the interrelationships between work and learning. Boud, Solomon, and Symes (2001) distinguish six ideal characteristics of work-based programs that, in our opinion, perfectly fit in an action learning framework:

1. A partnership between an external organization and an educational institution is established to foster learning.

2. Learners are in some contractual relationship (employee, trainee) with an external organization.

3. The program is based on the needs of the workplace and of the learner and not on the disciplines. In the professional curriculum, work is the curriculum.

4. Recognition and accreditation of prior knowledge and experience, and the identification of the learning the students wish to engage in, represent the starting point for the program.

5. The most significant element of a learning program is the action learning project. Action learning projects are oriented to the challenges of the actual work and the future needs of the learner and the organization.

6. The learning outcomes of the programs have to be assessed within a standardized framework.

Implementing action learning not only entails the design of the curriculum from a student perspective, but also recognizes the opportunities and constraints for learning

94 in the workplace. The action learning projects, which address crucial work-related issues, are important means for realizing realistic educational outcomes.

Does action learning work? Research on the educational outcomes of action learning is limited. For instance, De Winter Hebron and De Winter Hebron (1998) researched the potential learning effects of the action learning program in the Warsaw School of Agriculture. Their research showed a remarkable improvement on the pretest-posttest results in knowledge of different aspects of management. Cunningham (1991) interviewed 32 out of the 41 participants of the program 'Action Learning for Chief Executives' and found in his research that most participants benefited greatly from the program. Research generally reflects the two main fields for the application of action learning: the training of managers in a wide range of industries and management education programs in universities. The action learning literature mainly focuses on the introduction of action learning in management education and training and do not go into detail about the learning results. The introduction and application of action learning in different academic and industrial settings shows a persistent and on-going discussion about the opportunities and limitations of action learning and confronts educational experts with the resistance to change of those involved in conventional learning situations (Bourner, Cooper, \& France, 2000; Gasparski \& Botham, 1998; McLaughlin \& Thorpe, 1993; O'Hara, Webber, \& Reeve, 1996; Peattie, 1996). 


\section{Project work}

Project work finds its origin in the pragmatic educational philosophy of Dewey. Dewey (1907) wants to shift the center of gravity in education from the teacher and the textbook to the student. Education focuses on learning activities and prepares students for active participation in the life of a democratic society. Free inquiry in projects emphasizing process over product characterizes a Deweyan approach to education. Students are confronted with real world problems, which offer opportunities for exploration, discovery, and problem solving. Education is not a passive process but a process of active participation in social activities.

Project work is a form of cooperative education, in which students work in small groups on the solution to problems that originate from organizations outside the school context and by consequence have a high reality value. Smith and Dodds (1997) describe a number of conditions for projects:

1. A good project creates change, is bounded in scope, has a limited time scale and offers distinctive payoffs.

2. Projects can be centered on one department level or focus on a combination of departments. A project in one department must involve opportunities for gaining broader understandings than the confines of the department.

3. The project must provide a means for exploring a significant problem area relevant for the company and leading to involvement and responsibility for action.

4. The project should include all aspects of project management and project planning. It is an opportunity to demonstrate a broad range of competencies and skills.

A project is more than a process of data collection and interpretation in a specific domain. Taking action, communicating, managing, and implementing are integrating parts of the process. Handling relationships with stakeholders, developing and maintaining internal and external networks, and working with others in a team context are important features of project management.

Writing a project report and stating some general recommendations without taking action is not enough. "So long as there is no serious intention to act upon a report, it will be received with the greatest enthusiasm and unanimity; only when the path to practical action is opened is any danger seen to arise. This is because praising reports demands only eloquence, whereas taking action upon them calls for commitment" (Revans, 1971, p. 27). Therefore, coherent assessments of the learning process, the cooperation among students, the actions of the students, and the project results are necessary. 


\section{Workplace learning}

The interest in workplace learning has increased due to the heightened awareness that workplace competencies may contribute to business competitiveness. In the contemporary workplace, knowledge and learning are of crucial importance because knowledge and learning become connected with productivity and employee performance. Recently, learning in the workplace has become integrated in schools and workplace learning has become a formal component of education for developing work-related competencies (Boud \& Solomon, 2001).

Two ways to approach the workplace inside school can be distinguished (Barab \& Duffy, 2000). The first approach is the educational approach that focuses on the creation of a practice field in which the student engages in the kinds of problems, practices, or tasks that he might encounter in industry. In a practice field, students are engaged in the kind of activities that might take place in the real world. They work on problems and tasks as if they were derived from the real world. One of the best examples of this kind of practice is problem-based learning in which authentic and constructed problems are used as a driver for student learning. Professional education often works with a laboratory-like practice situation. In hospitality education, for instance, practice is being taught in a food lab or instruction kitchen and students demonstrate their skills on separate units. These kinds of practices generally focus on individualized ways of

96 learning.

The second approach originates from anthropology and considers learning as a function of taking part in a specific community. In a community of practice, students learn on the job and from working together. On the job learning is implicit, informal, tacit, and social, and so natural that one has to realize that any learning takes place at all. Students as beginning practitioners acquire the relevant skills by participating in practice. Teachers and students work closely together and are dependent on each other. "This interdependence promotes an atmosphere of joint responsibility, mutual respect, and a sense of personal and group identity" (Brown, 1994, p. 10). Learning is largely a process of becoming a member of the community of practice. "Learning viewed as situated activity has as its central defining characteristic a process that we call legitimate peripheral participation" (Lave \& Wenger, 1991, p. 29, italics in original). This is a process of increasing participation in the socio-cultural practice of a community by which students become members of that community.

"Viewing learning as legitimate peripheral participation means that learning is not merely a condition for membership, but is itself an evolving form of membership" (Lave \& Wenger, 1991, p. 53). Learning is an integral aspect of practice and concerns the whole person. "The central issue in learning is becoming a practitioner not learning 
about practice" (Brown \& Duguid, 1991, p. 48). The specific characteristics of the workplace cannot be simply replicated in a school. "It is a fundamental challenge for design - for both the school and the workplace - to redesign the learning environment so that newcomers can legitimately and peripherally participate in authentic social practice in rich and productive ways - to, in short, make it possible for learners to 'steal' the knowledge they need" (Brown \& Duguid, 1993, p. 11).

In learning theory, emphasis is placed on authentic human performance in differing social and educational contexts. Social and cooperative learning in real-world contexts and the attention to authentic tasks and work environments emphasizing meaningful learning are the issues that are brought to the center of educational reform (Cognition \& Technology Group at Vanderbilt, 1996; Glaser, Ferguson, \& Vosniadou, 1996). The value of learning in the workplace is based on the premise that the exposure of students to structured work experiences might enhance the acquisition and application of an integrated body of knowledge and skills. In the workplace, work experiences and learning experiences are closely connected. Characteristic for learning in the workplace is the balance that must be maintained between the demand-driven nature of the workplace and the learning opportunities for students. Although, it is easily asserted that work and learning go hand-in-hand in the workplace, the dynamics of the workplace often cause dysfunctional work or learning outcomes. Therefore, careful attention has to be given to the dynamic balance between work and learning, between the demand-driven business environment and the focus on student-centered learning. The workplace as a constructivist learning environment demands a dynamic balance between flexibility and desired outcomes, between student learning and labor productivity.

Outside school, the quality of the workplace is rather vulnerable to changes in the organizational environment and the emphasis on productivity. During work placements, students often experience that work comes first and learning comes in second place. As a result of the varying work circumstances, continuous tensions between the learning that actually takes place and the learning that should take place can be noticed. The workplace and real-life tasks are considered as authentic examples of constructivist learning environments which provide students with opportunities for learning that are not fully specified by the curriculum. In a professional work practice, students learn by actively participating in practice.

The value of the integration of learning and work in the workplace is based on the premise that structured work experiences can be used to enhance the acquisition of knowledge and skills. Research shows that the quality of learning, to a large extent, is dependent on the quality of the workplace (Onstenk, 1997; 2003; Van der Klink, 1999). 


\section{Problem statement and research questions}

Over the last decade, constructivism has been discussed as a new approach to education. Constructivism is one of the main themes in the educational discourse (Steffe \& Gale, 1995; Matthews, 1998; Phillips, 2000). However, there is little evidence that constructivist theories have been of significant relevance to pedagogical practice. The growing interest in constructivism has concentrated on theoretical issues and has neglected to consider educational practice. Despite the fact that "constructivists believe that theory and practice are fundamentally interlinked" (Mir \& Watson, 2000), relatively few attempts have been made to research constructivism in educational practice. That is why this study aims to investigate the principles of constructivist pedagogy in different educational practices: Can we find evidence for constructivist pedagogy in four different learning environments?

The question is approached from two different angles: the student perspective and the point of view of instructional designers. With reference to the students perspective we formulated the following research question: is there a difference in the degree of constructivism as perceived by students between the four learning environments studied? From the point of view of the instructional designers, the following research question was formulated: Is there a difference in the degree of perceived implementation of constructivist principles between instructional designers involved in

98 each of the four learning environments studied? Finally, a comparison is made between the perception of students and the opinion of the instructional designers. This leads to the research question: Is there a difference in the perceived degree of constructivism between students and instructional designers?

\section{Method}

\section{Programs}

In the present study, students from three different BA programs participated: International Hospitality Management, Leisure Management, and Retail Management. Within these programs, four different learning conditions were distinguished: problem-based learning $(\mathrm{PBL})$, problem-based learning combined with workplace learning ( $\mathrm{PBL} \& \mathrm{WPL}$ ), action learning (AL), and project work (PW).

Problem-based learning was first introduced to the programs in 1987. Since then PBL has been applied to curricula varying from hospitality and tourism management to teacher education and creative therapy. 
In several modules of the hospitality management program, students are involved in two activities: PBL ( 3 weeks) and workplace learning ( 3 weeks). The workplace is a commercially operated hotel with 28 bedrooms, a conference center, three restaurants, and kitchens. Students learn from experience by participating in all hospitality operations and services. In this learning environment, hospitality management students take responsibility for all operations.

Action learning is used as the main educational method in the second year of a retail management program. The retail industry provides jobs, assignments, and projects for the students; and the teachers of the retail program facilitate the action learning program.

In the third year of their study, leisure management students are assigned to a specific project. The commercial research and consultancy department of the institution is responsible for the acquisition of the projects, the facilitation of the projects, and the quality control. The projects are on a profit or non-profit basis and can be described as authentic and challenging. The projects have to achieve results and the findings of the research are really important for the customers. The students are assigned as project members of the research community and perform their day-to-day work in a research setting outside school.

\section{Subjects}

A total of 237 students and 14 instructional designers from three different programs in economics and business of a university of professional education participated in the study. Table 1 provides information on the students who participated in the study.

Table 1: Division of Students over Learning Conditions $(\mathrm{N}=237)$

\begin{tabular}{lcccc}
\hline & PBL & PBL \& WPL & Action learning & Project work \\
\hline $1^{\text {st }}$ year students & 42 & 27 & 24 & 15 \\
$2^{\text {nd }}$ year students & 41 & 34 & & 19 \\
$3^{\text {rod }}$ year students & 35 & 19 & & \\
\hline
\end{tabular}

\section{Instrumentation}

A questionnaire, which was developed by Tenenbaum, Naidu, Jegede, and Austin (2001), was used as an instrument to identify constructivist pedagogy in four different 
learning environments. Tenenbaum et al. (2001) conducted their study in two separate stages. In the first stage, they used qualitative methods to identify the essential features and instructional principles of constructivist pedagogy. They used the characteristics of constructivism for the second stage of their research, which was largely quantitative and aimed at the elaboration of the key features of constructivism. A questionnaire with a preliminary set of 150 items was developed to measure constructivist pedagogy. The 150-item questionnaire was subjected to a principal component analysis followed by Oblimin rotation with eigenvalue $>1.00$, to determine the number of factors. This process resulted in seven factors, which together accounted for $69.5 \%$ of the variance (Tenenbaum et al., 2001). After three additional reduction procedures 30 items remained in the short version of the constructivism questionnaire. In an additional procedure the short version of the questionnaire was administered to 271 students and a confirmatory factor analyses was used for validation of the factor structure. Confirmatory factor analysis showed that six of the seven factors are highly correlated and seem to share one underlying dimension. Tenenbaum et al. (2001) believe that the factor 'conceptual conflicts and dilemmas' is a unique factor, which probably represents constructivist pedagogy more than the other factors. In the final questionnaire, which was used in this research, the word 'unit' was replaced by 'module' because a module is used as the basic unit in our educational system. Factors and items are shown in table 2.

100 Table 2: Factors and items in the Tenenbaum Constructivism Survey

(Tenenbaum et al., 2001)

Factor 1: Arguments, discussions, debates

1. The module encouraged originality of ideas.

2. The module allowed for constant exchange of ideas between student and teacher.

3. Multiple perspectives of situations were often presented in the module.

4. I learned to develop mind tools in this module (e.g., critical thinking).

5. The module allowed for arguments, discussions and debates.

Factor 2: Conceptual conflicts and dilemmas

6. The module posed some dilemmas for me.

7. The module caused confusion among conceptual ideas for me.

8. The module caused conflicts for me among various concepts.

Factor 3: Sharing ideas with others

9. The module allowed for social interaction.

10. The module comprised a variety of learning activities.

11. I was given sufficient opportunities to express myself.

12. I was given sufficient opportunities to share my own experiences with others. 
Factor 4: Materials and resources targeted toward solutions

13. The module taught me how to arrive at appropriate answers.

14. The module resources effectively conveyed information to be learned.

15. The module included relevant examples.

Factor 5: Motivation toward reflections and concept investigation

16. The module enabled me to use knowledge acquired for abstract thinking.

17. The module taught me to investigate concepts.

18. The module motivated me to think reflectively.

19. The module encouraged me to examine several perspectives of an issue.

20. The module motivated me for further learning of related subjects.

21. The ideas in the module motivated me to learn.

Factor 6: Meeting students' needs

22. I felt pleased with what I learned in the module.

23. The module took into consideration my needs and concerns.

24. The module helped me to pursue personal goals.

25. The module helped me to benefit from my learning difficulties.

26. The module allowed for the negotiation of the instructional goals and objectives.

Factor 7: Making meaning, real-life examples

27. The module addressed real-life events.

28. The module was rich in examples.

29. The module focused more on making meaning of the learned concepts rather than just answering questions.

30. The learning environment encouraged me to think.

All items were scored using a 5-point Likert-scale with the following scale-anchors: $1=$ not at all; 2 = a little; $3=$ somewhat; $4=$ much; 5 = very much.

\section{Design and data collection}

The present study can be classified as a descriptive, cross-sectional field-study with an ex post facto design. Data were collected during a six-week period in May/June 2003, among a sample of students from four different learning environments (see Table 1). In the PBL condition, seven modules were included. Five modules met the criteria of the PBLWPL condition. One module is entirely built on project work and one module was in an action learning format. For each of the 14 modules of this study, the module coordinator, who was responsible for the design of the module, was approached to fill out the questionnaire from the instructional designer's perspective. The participation of the students and instructional designers was voluntary. Subjects were asked to spend a maximum of 15 minutes to fill out the 30 -item questionnaire on constructivist education adapted from Tenenbaum et al. (2001). 


\section{Statistical analysis}

The data were transmitted to the statistical software program SPSS 14 and analyzed using descriptive statistics, t-tests and analysis of variance.

\section{Results}

\section{Constructivism in four learning environments}

Research question 1: Is there a difference in the degree of constructivism as perceived by students between the four learning environments studied?

Table 3 summarizes the mean scores, standard deviation, and sample sizes for the students' constructivism responses in each of the four learning environments.

Table 3: Mean Constructivism Scores by Students in Four Learning environments $(N=237)$

\begin{tabular}{|c|c|c|c|}
\hline & Mean & Std. dev. & $\mathrm{N}$ \\
\hline Problem-based learning & 3.07 & .31 & 118 \\
\hline Problem-based learning \& workplace learning & 2.91 & .22 & 80 \\
\hline Action learning & 2.92 & .44 & 24 \\
\hline Project work & 2.97 & .54 & 15 \\
\hline Overall & 2.99 & .32 & 237 \\
\hline
\end{tabular}

The reliability of the 30-item scale, indicated by Cronbach's alpha, is .67. ANOVA indicates that a significant difference exists between the mean scores assigned by students in each of the four learning conditions $(F(3,233)=4.83 ; p=.003)$. This result is caused by the significant contrast between the PBL and the PBL \& WPL conditions. None of the other conditions showed significant differences.

The results of our study show that the overall mean score assigned by students (2.99 on the five-point constructivism scale) cannot be considered as strong evidence for the existence of constructivist pedagogy in the modules in this study. Although we lack comparative results from other universities, at least we can assume that a mean score of almost 3 on a five-point scale leaves ample room for improvement. However, the results of our study clearly show that the $\mathrm{PBL}$ condition has a significantly higher mean score on the constructivism scale than the other three settings. 
Table 4: Mean factor scores by students in four learning environments

\begin{tabular}{|c|c|c|c|c|c|c|c|}
\hline & & PBL & & Action & Project & & \\
\hline & & $N=118$ & $\mathrm{~N}=80$ & $N=24$ & $N=15$ & $F(3,233)$ & Sign \\
\hline Factor 1: & $\begin{array}{l}\text { Arguments, discussions, } \\
\text { debates }\end{array}$ & 3.05 & 2.78 & 2.95 & 3.05 & 3.55 & .015 \\
\hline Factor 2: & $\begin{array}{l}\text { Conceptual conflicts } \\
\text { and dilemmas }\end{array}$ & 2.95 & 2.91 & 2.56 & 2.31 & 5.82 & .001 \\
\hline Factor 3: & $\begin{array}{l}\text { Sharing ideas with } \\
\text { others }\end{array}$ & 3.17 & 2.98 & 3.26 & 3.35 & 2.83 & .039 \\
\hline Factor 4: & $\begin{array}{l}\text { Materials and resources } \\
\text { targeted toward solutions }\end{array}$ & 3.02 & 2.88 & 2.74 & 2.76 & 2.24 & $.085 \mathrm{~ns}$ \\
\hline Factor 5 : & $\begin{array}{l}\text { Motivation toward reflections } \\
\text { and concept investigation }\end{array}$ & 3.12 & 2.93 & 2.83 & 3.00 & 3.47 & .017 \\
\hline Factor 6: & $\begin{array}{l}\text { Meeting students' } \\
\text { needs }\end{array}$ & 3.02 & 2.94 & 2.85 & 2.71 & 2.28 & $.080 \mathrm{~ns}$ \\
\hline Factor 7: & $\begin{array}{l}\text { Making meaning, } \\
\text { real-life examples }\end{array}$ & 3.11 & 2.95 & 3.16 & 3.42 & 4.34 & .005 \\
\hline
\end{tabular}

The profiles of the four learning environments in Table 4 show that the dominant factors in PBL are factors 3 (sharing ideas with others) and 5 (motivation toward reflections and concept investigation). Most dominant in PBL \& WPL, project work, and action learning are factors 3 (sharing ideas with others) and 7 (making meaning, real-life examples). These results suggest an overlap between these three learning environments.

ANOVA on the results of Table 4 indicate significant differences between educational conditions on all factors, except for factor 4 (materials and resources targeted toward solutions) and 6 (meeting students' needs). A significant difference can be observed between PBL and PBL \& WPL on factor 1 (arguments, discussions and debates). Factor 2 (conceptual conflicts and dilemmas) reveals significant differences between PBL and project work and between PBL \& WPL and project work. Factor 7 (making meaning, real-life examples) shows a significant contrast between project work and PBL \& WPL.

Implementation of constructivist principles by instructional designers

Research question 2: Is there a difference in the degree of implementation of constructivist principles between instructional designers involved in each of the four 
learning environments studied? Table 5 summarizes the mean scores, standard deviation, and sample sizes for the instructional designers' constructivism responses in each of the four learning environments. Analysis on the results of table 5 indicates no significant differences between the four conditions.

Table 5: Mean Constructivism Scores by Instructional Designers $(N=14)$

\begin{tabular}{llll}
\hline & Mean & Std. dev. & $\mathrm{N}$ \\
\hline Problem-based learning & 3.39 & .37 & 7 \\
Problem-based learning \& workplace learning & 3.39 & .78 & 5 \\
Action learning & 2.93 & - & 1 \\
Project work & 2.87 & - & 1 \\
\end{tabular}

\section{Comparison between students and instructional designers}

Research question 3: Is there a difference in the perceived degree of constructivism between students and instructional designers?

The overall mean on the 30 item constructivism scale is 2.99 for students $(N=237)$ and

3.32 for instructional designers $(N=14)$. This difference is significant $(t=-2.25 ; p=.04)$,

104 which implies that instructional designers differ from students regarding the degree to which they perceive their module to comply with constructivist principles.

As shown in Table 6 instructional designers generally perceive their modules to be more complying to constructivist principles than students do. Only project work shows a reversed outcome: students rate this condition as more constructivist than instructional designers. Although the mean constructivist score assigned by students and instructional designers differs in each of the four learning environments, only one of scores is statistically significant: compared with students, instructional designers rate the PBL modules as significantly more conforming to constructivism.

Table 6: Mean Constructivism Scores by Students and Instructional Designers in Four Learning environments

\begin{tabular}{llll}
\hline & Students & Instructional designers \\
& $\mathrm{N}=237$ & $\mathrm{~N}=14$ & \\
\hline Problem-based learning & 3.07 & & $\mathrm{t}(123)=2.61 ; \mathrm{p}=.01$ \\
Problem-based learning \& workplace learning & 2.91 & 3.39 & $\mathrm{~ns}$ \\
Action learning & 2.92 & 3.39 & $\mathrm{~ns}$ \\
Project work & 2.97 & 2.93 & $\mathrm{~ns}$ \\
\hline
\end{tabular}


Although the difference between students and instructional designers in the PBL\&WPL condition is even larger than in the PBL condition, this difference is not significant, because the number of subjects involved in the PBL\&WPL condition is small, and the difference in variance is much larger, than in the PBL condition.

Table 7 reports results comparing students and instructional designers on the seven factors. The perception of students and instructional designers differs significantly with respect to factor 1 (arguments, discussions, debates) $(F=4.11 ; p=.04$ ), factor 3 (sharing ideas with others) ( $F=5.69 ; p=.018$ ) and factor 7 (making meaning, real-life examples) $(F=16.64 ; p=.000)$.

Table 7: Comparison between mean scores of Students and Instructional Designers on the Seven Components

\begin{tabular}{|c|c|c|c|c|c|c|}
\hline & & Overall & Students & Instructional & & \\
\hline & & & & Designers & $\mathrm{F}$ & \\
\hline & & $N=251$ & $N=237$ & $N=14$ & $(1,249)$ & Sign \\
\hline Factor 1: & $\begin{array}{l}\text { Arguments, discussions, } \\
\text { debates }\end{array}$ & 2.97 & 2.95 & 3.29 & 4.11 & .044 \\
\hline Factor 2: & $\begin{array}{l}\text { Conceptual conflicts } \\
\text { and dilemmas }\end{array}$ & 2.87 & 2.86 & 3.10 & 1.51 & $.221 \mathrm{~ns}$ \\
\hline Factor 3: & $\begin{array}{l}\text { Sharing ideas with } \\
\text { others }\end{array}$ & 3.15 & 3.13 & 3.55 & 5.69 & .018 \\
\hline Factor 4: & $\begin{array}{l}\text { Materials and resources } \\
\text { targeted toward solutions }\end{array}$ & 2.94 & 2.93 & 3.19 & 2.13 & $.146 \mathrm{~ns}$ \\
\hline Factor 5 & $\begin{array}{l}\text { Motivation toward reflections } \\
\text { and concept investigation }\end{array}$ & 3.04 & 3.02 & 3.26 & 2.64 & $.105 \mathrm{~ns}$ \\
\hline Factor 6 : & $\begin{array}{l}\text { Meeting students' } \\
\text { needs }\end{array}$ & 2.97 & 2,96 & 3.16 & 2.02 & . $157 \mathrm{~ns}$ \\
\hline Factor 7: & $\begin{array}{l}\text { Making meaning, } \\
\text { real-life examples }\end{array}$ & 3.11 & 3.08 & 3.66 & 16.64 & .000 \\
\hline
\end{tabular}

\section{Conclusion and discussion}

The main research question for the present study was: Can we find evidence for constructivist pedagogy in four different learning environments? This question was approached both from the perspective of the students and the instructional designers. Students, on average, perceive the presence of the main aspects of constructivist pedagogy in the different learning environments. Although the instructional designers 
positively assess the application of constructivist principles in the modules, even their mean score leaves ample room for improvement. The theoretical framework of constructivism has not yet filtered through to the practice of educational designers. It is not surprising that educationalists that adhere to constructivist views of education still have a lot of work to do in convincing teachers and students of the benefits of constructivist pedagogy.

Especially two conditions, PBL and PBL \& WPL, show significant differences in the degree of perceived constructivism. These differences could be the result of two elements. First, the specific way in which workplace learning in a hospitality environment is designed (the structures in the workplace) and, second, the formalized and standardized work procedures and instructions for the students (the procedures in the workplace). These structures and procedures focus on conformance of behavior and limit the degrees of freedom for students toward self-management in the workplace and thereby limit the opportunities for self-directed learning. Considered on its own, the workplace as an authentic learning environment is obviously an insufficient guarantee for constructivist learning to take place.

Contrary to the students, instructional designers perceive no significant differences between the four learning environments. For an explanation, we can either look at characteristics of the perceiver or at the object of perception. Instructional designers might be biased and primarily observe or stress the similarities between the four learning environments. Alternatively, we could hypothesize that instructional designers always apply the same set of principles, which would lead to similar educational formats, under different names. Particularly when the PBL paradigm constitutes the overarching educational philosophy, like in the university in this study, this will create some shared characteristics between learning environments. Another explanation for the different perceptions of students and instructional designers could be attributed to diverse interpretations of the concepts used in the questionnaire. Finally, a statistical explanation could be that because of the small number of instructional designers, the power of the testing procedure is rather low.

Instructional designers generally perceive their PBL modules to be more constructivist than students. Only project work shows a reversed outcome: students rate this condition as more constructivist than instructional designers. A possible explanation is that students and instructional designers assign different weights to different aspects of constructivism. This raises important and interesting questions about the nature and dimensions of the epistemological beliefs that students and instructional designers hoid. 
The present study was limited to four learning environments within one single university. A second limitation was that only students from the programs in the sector 'economics and management' were included in the study and that the sample was not equally composed of first, second, and third year students. A third limitation is related to the instrumentation applied. We used the questionnaire developed by Tenenbaum et al. (2001) since it was specifically developed for measuring constructivist pedagogy and therefore the construction of a new instrument seemed unnecessary.

The generalization of the results of this study is limited. We suggest that the study should be extended to different programs and be repeated in other universities, particularly universities that apply constructivist pedagogy in their curriculum. Replication of the study would serve several purposes. First, it would contribute to the determination of benchmarks for constructivism in higher education. Second, it would offer opportunities to cross-validate and test the construct validity of the constructivism questionnaire of Tenenbaum et al. (2001). Another line of research in extension of the present study might concern the investigation of the effectiveness and efficiency of constructivist pedagogy compared to traditional educational approaches. The assumption, implicit in the present study, that application of constructivist principles will lead to a more desirable educational payoff, will also need explicit testing in additional studies.

Problem-based learning is consistent with constructivist views of learning. PBL can be considered as the almost ideal application of constructivist principles, because PBL supports active and cooperative knowledge construction, and focuses on problem solving and in-depth understanding (Camp, 1996; Dolmans, Wolfhagen, Van der Vleuten, \& Wijnen, 2000; Savery \& Duffy, 1996). For the moment, considering the result of this study that PBL proved to be perceived as most complying to constructivist pedagogy, we would advise educational designers to continue capitalizing on the constructivist principles of $\mathrm{PBL}$. 


\section{References}

Albanese, M. A., \& Mitchell, 5. (1993). Problem-based learning: A review of literature on its outcomes and implementation issues. Academic Medicine, 68(1), 52-81.

Anderson, J. R., Greeno, J. G., Reder, L. M., \& Simon, H. A. (2000). Perspectives on learning, thinking, and activity. Educational Researcher, 29(4), 11-13.

Barab, S. A., \& Duffy, T. M. (2000). From practice fields to communities of practice. In D. H. Jonassen and S. M Land (Eds.), Theoretical Foundations of Learning Environments (pp. 25-55). Mahwah, NJ: Lawrence Erlbaum Associates.

Barrows, H. S., \& Tamblyn, R. M. (1980), Problem-Based Learning. Springer: New York.

Bentzen-Bilkvist, A., Gijselaers, W. H., \& Milter, R. G. (Eds.), (2002). Educational Innovation in Economics and Business VII. Educating Knowledge Workers for Corporate Leadership: Learning into the Future. Dordrecht: Kluwer Academic Publishers.

Bereiter, C. (1994). Constructivism, socioculturalism, and Popper's world 3. Educational Researcher, $23(7), 21-23$.

Billett, S. (1996). Situated learning: Bridging sociocultural and cognitive theorizing. Learning and Instruction, 6(3), 263-280.

Borghans, L. Gijselaers, W. H., Milter, R. G., \& Stinson, J. E. (Eds.), (2000). Educational Innovation in Economics and Business V. Business Education for the Changing Workplace. Dordrecht: Kluwer Academic Publishers.

Boud, D., \& Solomon, N. (2001). Repositioning universities and work. In D. Boud \& N. Solomon (Eds.), Work-based Learning: A New Higher Education? (pp. 18-33). Buckingham: The Society for Research into Higher Education and Open University Press.

Boud, D., Solomon, N., \& Symes, C. (2001). New practices for new times. In D. Boud \& N. Solomon (Eds.), Work-based Learning: A New Higher Education? (pp. 3-17). Buckingham: The Society for Research into Higher Education and Open University Press.

Bouhuijs, P. (1993). Problem-Based Learning as an Educational Strategy. Maastricht: Network Publications.

Bourner, T., Cooper, A., \& France, L. (2000). Action learning across a university community. Innovations in Education and Training International, 37(1), 2-9.

Brown, A. L. (1994). The advancement of learning. Educational Researcher, 23(8), 4-12.

Brown, J. S., \& Duguid, P. (1991). Organizational learning and communities-of-practice: Toward a unified view of working, learning, and innovation. Organization Science, 2(1), 40-57.

Brown, J. S., \& Duguid, P. (1993). Stolen knowledge, Educational Technology, March, 10-15. Retrieved May 21, 2009, from http://www2.parc.com/ops/members/brown/papers/stolenknow.html

Camp, G. (1996). Problem-based learning: A Paradigm shift or a passing fad. Medical Education Online, 1(2). Retrieved May 21, 2009, from http://www.med-ed-online.org/volume1.htm

Capon, N., \& Kuhn, D. (2004). What's so good about problem-based learning? Cognition and Instruction, 22(1), 61-79. 
Choo, C. W. (1998). The Knowing Organization. How Organizations Use Information to Construct Meaning, Create Knowledge, and Make Decisions. New York: Oxford University Press.

Cognition \& Technology Group at Vanderbilt. (1996). Multimedia environments for enhancing learning in mathematics. In S. Vosniadou, E. de Corte, R. Glaser \& H. Mandl (Eds.), International Perspectives on the Design of Technology-Supported Learning Environments (pp. 285-305). Mahwah, NJ: Lawrence Erlbaum Associates.

Cunningham, I. (1991). Action learning for chief executives. In M. Pedler (Ed.), Action learning in Practice (pp. 319-340). Aldershot: Gower.

Davis, S. M., \& Botkin, J. W. (1994a). The Monster under the Bed. How Business is Mastering the Opportunity of Knowledge for Profit. London: Simon \& Schuster.

Davis, S. M., \& Botkin, J. W. (1994b). The coming of knowledge-based business. Harvard Business Review, 72(5), 165-170.

De Corte, E. (1995). Fostering cognitive growth: A perspective from research on mathematics learning and instruction. Educational Psychologist, 30(1), 37-46.

De Corte, E. (2000). Marrying theory building and the improvement of school practice: A permanent chatlenge for instructional psychology. Learning and instruction, 10(3), 249-266.

De Geus, A. (1997). The Living Company: Growth, Learning and Longevity in Business. London: Nicholas Brealey Publishing.

Dewey, J. (1907). The School and Society. Chicago: University of Chicago Press.

De Winter Hebron, C., \& De Winter Hebron, D. J. (1998). Applying action learning principles to academic seminars: A study in praxiological action. In W. W. Gasparski \& D. Botham (Eds.), Action Learning. Praxiology: The International Annual of Practical Philosophy and Methodology, Volume 6 (pp. 105-127). New Brunswick: Transaction Publishers.

Dochy, F. J. R. C. (1992). Assessment of Prior Knowledge as a Determinant for Future Learning: The Use of Prior Knowledge State Tests and Knowledge Profiles. Utrecht: Uitgeverij Lemma.

Dochy, F., Heylen, L., \& Van de Mosselaer, H. (2000). Coöperatief Leren in een Krachtige Leeromgeving: Handboek Probleemgestuurd Leren in de Praktijk. Leuven: Acco.

Dochy, F., Segers, M., Van den Bossche, P., \& Gijbels, D. (2003). Effects of problem-based learning: A meta-analysis. Learning and instruction, 13(5), 533-568.

Dolmans, D. H. J. M. (1994). How Students Learn in a Problem-Based Curriculum. Maastricht: Universitaire Pers.

Dolmans, D. H. J. M., Wolfhagen, I. H. A. P., Van der Vleuten, C. P. M., \& Wijnen, W. H. F. W. (2000). Probleemgestuurd Onderwijs in het Hoger Onderwijs: Een Hype of een Paradigmaverandering? In J. Van der Linden \& E. Roelofs (Eds.), Leren in dialoog. Een discussie over samenwerkend leren in onderwijs en opleiding (pp. 179-195). Groningen: Wolters-Noordhoff.

Dolmans, D. H. J. M., Gijselaers, W. H., Moust, J. C., De Grave, W. 5., Wolfhagen, I. H. A. P., \& Van der Vleuten, C. P. M. (2002). Trends in research on the tutor in problem-based learning: Conclusions and implications for educational practice and research. Medical Teacher, 24(2), 173-180.

Donnenberg, O. (Ed.), (1999). Action Learning: Ein Handbuch. Stuttgart: Klett-Cotta. 
Dotlich. D. L., \& Noel, J. L. (1998). Action Learning. How the World's Top Companies are Re-creating their Leaders and Themselves. San Francisco: Jossey-Bass Publishers.

Drucker, P. F. (1999). Management Challenges for the 21st Century. Oxford: Butterworth Heinemann.

Dijstelbloem, H., \& Schuijt, C. J. M. (Eds.), (2002). De Publieke Dimensie van Kennis. Den Haag: Sdu Uitgevers.

Ernest, P. (1995). The one and the many. In L. P. Steffe \& J. Gale (Eds.), Constructivism in Education (pp. 459-486). Hillsdale: Lawrence Erlbaum Associates.

Gasparski, W. W., \& Botham, D. (Eds.), (1998). Action Learning. Praxiology: The International Annual of Practical Philosophy and Methodology, Volume 6. New Brunswick: Transaction Publishers.

Geelan, D. R. (1997). Epistemological anarchy and the many forms of constructivism. Science \& Education, 6(1-2), 15-28.

Gijselaers, W. H. (1995). Perspectives on problem-based learning. In W. H. Gijselaers, D. T. Tempelaar, P. K. Keizer, J. M. Blommaert, E. M. Bernard \& H. Kasper (Eds.), Educational Innovation in Economics and Business Administration: The Case of Problem-Based Learning (pp. 39-52). Dordrecht: Kluwer Academic Publishers.

Glaser, R., Ferguson, E. L., \& Vosniadou, 5. (1996). Introduction: Cognition and the design of environments for learning. In S. Vosniadou, E. de Corte, R. Glaser \& H. Mandl (Eds.), International Perspectives on the Design of Technology-Supported Learning Environments (pp. 1-12). Mahwah: Lawrence Erlbaum Associates.

110 Hay, K. E., \& Barab, S. A. (2001). Constructivism in practice: A comparison and contrast of apprenticeship and constructionist learning environments. The Journal of the Learning Sciences, $10(3), 281-322$.

Hendry, G. D., Frommer, M., \& Walker, R. A. (1999). Constructivism and problem-based learning. Journal of Further and Higher Education, 23(3), 359-371.

Jacobs, A., Dolmans, D., Wolfhagen, I., \& Scherpbier, A. (2003). Validation of a short questionnaire to assess the degree of complexity and structuredness of PBL problems. Medical Education, 37(11), 1001-1007.

Lave, J., \& Wenger, E. (1991). Situated Learning: Legitimate Peripheral Practice. Cambridge, UK: Cambridge University Press.

Marlowe, B. A., \& Page, M. L. (1998). Creating and Sustaining the Constructivist Classroom. Thousand Oaks, CA: Corwin Press.

Marquandt, M. J. (1999). Action Learning in Action: Transforming Problems and People for World-Class Organizationa/ Learning. Palo Alto, CA: Davies-Black Publishing.

Matthews, M. R. (Ed.), (1998). Constructivism in Science Education: A Philosophical Examination. Dordrecht: Kluwer Academic Publishers.

McGill, I., \& Beaty, L. (1995). Action Learning: A Guide for Professional, Management and Educational Development. London: Kogan Page. 
McLaughlin, H., \& Thorpe, R. (1993). Action learning 3/4 a paradigm in emergence: The problems facing a challenge to traditional management education and development. British Journal of Management, 4(1), 19-27.

Meister, J. C. (1998). Corporate Universities: Lessons in Building a World-Class Work Force. New York: McGraw-Hill.

Milter, R. G., Stinson, J. E., and Gijselaers, W. H. (Eds.), (1998). Educational Innovation in Economics and Business III: Innovative Practices in Business Education. Dordrecht: Kluwer Academic Publishers.

Mir, R., \& Watson, A. (2000). Strategic management and the philosophy of science: The case for a constructivist methodology. Strategic Management Journal, 21(9), 941-953.

Morris, J. (1994). Action learning: The long haul. In J. Prior (Ed.), Gower Handbook of Training and Development (pp. 524-537). Aldershot: Gower.

Moust, J. H. C., Bouhuijs, P. A. J., \& Schmidt, H. G. (1997). Probleemgestuurd Leren. Groningen: Wolters-Noordhoff.

Mumford, A. (Ed.), (1997). Action Learning at Work. Aldershot: Gower.

Nonaka, 1. (1991). The knowledge-creating company. Harvard Business Review, 69(6), 96-104.

Nonaka, I., and Takeuchi, H. (1995). The Knowledge-Creating Company: How Japanese Companies Create the Dynamics of Innovation. New York: Oxford University Press.

O'Hara, S., Webber, T., \& Reeve, 5. (1996). Action learning in management education. Education and Learning, 35(8), 16-21.

Onstenk, J. (1997). Lerend Leren Werken: Brede Vakbekwaamheid en de Integratie van Leren, Werken en Innoveren. Delft: Eburon, Academisch Proefschrift.

Onstenk, J. (2003). Werkplekleren in de Beroepskolom: Naar een Integratie van Binnen-en buitenschools Leren. Den Haag: Onderwijsraad.

Otting, $H .(2000)$. Constructivisme als uitgangspunt voor een onderwijsconcept. Tijdschrift voor Hoger Onderwijs, 18(3), 146-161.

Otting, H., \& Peeters, J. M. (1986). Probleemgestuurd Onderwijs: Eindverslag. Deventer: AMA.

Peattie, K. (1996). Action learning in action. The teaching company scheme. Management Learning, 27(1), 87-112.

Pedler, M. (Ed.), (1991). Action Learning in Practice. Aldershot: Gower.

Phillips, D. C. (1995). The good, the bad, and the ugly: The many faces of constructivism. Educational Researcher, 24(7), 5-12.

Phillips, D. C. (2000). An opinionated account of the constructivist landscape. In D. C. Phillips (Ed.), Constructivism in Education: Opinions and Second Opinions on Controversial Issues. Ninety-ninth Yearbook of the National Society for the Study of Education. Part 1 (pp 1-16). Chicago: The University of Chicago Press.

Prawat, R. S. (1996). Constructivisms, modern and postmodern. Educational Psychologist, 31(3/4), 215-225.

Reid, M. (1997). The IMC experience. in A. Mumford (Ed.), Action Learning at Work (pp. 42-54). Aldershot: Gower. 
Revans, R. W. (1971). Developing Effective Managers: A New Approach to Business Education. London: Praeger.

Revans, R. W. (1991). Action learning: Its origins and nature. In M. Pedler (Ed.), Action Learning in Practice (pp. 3-15). Aldershot: Gower.

Revans, R. W. (1997). The learning equation. In A. Mumford (Ed.), Action Learning at Work (pp. XXI-XXII). Aldershot: Gower.

Revans, R. W. (1998). ABC of Action Learning: Empowering Managers to Act and to Learn from Action. London: Lemos \& Crane.

Savery, J. R., \& Duffy, T. M. (1996). Problem based learning: An instructional model and its constructivist framework. In B. G. Wilson (Ed.), Constructivist Learning Environments: Case Studies in Instructional Design (pp. 135-148). Englewood Cliffs, NJ: Educational Technology Publications.

Schmidt, H. G. (2001). Probleemgestuurd onderwijs: Historie van een constructivistische aanpak van hoger onderwijs. Onderzoek van Onderwijs, 30(4), 47-49.

Schmidt, H. G., \& Gijselaers, W. H. (1990). Causal modeling of problem-based learning. Boston, MA: Paper presented at the Annual Meeting of the American Educational Research Association.

Slavin, R. E. (1991). Synthesis of research on cooperative learning. Educational Leadership, 49(5), 71-82.

Smith, B., \& Dodds, B. (1997). Developing Managers through Project-Based Learning. Aldershot: Gower.

Steffe, L. P., \& Gale, J. (Eds.), (1995). Constructivism in Education. Hillsdale: Lawrence Erlbaum

\section{Associates.}

Tenenbaum, G., Naidu, 5., Jegede, O., \& Austin, J. (2001). Constructivist pedagogy in conventional on-campus and distance learning practice: An exploratory investigation. Learning and Instruction, 11(2), 87-111.

Van de Klink, M. R. (1999). De Effectiviteit van Werkplekopleidingen. Enschede: Universiteit Twente, Academisch Proefschrift.

Vernon, D. T. A., \& Blake, R. L. (1993). Does problem-based learning work? A meta-analysis of evaluative research. Academic Medicine, 68(7), 550-563.

Von Glasersfeld, E. (1999). Piaget's legacy: Cognition as adaptive activity. In A. Riegler,

M. Peschl \& A. Von Stein (Eds.), Understanding Representation in the Cognitive Sciences: Does Representation Need Reality? (pp. 283-287). New York: Kluwer Academic/Plenum Publishers.

Von Glasersfeld, E. (2000). Problems of constructivism. In L. P. Steffe \& P. W. Thompson (Eds.), Radical Constructivism in Action: Building on the Pioneering Work of Ernst von Glasersfeld (pp. 3-9). London: RoutledgeFalmer.

Weinstein, K. (1999). Action Learning: A Practical Guide. Aldershot: Gower. Wetenschappelijke Raad voor het Regeringsbeleid (WRR). (2002). Van Oude en Nieuwe Kennis: De Gevolgen van ICT voor het Kennisbeleid. Den Haag: SDU Uitgevers. 


\section{Critical task characteristics in problem-based learning}

Published as:

Otting, H. \& Zwaal, W. (2006)

Critical task characteristics in problem-based learning

Industry \& Higher Education, 20(5), 347-357. 


\begin{abstract}
Tasks and problems in problem-based learning (PBL) are supposed to trigger and structure the learning process. The quality of problems in PBL is generally regarded as an important driver for individual and collaborative learning processes. Although the importance of the PBL-task is widely recognized, a lack of empirical findings and guidelines for the construction and evaluation of PBL-tasks can be noted. The main goal of this study is to develop a valid and useful checklist for construction and evaluation of PBL-tasks. A checklist with critical characteristics of PBL-tasks would serve two purposes: first, it might support instructional designers in creating and constructing appropriate PBL-tasks, and secondly it provides a tool, which can be applied to evaluate PBL-tasks. Data for this study have been gathered in a sample of undergraduate students and instructors of a hospitality management programme. Students and instructors filled out a questionnaire with 94 importance and performance statements covering nine characteristics of PBL-tasks. Results show that an instrument with 44 items and six factors seems to cover the key characteristics of PBL-tasks.
\end{abstract}

Keywords: constructivism, problem-based learning, task characteristics. 


\section{Introduction}

Over the last decade, constructivism has gained considerable influence in the educational discourse. The traditional views of education and the focus on absolute truth are being replaced by a diversity of more dynamic, pluralist, and relativist conceptions (Phillips, 1995; 2000; Von Glasersfeld, 1995; 1998; 2000). Constructivist conceptions of knowledge are based on the assumption that knowledge is a personal construction of meaning that results from a social negotiation process. As direct comparison of the constructed knowledge with reality is not possible, intersubjective consensus is needed to decide on the viability or usefulness of knowledge. Constructivism emphasizes the importance of collaborative and interactive opportunities for learning in authentic contexts. Authentic learning contexts imply clear correlations between the school settings and the professional formats, as they exist outside the classroom (Petraglia, 1998). Constructivist learning environments can be seen as places where students work together on problem-solving activities and use a variety of tools and information resources in the pursuit of learning goals. In education, constructivist views of knowledge and learning are increasingly gaining recognition. Many of the contemporary theories and methods of learning like activity theory, situated learning, case-based reasoning, project-based learning and problem-based learning share beliefs that are in line with (social) constructivism (Engeström, 1999; Jonassen, Peck, \& Wilson, 1999; Larochelle, Bednarz, \& Garrison, 1998; Steffe \& Gale, 1995; Wilson, 1996).

Problem-based learning (PBL) is an educational paradigm that is widely established in many academic fields and is recognized as a valuable approach to effective learning and competency development (Barrows \& Tamblyn, 1980; Schmidt, 1983; Schwartz, Mennin, \& Webb, 2001). In problem-based learning, the focus of the learning activities is on solving real-world problems (Jonassen, 1997; 2000; Barrows \& Tamblyn, 1980; Boud \& Feletti, 1991). Problem-based learning is an effective, efficient, and motivating approach, which is in line with the latest insights in the principles of learning. Notwithstanding these claims, successful implementation of problem-based learning involves significant changes in thinking about knowledge, learning and teaching by administrators, teachers and students (Schwartz et al, 2001). That is exactly why constructivist theories and views of knowledge and learning play an important role in the debate on educational innovation.

It is generally assumed that three factors influence the functioning of problem-based learning groups: prior knowledge, tutor behavior, and the quality of tasks (Schmidt \& Gijselaers, 1990). First, a review of research on the effect of prior knowledge on learning outcomes showed that the level of existing knowledge has a strong 
relationship with performance (Dochy, Segers, \& Buehl, 1999). Second, the tutor's knowledge of problem-based learning and his or her understanding of the underlying constructivist views on knowledge and learning influence the facilitation of self-directed, constructive, and collaborative learning by students (Dolmans, Gijselaers, Moust, De Grave, Wolfhagen, \& Van der Vleuten, 2002; Silén, 2006). Third, the quality of the tasks in problem-based learning is considered as one of the key factors of a learning process that leads to successful problem solving and knowledge generation. The quality of learning is largely dependent on the quality of the PBL-tasks' (Schmidt \& Gijselaers, 1990; Jacobs, Dolmans, Wolfhagen, \& Scherpbier, 2003; Jacobs, Wolfhagen, Dolmans, \& Scherpbier, 2004). It has long been assumed that learning how to solve well-structured problems has a positive effect on the learning to solve structurally identical problems in professional practice or novel problems in different contexts. However, the transfer of problem solving skills from one situation to another can be problematical. Students find it hard to apply problem-solving skills from well-structured to ill-structured problems or from the school context to professional practice (Jonassen, 1997; 2000; 2003). Therefore, attention has to be paid to the effect of task characteristics on students' learning.

Problem solving and learning from problems are at the heart of problem-based learning. An analysis of the critical components of PBL-problems could serve three purposes.

First, the knowledge of the critical problem characteristics could support instructional designers in the construction of new PBL-problems.

Second, the guidelines for developing PBL-problems are mainly based on personal experiences and are not supported by research findings.

Third, knowledge of the critical components of PBL-problems could be used to evaluate the quality of problems in a curriculum.

Therefore, this study will focus on the different factors that characterize the tasks in a problem-based learning environment. We will identify and review nine different characteristics of PBL-tasks. These nine characteristics formed the basis for the development of a questionnaire for measuring PBL-tasks.

\section{The characteristics of PBL-tasks}

Tasks in problem-based learning are considered as essential elements for stimulating students to identify learning issues. The type of task determines largely the students'

\footnotetext{
PBL-tasks refer to the different tasks that are used in PBL-settings. PBL-problems are a specific subset of PBL-tasks and are sometimes referred to as problem tasks or simply, problems. This study neither intents to develop a new taxonomy for PBL-tasks nor searches for the empirical grounding of existing classifications of PBL-tasks.
} 
learning activities and if intended or unintended learning issues will be addressed. Do students identify the same learning issues as faculty? Do students actually study the issues they are supposed to study and do they achieve the faculty objectives or are the learning issues more or less unrelated to the specific problem field and address a general problem area or more remotely related issues? A study by Dolmans (1994) showed an average overlap of over $60 \%$ of the students' learning goals to faculty objectives. Well-structured paper-based problems enable students to identify learning issues that were intended by the faculty. In their study, Mpofu, Das, Murdoch, and Lanphear (1997) found overlaps from $55-85 \%$ to $100 \%$ between student learning issues and faculty objectives of six different themes in an Introduction to Medicine module. In problem-based learning, students are self-directed learners who take responsibility for their own learning. Therefore, a problem-based curriculum should leave enough space for students to decide on their own learning issues. Research by Van den Hurk, Wolfhagen, Dolmans, and Van der Vleuten 1999 showed that first-year students restrict themselves more to the content of the learning issues generated in the PBL-group, whereas students in their later years use a broader approach and follow their own interests. Through the years, students become more able to decide on their own learning issues and develop into self-directed learners.

As tasks are the major triggers for generating learning issues, careful attention has to be paid to the characteristics of the tasks. Is there a relation between the characteristics of a task and specific learning issues? Which design features of PBL-tasks can be discerned and how do they affect learning? Good advice on how to design tasks is generally based on the instructional designer's personal understandings of problem-based learning. Moreover, the literature on the factors that influence the design of PBL-tasks shows many practical guidelines and refers to task attributes like prior knowledge, structuredness, complexity, and authenticity (Schmidt \& Moust, 1996; Dolmans \& Snellen-Balendong, 1997; Dolmans, Snellen-Balendong, Wolfhagen, \& Van der Vleuten, 1997; Duch, 2001; Ten Berge, Ramaekers, \& Pilot, 2004). However, the principles for effective case design "should no longer be exclusively centered on experience-based knowledge, but also on evidence-based knowledge" (Dolmans et al., 1997, p. 185).

Empirical research on the specific characteristics of PBL-tasks does not reveal comprehensive insight in how to design problems or tasks. Jacobs et al. (2004) developed and validated a short questionnaire for measuring essential features of PBL-tasks. Confirmatory factor analysis showed that a two-factor model with structuredness and complexity did not fit well. Therefore, they modified the model and developed a three-factor model with the factors 'too simple, too difficult, and too structured', which showed a better data-model fit. 
What students already know is one of the most important prerequisites for successful learning to take place. A problem should build on the students' prior knowledge and at the same time be challenging enough to stimulate the learning processes. Jacobs et al. (2004) suggest questions for further research in the relation between the PBL-task and the level of prior knowledge, because activation of prior knowledge is generally considered as an important prerequisite for successful problem solving. Realistic and relevant problems challenge the students' abilities and stimulate problem-solving processes. Therefore, further research is needed to show how the practices in the work field are represented in the PBL-tasks. Another suggested research question regards the degree of internal coherence in a module. Do the problems and tasks have meaningful relationships with other problems in the module? Finally, Jonassen (2000) stresses the importance of the domain specific nature of a problem and its relevance for higher professional education.

In this study, we have identified nine characteristics of tasks that might influence the students' learning in PBL.

\section{Structuredness}

Jonassen (2000) has described a design theory of problem solving focused on two main elements of problems: structuredness and complexity. A distinction can be made

118 between well-structured and ill-structured problems. "Well-structured problems are constrained problems with convergent solutions that engage the application of a limited number of rules and principles within well-defined parameters. IIl-structured problems possess multiple solutions, solution paths, fewer parameters and less manipulability, and contain uncertainty about which concepts, rules, and principles are necessary for the solution or how they are organized and which solution is best" (Jonassen, 1997, p. 65).

In everyday life and professional practice, problems are ill structured and open-ended with many possible solutions paths. III-structured problems possess many elements that are unknown or do not contain all the information that is needed for the solution (Hernandez-Serrano \& Jonassen, 2003). Cho and Jonassen (2002) provided evidence that solving ill-structured problems requires effective support for the production of argumentations and conceptualizations during group discussions. Instructional designs for well-structured problems find their theoretical background in information processing theory. Instructional designs for ill-structured problems build on the theories and methods from constructivism and situated cognition (Jonassen, 1997). 


\section{Complexity}

"Problem complexity is defined by the number of issues, functions, or variables involved in the problem; the degree of connectivity among those properties; the type of functional relationships among those properties; and the stability among the properties of the problem over time" (Jonassen, 2000, p. 67-68).

It is assumed that complex problems are more difficult to solve because complex problems require more cognitive operations than simple problems. However, the level of complexity should be neither too complex nor too simple. If a problem is too complex, students might become frustrated and de-motivated because they are unable to come to a reasonable explanation of the phenomenon under study. Too simple problems become boring and do not challenge students to active learning. Therefore, the complexity of a problem must build on the students' prior knowledge and the understandings already achieved, and should address learning possibilities that lay in Vygotsky's (1978) 'zone of proximal development', the mental space between the students' actual and potential cognitive functioning.

\section{Prior knowledge}

If the amount of prior knowledge is insufficient, students will have trouble in solving the problem. Consequently, the learning process will be impeded and students will quickly loose interest in the learning task. Studies by Dochy (1992), and Dochy et al. (1999) have shown that prior knowledge is an important predictor for study success. Refined assessment procedures like assessment and development centers and simple but accurate measures of prior knowledge such as multiple choice or true-false question could be used to assess the prior knowledge state of the learners. The information on the students' prior knowledge is not only of relevance to instructional designers for developing and selecting PBL-tasks but is an essential element for knowledge generation processes in PBL-groups which are based on the constructive friction between what the students already know and what they should be learning.

\section{Personal relevance}

In a constructivist view of learning, emphasis is placed on the active role of the student, which can be activated by confronting the student with problems that are of personal relevance. Do the students consider the PBL-tasks as challenging and relevant for their personal development? If students are able to link their personal interests with the problem and gain ownership of the problem, they will perceive the learning task as more interesting and will put effort in solving the problem. Aviram (2000) makes a useful distinction between content-oriented relevance and motivational relevance. 
Motivational relevance can be seen as the student's decision on the relevance of the learning topic. Content-oriented relevance is a decision of an expert regarding learning contents and contributes to the factor professional relevance.

\section{Professional relevance}

Tasks that relate to the students' later professional practices have a strong motivating value for the students, because they address students in their role as beginning practitioners. The context of the professional practice matters to students. Authentic tasks and problems derived from the future profession should be integrated in the learning environment. Not only should the learning environment and the application environment correspond, but knowledge acquisition and application should converge (Van der Vleuten, Dolmans, \& Scherpbier, 2000). Moreover, it is expected that students rate the quality of the problem as high if the students perceive direct links between the problem and the professional context. Learner ownership of the problem is essential for the development of responsibility for and management of the learning process. The end-of-the-chapter questions that are typical for many textbook inspired tasks do not sufficiently represent the genuine professional context and therefore cannot be considered as professionally relevant or authentic.

\section{Domain specificity}

Content or subject matter knowledge can be distinguished into domain knowledge and topic knowledge (Alexander, Kulikowich, \& Schulze, 1994). The distinction between domain knowledge and topic knowledge is especially helpful in the context of problem-based learning because students should not only be involved in a problem solving process, but are also supposed to use the problem as an example of a broader knowledge domain and should gain more general knowledge of the field of study. Knowledge does not transfer easily between different domains. Even within a domain, knowledge transfer can sometimes be difficult. The knowledge of a specific topic will be more readily accessible if this knowledge has been acquired by solving a meaningful problem in the context of a professional domain (Van der Vleuten et al., 2000).

\section{Internal coherence}

A modular structured PBL-curriculum is organized around module themes. In a thematic-modular curriculum, a careful selection of the problems is needed in order to ensure that the subject matter is covered (Williams, 1992). PBL-tasks should be sequenced consistent with the logical structure the domain and should address key issues of the module theme. From a didactical point of view, the interrelatedness of the problem with other problems in the module can be seen as a measure of internal 
coherence. Van Merriënboer, Kirschner, and Kester (2003) point out to the risk that authentic learning tasks in constructivist learning environments such as PBL may confront novice learners with cognitive overload. Complex problems should be avoided at the start of a programme. Students should first encounter authentic but simple tasks before they encounter complex learning tasks. The selection and sequencing of the problems should challenge existing knowledge and support the changing learning needs of the students during the successive phases of the curriculum.

\section{Cooperation}

In an authentic learning context, students are exposed to realistic and unique tasks. "The idea that authentic learning only occurs in collaboration with others has become the central pillar of constructivist orthodoxy and is the one on which practically every other principle is dependent to some extent" (Petraglia, 1998, p. 77).

Problem-based learning involves authentic and collaborative learning processes in which students are critically dependent on one another. In this collaborative learning situation, students work toward a common goal and are jointly responsible for delivering optimal learning results both as an individual and as a group. Salomon (1998, p. 7) argues that "one of the most important and interesting outcomes of constructivist learning environments might be students' improved ability to work in a team to solve new, complex and ill-structured real-life problems, showing their coordinated abilities to access information and turn it into viable knowledge. Knowledge, then, would not be something possessed for its own sake, but rather something accessed and constructed when needed to solve a problem or design something useful".

\section{Presentation}

The design of PBL-tasks can be a difficult, complex, and time-consuming activity. PBL-tasks are not exercises in grammar or semantics containing false distracters and undesirable elaborations but are clear and to-the-point descriptions of real-life situations. The design of problems not only involves a true-to-life rendering of the problem and a truthful description of the problem space, but also decisions about the amount and relevance of the information provided. A problem should include semantic information and situational information. There is no such thing as a standard problem or a standard task description and therefore a 'one format fits all' approach should be avoided. The presentation of a task must be in accordance with the authentic and real-life situations it represents. Recent research has shown that the form, sequencing, and organization of the problem information influence the perception of information and the activation of cognitive processes (Jonassen, 2003) 


\section{Research questions}

1. Do the empirical data confirm the expected constellation with nine factors?

2. How do students assess the importance and performance of PBL-tasks? [PI ratings students]

3. How do instructors assess the importance and performance of PBL-tasks? [P] ratings instructors]

4. What are the differences between student and instructor ratings on importance and performance of the PBL-task characteristics?

\section{Method}

\section{Instrumentation}

In the first phase of research, a questionnaire with 94 items was developed.

Structuredness and complexity were used as two basic elements of a problem. Several other factors, which were related to problem quality (presentation, domain specificity, internal coherence, personal relevance, prior knowledge, cooperation, and professional relevance), were introduced. The original questionnaire consisted of 94 items divided over 9 scales. In a pilot-test of the questionnaire, subjects indicated that a list of 94 items was perceived as too long, and would negatively affect the response-rate. Therefore, we decided to split the questionnaire and to present different blocks of items to different groups of subjects.

\section{Participants}

We are not only interested in students' opinions about problems. We have also asked PBL-tutors to fill out the questionnaire in order to obtain information about the tutors' opinions about the different aspects of the PBL-tasks. Data for this study have been gathered in a sample of students $(n=106)$ and instructors $(n=12)$ of a degree programme in hospitality management. Students and tutors were briefed about the purpose of research. The questionnaires were filled out during one of the two weekly PBL-sessions. The questionnaire covers the nine characteristics of PBL-tasks and 94 statements of importance and performance ratings. For each statement respondents indicated on a ten-point scale whether they considered the item to be 'very unimportant' (1) to 'very important' (10) and whether or not the current PBL-tasks satisfied the item (1= 'strongly disagree', $10=$ 'strongly agree'). 


\section{Results}

\section{Data reduction and scale construction}

To determine the number and structure of the factors, data were analyzed using the Multiple Group Method (MGM) of confirmatory factor analysis on the 94 items of the questionnaire. Nunnally (1978) and Kiers (2002) consider the Multiple Group Method as a simple and useful approach to test the presence of factors. The decision to retain items and factors was based on three criteria.

- First, for every item the score on the corrected item-total correlation should be higher on the appropriate factor than on any of the other factors. If the item does correlate higher with another factor than the appropriate factor, it is considered as a mismatch.

- Second, for each item the score on the corrected item-total correlation should have a loading of $\geq .50$.

- Third, for a factor to be retained it has to have at least three items loading $\geq .50$.

The overall results of the Multiple Group Method in table 1 show that the application of the first criterion resulted in a mismatch of 40 items. Nine items did not meet the second criterion and finally one factor did not satisfy the third criterion because a minimum of three items per scale was considered necessary. Therefore, 'Complexity' was dropped as a separate scale.

Table 1: Overall results MGM analysis

\begin{tabular}{lcccccc}
\hline & Items & Crit. 1 & Crit. 2 & Crit.3 & $\begin{array}{l}\text { Remaining } \\
\text { items }\end{array}$ & $\begin{array}{c}\text { Cronbach's } \\
\text { alpha }\end{array}$ \\
\hline Prior knowledge & 6 & - & - & - & 6 & .83 \\
Structuredness & 15 & 2 & - & - & 13 & .92 \\
Presentation & 6 & 6 & - & - & 0 & - \\
Complexity & 14 & 9 & 4 & 1 & 0 & - \\
Domain specificity & 11 & 8 & 3 & - & 0 & - \\
Internal coherence & 6 & 2 & - & - & 4 & .81 \\
Personal relevance & 14 & 6 & 1 & - & 7 & .88 \\
Cooperation & 14 & 2 & 1 & - & 11 & .91 \\
Professional relevance & 8 & 5 & - & - & 3 & .78 \\
\hline
\end{tabular}


The overall results show that 44 items and six factors seem to cover the key characteristics of PBL-tasks. Three factors, which were hypothesized, did not satisfy the criteria: complexity, domain specificity, and presentation. The Alpha on the six remaining factors ranges from .78 to .92 . The following analyses will be based on the six factors and 44 items. The appendix shows the 44 items defining the six factors related to the characteristics of PBL-tasks.

Performance -Importance ratings students

Table 2: Mean Performance - Importance ratings students

\begin{tabular}{llllll}
\hline & Performance & Importance & T & DF & P \\
\hline Prior knowledge & 6.51 & 7.02 & -2.08 & 107 & .040 \\
Professional relevance & 6.81 & 7.24 & -2.02 & 101 & .046 \\
Internal coherence & 6.60 & 7.83 & -5.23 & 96.5 & .000 \\
Structuredness & 6.52 & 7.25 & -3.55 & 107 & .001 \\
Cooperation & 6.90 & 7.81 & -4.82 & 101 & .000 \\
Personal relevance & 6.88 & 7.60 & -3.21 & 101 & .002 \\
Overall & 6.70 & 7.46 & & & \\
\end{tabular}

124 The results in table 2 show that ranking the mean performance and importance ratings of the six dimensions, would indicate that 'cooperation' ranks first on performance and 'internal coherence' ranks first on importance. The test for differences between the students' performance and importance ratings shows a significant difference for all six dimensions. Students value the performance on all factors lower than the importance.

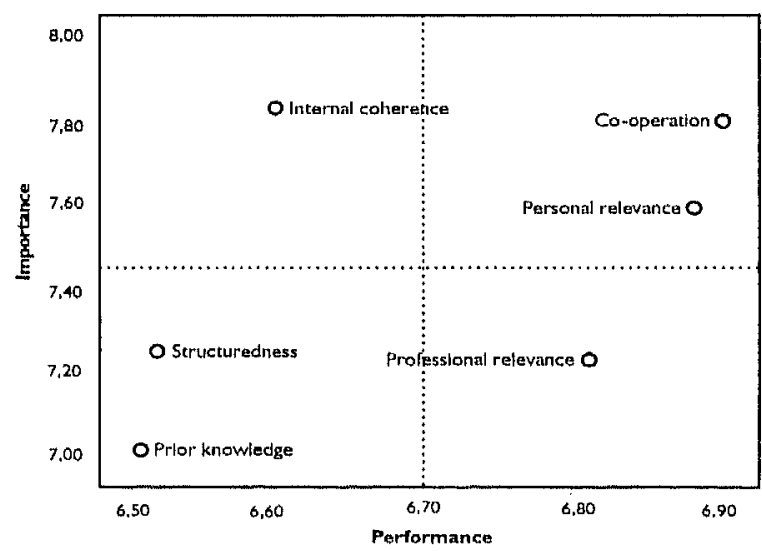

Figure 1: Performance - Importance ratings by students 
The performance-importance graph of the student ratings (figure 1) offers an opportunity to identify the task characteristics which are above or below average on performance combined with the relative importance of the particular characteristic. Serious attention should be paid to 'internal coherence' which is considered to be an important but underperforming factor.

\section{Performance-Importance ratings instructors}

The results in table 3 show that ranking the mean performance and importance ratings of the six dimensions would indicate that 'internal coherence' ranks first on performance and 'cooperation' and 'personal relevance' rank first on importance. The test for differences between the performance and importance ratings for instructors shows a significant difference for four of the six dimensions. Instructors value the performance on all those four factors lower than the importance ratings.

Table 3: Mean Performance - Importance ratings instructors

\begin{tabular}{llllll}
\hline & Performance & Importance & T & DF & $p$ \\
\hline Prior knowledge & 5.87 & 7.42 & -2.53 & 22 & .019 \\
Professional relevance & 6.88 & 7.44 & -1.09 & 21 & .287 \\
Internal coherence & 6.93 & 8.23 & -2.36 & 21 & .028 \\
Structuredness & 6.54 & 6.42 & .13 & 21 & .899 \\
Cooperation & 6.39 & 8.35 & -3.21 & 21 & .004 \\
Personal relevance & 6.36 & 8.35 & -3.04 & 21 & .006 \\
Overall & 6.50 & 7.70 & & & \\
\hline
\end{tabular}

The performance-importance graph of the instructors' ratings (figure 2) offers an opportunity to identify the task characteristics which are above or below average on performance combined with the relative importance of the particular characteristic. Serious attention should be paid to 'cooperation' and 'personal relevance' which are considered to be important but underperforming factors, according to the instructors. 


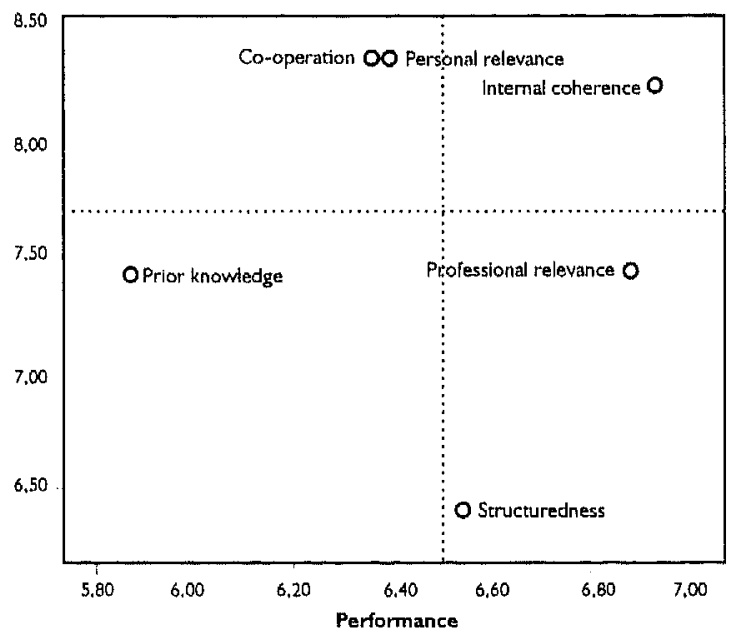

Figure 2: Performance - Importance ratings by instructors

\section{Comparison between students and instructors}

结 If we compare the mean performance ratings by students and instructors in table 4, the test shows no significant differences between the mean performance ratings of students and instructors. With regard to the importance ratings, only one significant

126 difference was detected. Instructors value personal relevance as significantly more important as students do $(t=-2.25 ; D F=55 ; p=.028)$.

In comparing the performance-importance graphs of students and instructors, it seems to show some disagreement in their allocation of the six task characteristics. Except for two factors, 'prior knowledge' and 'professional relevance' the other four factors have been placed in different quadrants. 
Table 4: Comparison of the performance-importance graphs of students and instructors

\begin{tabular}{lll}
\hline & Students & Instructors \\
\hline Quadrant 1: & Cooperation & Internal coherence \\
High performance/high importance & Personal relevance & \\
Quadrant 2: & Internal coherence \\
Low performance/high importance & & Cooperation \\
Quadrant 3: & Prior knowledge & Personal relevance \\
Low performance/low importance & Structuredness & Prior knowledge \\
Quadrant 4: & & \\
High performance/low importance & & Professional relevance
\end{tabular}

If quadrant one and two are combined (the high importance factors) and compared to quadrant three and four (low importance), a full match between students and instructors occurs. The differences in positioning the factors appear to be mainly attributable to the way performance has been assessed by students and instructors. However, none of these performance ratings differed statistically significant.

Table 5: Factor ranking by students and instructors

\begin{tabular}{llccc}
\hline & \multicolumn{2}{c}{ Performance } & \multicolumn{2}{c}{ Importance } \\
\hline & Students & Instructors & Students & Instructors \\
Cooperation & 1 & 4 & 2 & 1 \\
Internal coherence & 4 & 1 & 1 & 3 \\
Personal relevance & 2 & 5 & 3 & 1 \\
Professional relevance & 3 & 2 & 5 & 4 \\
Structuredness & 5 & 3 & 4 & 6 \\
Prior knowledge & 6 & 6 & 6 & 5 \\
\hline
\end{tabular}

The agreement between students and instructors is further illustrated in table 5, which shows the ranking of the six factors by both students and instructors. Students and instructors agree that cooperation and internal coherence are the factors that are not only important but also show high performance scores. Students and instructors also agree on the low position of the factors structuredness and prior knowledge. 


\section{Discussion and conclusions}

The aim of this study was to identify the factors that are characteristic for PBL-tasks and to develop a checklist for evaluative and constructive purposes. In the literature review, nine factors were described that could potentially contribute to the analysis of the quality of PBL-tasks. In the first phase of research, a questionnaire with 95 items covering the nine factors was developed. The analysis with the Multiple Group Method, an appropriate and simple method for confirmatory factor analysis (Kiers, 2002), showed that a final set of $\mathbf{4 4}$ items met the criteria. Although the literature review showed that nine factors were indicative for the characterization of PBL-tasks, empirical support could only be found for six of the nine factors. Three of the presumed critical factors did not find empirical support in this study: complexity, presentation, and domain specificity. It is remarkable that the factor complexity, which is widely considered as an important characteristic and one of the most outstanding features of PBL-problems (Jonassen, 2000), did not emerge. However, our findings are in line with Jacobs et al. (2003), who showed in their study that the factors complexity and structuredness did not fit the data very well. Therefore, they replaced the two-factor model (structuredness and complexity) by a three-factor model with the factors too simple, too difficult, and too well structured. It seems that complexity is a theoretical construct that still lacks solid empirical underpinnings. Further, data analysis did not show a firm empirical basis for the factors domain specificity and problem

128 representation, so the expected constellation with nine factors that are characteristic for PBL-tasks did not emerge. However, the suggestions by Jacobs et al. (2003) for further research of three other characteristics of PBL-problems (professional relevance, prior knowledge, and internal coherence) turned out to be very relevant, because these factors could be empirically confirmed. Moreover, the results on the remaining two factors, cooperation and personal relevance, indicate that students could clearly distinguish these factors as PBL-problem characteristics. Obviously, continuation of research is needed for cross-validation of the questionnaire, taking into account that the length of the questionnaire should be further reduced to make it more workable and usable as a checklist.

The performance and importance ratings of the students show that they systematically value the importance of specific PBL-problem characteristics as higher than the actual performance. The instructors also rate the importance factors in four out of six cases significantly higher than performance. Apparently, the imbalance between performance and importance aspects of PBL-problems suggests that performance should be improved. However, this explanation is open to misinterpretation because importance ratings cannot be simply used as criterion for performance. 
Students and instructors rank the importance and performance of the six factors differently. However, there is a reasonable agreement between students and instructors on the importance of the six factors. Both students and instructors value the importance of the factors cooperation, internal coherence, and personal relevance higher than the factors professional relevance, structuredness, and prior knowledge. The performance ratings of the students on cooperation and personal relevance are in line with their importance ratings on the same factors. Further analysis of the exact nature of the points of agreement and disagreement between the importance and performance ratings is needed.

Problem tasks address different learning issues than application tasks and study tasks differ from discussion tasks. The variety of tasks in PBL is essential for the stimulation of the students' learning processes. Therefore, a one-size-fits-all approach to the design of PBL-tasks is doomed to fail because of the necessary need for variation in tasks. More research is needed into the characteristics of PBL-tasks in order to find out which factors meet the students' and instructors' expectations and standards. The different types of problems in PBL always ask for the fine-tuning of the relative weight of each factor in a problem. For instance, problems in the beginning of a course should be more structured than the problems at the end of a course, because unstructured problems may make a demand on the students' collaborative learning capacities and require a well-organized prior knowledge base.

How students and instructors perceive and value PBL-tasks influences how and what students will learn. However, the instructors' intentions and decisions on the design of a PBL-problem may not always correspond with the way students experience and judge the task. Does the PBL task evoke intended learning issues? Further research is needed to assess if the designers' intended learning issues for a PBL-task correspond to the students' learning activities.

Curriculum design, module design, and task design must be approached from an integrative perspective. The design of a task must be seen in relation to the objectives of the curriculum and the goals of the module. Tasks are closely connected with other tasks and accentuate not only different content areas but also diverge on the factors in question. How to compose a coherent unit with a diversity of PBL-tasks and how to the design PBL-problems remain prominent and challenging aspects of problem-based learning. 


\section{References}

Alexander, P., Kulikowich, J., \& Schulze, S. (1994). The influence of topic knowledge, domain knowledge, and interest on the comprehension of scientific exposition. Learning and Individual Differences, 6, 379-397.

Aviram, A. (2000). Beyond constructivism: autonomy-oriented education. Studies in Philosophy and Education, 19, 465-489.

Barrows, H. S., \& Tamblyn, R.M. (1980). Problem-based Learning: an Approach to Medical Education. New York: Springer.

Boud, D., \& Feletti, G. (Eds.) (1991). The Challenge of Problem-based Learning. London: Kogan Page.

Cho, K-L., \& Jonassen D. H. (2002). The effects of argumentation scaffolds on argumentation and problem solving. Educational Technology Research and Development, 50(3), 5-22.

Dochy, F. J. R. C. (1992). Assessment of Prior Knowledge as a Determinant for Future Learning. The Use of Prior Knowledge State Tests and Knowledge Profiles. Utrecht: Lemma.

Dochy, F., Segers, M., \& Buehl, M. M. (1999). The relation between assessment practices and outcomes of studies: the case of research on prior knowledge. Review of Educational Research, 69(2), 145-186.

Dolmans, D. H. J. M. (1994). How Students learn in a Problem-based Curriculum. Maastricht: Universitaire Pers Maastricht.

Dolmans, D. H. J. M., \& Snellen-Balendong, H. (1997). Constructie van taken in probleemgestuurd onderwijs. Groningen: Wolters-Noordhoff.

Dolmans, D. H. J. M., Snellen-Balendong, H., Wolfhagen, I. H. A. P., \& Van der Vleuten, C. P. M. (1997). Seven principles of effective case design for a problem-based curriculum. Medical Teacher, 19(3), 185-190.

Dolmans, D. H. J. M., Gijselaers, W. H., Moust, J. H. C., De Grave, W. S., Wolfhagen, I. H. A. P., \& Van der Vleuten, C. P. M. (2002). Trends in research on the tutor in problem-based learning: conclusions and implications for educational practice and research. Medical Teacher, 24(2), 173-180.

Duch, B. J. (2001). Writing problems for deeper understanding. In B. J. Duch, S. E. Groh \& D. E. Allen (Eds.), The Power of Problem-based Learning (pp. 47-53). Sterling: Stylus Publishing.

Engeström, Y. (1999). Activity theory and individual and social transformation. In Y. Engeström, R. Miettinen \& R-L. Punamäki (Eds.), Perspectives on Activity Theory (pp. 19-38). Cambridge: Cambridge University Press.

Hernandez-Serrano, J., \& Jonassen, D. H. (2003). The effects of case libraries on problem solving. Journal of Computer Assisted Learning, 19, 103-114.

Jacobs, A.E. J. P., Dolmans, D. H. J. M., Wolfhagen, I. H. A. P., \& Scherpbier, A. J. J. A. (2003). Validation of a short questionnaire to assess the degree of complexity and structuredness of PBL problems', Medical Education, 37, 1001-1007.

Jacobs, A. E. J. P., Wolfhagen, I. H. A. P., Dolmans, D. H. J. M., \& Scherpbier, A. J. J. A. (2004). Meten van complexiteit en gestructureerdheid van pgo-problemen. Onderwijsinnovatie, 1, 17-24. 
Jonassen, D. H. (1997). Instructional design models for well-structured and ill-structured problem-solving learning outcomes. Educational Technology Research and Development, 45(1), 65-94.

Jonassen, D. H. (2000). Toward a design theory of problem solving. Educational Technology Research and Development, 48(4), 63-85.

Jonassen, D. H. (2003). Using cognitive tools to represent problems. Journal of Research on Technology in Education, 35(3), 362-381.

Jonassen, D. H., Peck, K. L., \& Wilson, B. G. (1999). Learning with Technology: A Constructivist Perspective. Upper Saddle River: Prentice Hall.

Kiers, H. (2002). De Multipele Groep Methode. Groningen: Unpublished document.

Larochelle, M., Bednarz, N., \& Garrison, J. (Eds.), (1998). Constructivism and Education. Cambridge, Cambridge University Press.

Mpofu, D. J. S., Das, M., Murdoch, J. C., \& Lanphear, J. H. (1997). Effectiveness of problems used in problem-based learning. Medical Education, 31, 330-334.

Nunnally, J. C. (1978). Psychometric Theory. New York: McGraw-Hill.

Petraglia, J. (1998). Reality by Design. The Rhetoric and Technology of Authenticity in Education. Mahwah: Lawrence Erlbaum Associates.

Phillips, D. C. (1995). The good, the bad, and the ugly: the many faces of constructivism. Educational Researcher, 24(7), 5-12.

Phillips, D. C. (2000). An opinionated account of the constructivist landscape. In D. C. Phillips (Ed.), Constructivism in Education. Opinions and Second Opinions on Controversial issues. Ninety-ninth Yearbook of the National Society for the Study of Education (pp. 1-16). Chicago: The University of Chicago Press.

Salomon, G. (1998). Novel constructivist learning environments and novel technologies: some issues to be concerned with. Research Dialogue in Learning and Instruction, 1(1), 3-12.

Shapiro, A. M. (2004). How including prior knowledge as a subject variable may change outcomes of learning research. American Educational Research Journal, 41(1), 159-190.

Schmidt, H. G. (1983). Problem-based learning: rationale and description. Medical Education, 17, $11-16$.

Schmidt, H. G., \& Gijselaers, W. H. (1990). Causal Modeling of Problem-based Learning. Boston: Paper presented at the Annual Meeting of the American Educational Research Association.

Schmidt, H., \& Moust, J. (1996). Construeren van probleemtaken voor probleemgestuurd leren. VELON, Tijdschrift voor Lerarenopleiders, 17(3), 5-7.

Schwartz, P., Mennin, S., \& Webb, G. (2001). Problem-based Learning, Case Studies, Experience and Practice. London: Kogan Page.

Silén, C. (2006). The tutor's approach in base groups (PBL). Higher Education, 51, 373-385.

Steffe, L. P., \& Gale J. (Eds.), (1995). Constructivism in Education. Hillsdale: Lawrence Erlbaum Associates.

Ten Berge, H., Ramaekers, S., Pilot, A. (2004). The design of authentic tasks that promote higher order learning. Paper presented at the EARLI-SIG Higher Education/KIT-conference. 
Van den Hurk, M. M., Wolfhagen, I. H. A. P., Dolmans, D. H. J. M., \& Van der Vleuten, C. P. M.

(1999). The impact of student-generated learning issues on individual study time and academic achievement. Medical Education, 33, 808-814.

Van der Vleuten, C. P. M., Dolmans, D. H. J. M., \& Scherpbier, A. J. J. A. (2000). The need for evidence in education. Medical Teacher, 22(3), 246-250.

Van Merriënboer, J. G., Kirschner, P. A., \& Kester, L. (2003). Taking the load off a learner's mind: instructional design for complex learning. Educational Psychologist, 38(1), 5-13.

Von Glasersfeld, E. (1995). Radical Constructivism: A Way of Knowing and Learning. London: The Falmer Press.

Von Glasersfeld, E. (1998). Cognition, construction of knowledge, and teaching. In M. R. Matthews (Ed.), Constructivism in Science Education. A Philosophical Examination (pp. 11-30). Dordrecht: Kluwer Academic Publishers.

Von Glasersfeld, E. (2000). Problems of constructivism. In L. P. Steffe \& P. W. Thompson (Eds.), Radical Constructivism in Action. Building on the Pioneering Work of Ernst von Glasersfeld (pp. 3-9). London: RoutledgeFalmer.

Vygotsky, L. S. (1978). Mind in Society: The Development of Higher Psychological Processes. Cambridge, MA: Harvard University Press.

Wilson, B. G. (Ed.), (1996). Constructivist Learning Environments: Case Studies in Instructional Design. Englewood Cliffs, NJ: Educational Technology Publications.

Williams, S. M. (1992). Putting case-based instruction into context: examples from legal and medical education. The Journal of the Learning Sciences, 2(4), 367-427. 
General conclusions and discussion 


\section{General conclusions and discussion}

The preparation of students for their future work environment demands that students in higher education gain in-depth knowledge about a certain field of practice and know how to apply their knowledge and skills into practice. Students should acquire the necessary skills to define and pursue their learning needs, and must be capable of using the appropriate knowledge resources to critically evaluate if their learning outcomes meet pre-set criteria. They should not only be motivated for active, individual, and self-directed learning but should also be able to collaborate in project teams and work groups. Typical examples of learning environments that emphasize individual and collaborative knowledge construction are problem-based learning, action learning, and project-based learning. These learning environments all share the emphasis on constructive learning in collaboration with other students, and stress the importance of practice to serve as a vehicle for learning and to gain in-depth knowledge about a certain field of practice. The increasing pace, with which new technologies and work practices are introduced, question traditional approaches that focus on the transmission of existing knowledge to education. That is why constructivist approaches to education have come to the fore. Constructivism offers an alternative to traditional approaches to education by emphasizing students' self-directed and active learning from solving real-life problems in learning environments that advance collaboration between students to construct new knowledge on the basis of what students already know.

\section{Discussion of the main findings}

The studies in the present thesis focused on two different aspects of constructivism. The first line of research focused on students' epistemological beliefs and conceptions of knowledge and learning (see Chapter 2 and 3). The second line of research analyzed links between constructivism and its consequences for design of educational practice (Chapter 4 and 5).

\section{Chapter 2: The structural relationship between students' epistemological beliefs and conceptions of teaching and learning}

Chapter 2 examined structural relationships between students' epistemological beliefs and conceptions of teaching and learning in a problem-based learning environment. First, the question was addressed: What are the epistemological beliefs and conceptions of teaching and learning held by the students in our sample? Second, relationships were identified between students' epistemological beliefs and conceptions of teaching and learning. 


\section{Epistemological beliefs}

Epistemological beliefs can be conceptualized as a system of multidimensional beliefs on knowledge and knowing that are more or less independent from one another and may develop in synchrony. The validation of Chan and Elliott's (2002; 2004a)

Epistemological Beliefs Questionnaire (EBQ) with confirmatory factor analysis showed satisfactory goodness of fit indexes and a coherent set of four dimensions of epistemological beliefs - innate /fixed ability, learning effort/process, authority/expert knowledge, and certainty of knowledge - were distinguishable. These findings are in line with prior research by Chan (2008), and Chan and Elliott (2002; 2004a) and support Schommer's (1990) characterization of epistemological beliefs as a system of more or less independent dimensions. The studies in chapter two showed that the students' mean scores on the learning effort/process dimension of the EBQ were well above the midpoint of the scale indicating that students viewed learning predominantly as a process of understanding and students tended to believe that knowledge and understanding is acquired through self-directed learning activities. The students' mean score on the certainty of knowledge dimension of the EBQ indicated that students generally believed that knowledge is certain and does not change. On the dimension, innate/fixed ability and expert knowledge students' mean scores were below the midpoint of the scales. The students' scores on the four dimensions of the EBQ can be seen as an indication of the tendency to believe in constructivist views of knowledge and knowing

Conceptions of teaching and learning

Confirmatory factor analysis of the Teaching and Learning Conceptions Questionnaire (TLCQ) resulted in satisfactory goodness of fit indices and the two-factor structure confirmed previous findings (Chan, 2001; Chan \& Elliott, 2004a; Chan, Tan, \& Khoo, 2007). The majority of the students in our studies held a constructivist conception of teaching and learning, which is in agreement with a previous study by Chan et al. (2007). The studies show that students, who are educated in an educational system based on constructivist principles, had a conception of education that matched the problem-based learning environment. However, a minority of the students still adhered to a traditional conception of teaching and learning indicating that students may encounter difficulties to successfully participate in constructivist forms of higher education. Students with an educational background in more traditional forms of education need a comprehensive introduction to problem-based learning focusing on how learning takes place in PBL-groups and what kind of learning is expected from the students. An explanation of problem-based learning in relation to its constructivist principles might advance students' awareness of their beliefs about knowledge and knowing, which also contributes to the development of more constructivist conceptions of teaching and learning. Explicit attention to the backgrounds and principles of 
constructivism and problem-based learning prepares students effectively to the demands that constructivist approaches to higher education pose on the students (Kaartinen-Koutaniemi \& Lindblom-Ylänne, 2008; Kember, 2001).

The structural relationship between epistemological beliefs and conception of teaching and learning

Structural relationships were established between the dimensions of students' epistemological beliefs and the traditional and constructivist conception of teaching and learning. Elimination of three non-significant paths led to a revised model with satisfactory goodness of fit indices indicating a well-fitting model (Bentler, 2006; Hancock \& Mueller, 2005). Significant paths were established from authority/expert knowledge to conceptions of teaching and learning. The strong positive relation from authority/expert knowledge dimension to the traditional conception of teaching and learning indicates that students, who endorse this position, recognize the expertise of the teacher. Contrary, the negative relation from the authority/expert dimension to the constructivist conception indicates that students less depend on the teacher as a source of authority and expertise. Students, who believe in knowledge as certain and unchangeable, generally have a traditional conception of teaching and learning. However, between the epistemological certainty of knowledge dimension and the constructivist conception of teaching and learning no significant path could be established. The learning process/effort dimension has a positive relation to the constructivist conception of teaching and learning and a negative relation to the traditional conception of teaching and learning. No significant relations could be established between the dimension innate/fixed ability and conceptions of teaching and learning. Students, who positively value own learning efforts and less depend on the teacher as an expert, have a constructivist conception of teaching and learning. Contrary, students believing in the certainty of knowledge and the authority of the teacher have a traditional conception of teaching and learning.

More advanced epistemological beliefs are positively related to constructivist conceptions of teaching and learning, and negatively related to traditional conceptions of teaching and learning. Traditional epistemological beliefs are negatively related to constructivist conceptions of teaching and learning, and these beliefs are positively related to traditional conceptions of teaching and learning. Though not all students in a problem-based learning environment subscribe to constructivist principles of teaching and learning, the strengths of structural relations between epistemological beliefs and conceptions of teaching and learning shows a consistent pattern. The immersion of students in a problem-based learning environment seems to affect students' beliefs and conceptions, but it is not self-evident that all students change their epistemological beliefs and conceptions of teaching and learning in the desired direction. Innovations 
in higher education should pay more attention to the beliefs that students have about knowledge, learning, and teaching to ascertain that students understand what and how they should learn in a constructivist learning environment.

\section{Discussion of the structural model}

When we compare our structural model with Chan and Elliott's (2004a) model several topics for discussion emerge. First, the relations we established between the dimension learning effort/process and the conceptions of teaching and learning differ from Chan and Elliott's (2004a) findings. They established a significant negative relation from the dimension learning effort/process to the constructivist conception of teaching and learning indicating that the students' belief in their own learning effort/process are at odds with a constructivist conception of teaching and learning. The positive relationship that was established between learning effort/process and the constructivist conception of teaching and learning is in line with a constructivist educational philosophy and problem-based learning. Second, this research shows significant relations between the dimension authority/expert knowledge and the conceptions of teaching and learning. Chan and Elliott established a relation from expert knowledge to the traditional conception of teaching and learning. Third, contrary to Chan and Elliott's (2004a) findings, who demonstrated a positive significant path between innate ability and the traditional conception of teaching and learning, we could not establish relations from innate ability to conceptions of teaching and learning. Four, both our studies and Chan and Elliott's (2004a) study established a positive relation between certainty of knowledge and the traditional conception of teaching and learning. Students still acknowledge the importance of the teacher as the person who teaches knowledge that is certain and does not change.

Coming back to the main research question regarding the possible structural relationship between students' epistemological beliefs and conceptions of teaching and learning, it can be concluded that structural relationships between students' epistemological beliefs and conceptions about teaching and learning were established. This study shows that an educational philosophy grounded in social constructivism and exemplified by problem-based learning is reflected in the relationship between dimensions of epistemological beliefs and conceptions about teaching and learning. Core concepts from constructivism and problem-based learning seem to go hand in hand with the constructivist conceptions about teaching and learning that the majority of the students hold. 


\section{Chapter 3: International hospitality management students' epistemological beliefs and conceptions of teaching and learning}

The hospitality industry is one of the most global service industries. In the international hotel industry, standardized services and local culture go hand in hand to provide unique experiences to a wide variety of international guests. The provision of high contact services can only be successful if management and employees are service-driven, empowered, committed and last but not least well-educated. It is generally supposed that international hospitality management school adequately educate their students for their future careers in the hospitality industry. Graduates should not only have acquired a comprehensive body of knowledge and skills but they must also be competent to apply their knowledge and skills to the practice of the hospitality industry. Management competencies like leadership, team work, collaboration, intercultural sensitivity, ethical decision making, and problem solving are essential for the global hospitality industry. These requirements do not only affect what students have to learn but also how they should learn (Gijbels, Van de Watering, Dochy, \& Van den Bossche, 2006; McCuddy, Van den Bosch, Martz, Matveev, \& Morse, 2007). Modern views on learning consider learning as a personal and social knowledge construction process that is integrated in and inseparable from cultural practice (Petraglia, 1998; Phillips, 2000; Terhart, 2003). In this way it opposes the view that knowledge is independent of its social context, can be codified, and can be transmitted through education which takes place outside practice. The question has been raised over and over whether new ways of education are necessary to bridge education with practice, implying that next to the importance of what is learned, also explicit attention should be paid to how learning takes place. The question has been raised over an over whether new ways of education are necessary to bridge education with practice, implying that next to the importance of what is learned, also explicit attention should be paid to how learning takes place. Some consider it as evident that traditional approaches to education emphasizing reproduction of existing knowledge are insufficient to educate tomorrow's workforce. They argue that new approaches to teaching and learning, combining action and reflection to contribute to the creation of new knowledge and knowing, are needed. In their view, students must develop critical thinking and problem solving skills and play an active role in the knowledge construction processes that are essential for advancing knowledge (Cho, Schmelzer, \& McMahon, 2002; Lave \& Wenger, 1991). It is assumed that constructivist learning environments enable students as self-responsible and self-directed learners to develop useful competencies like problem solving, learning to learn, creative thinking, leadership, and technical and business literacy (Meister, 1998; Simons, Van der Linden, \& Duffy, 2000). In chapter three, we acknowledge the vital importance of educating students in constructivist learning environments like problem-based learning to become 
able practitioners that have acquired the knowledge and skills that are relevant for their career in the hospitality industry. Our study of hospitality management students' epistemological beliefs and conceptions about teaching and learning shows that many students have more sophisticated epistemological beliefs and conceptions of teaching and learning are in line with constructivist educational principles. When we look more in detail, our findings showed that international hospitality management students generally tend not to believe in the authority and expertise of the teacher and there are indications that they tend to believe that knowledge is certain. They believe that investing time and energy in learning might lead to study success, which is in line with their relatively high mean scores on the constructivist conception of teaching and learning, and the low mean scores on the traditional conception of teaching and learning. The in-depth analysis in the present study brings two other issues to the fore: the influence of the cultural and the educational context, and the issue of domain specificity.

The cultural context

It has been argued that problem-based learning is a typical Western approach to education and that students who are educated in non-Western cultures with a more traditional focus on learning as memorization might experience difficulties (Zhang \& Brunton, 2007). The cultural context is often used to explain inconclusive results on the dimensions of epistemological beliefs (Chan \& Elliott 2004b; Clarebout, Elen, Luyten, \&

140 Bamps, 2001). For instance, Chan (2000; 2004) and Chan and Elliott (2002; 2004a; 2004b) emphasized the role of the cultural value system and the Confucian philosophy in explaining the relatively high mean score of the Chinese students on the learning effort/process dimension. However, students in both our studies valued the learning effort/process dimension well above the mean of the scale demonstrating the belief in learning for understanding. Studying in higher education requires considerable effort and skills. It seems unlikely that the cultural factor, especially the philosophy of Confucianism, fully explains the differences in mean scores. Even when we compare the mean scores of the Chinese students with all other students in the sample no significant differences were found, which might indicate that educational factors e.g. the emphasis on active, collaborative, and constructive learning in problem-based learning rather than cultural factors explain the relatively high scores on the learning effort/process dimension. Additional research is necessary to establish the potential impact of different educational contexts on the various dimensions of epistemological beliefs.

\section{Domain specificity}

The model of structural relations between students' epistemological beliefs and conceptions about teaching and learning is essentially not influenced by the domain 
specific nature of the sample of hospitality management students. The relationship that could be established followed the same pattern as was found in the study in chapter two. When we look at the relationships individually, the relationships between the epistemological beliefs learning effort/process and certainty of knowledge with the conceptions about teaching and learning are stronger in the domain specific sample, which is an indication that there may be some influence of domain specificity. If, and in how far the issue of domain specificity and domain generality in studies of epistemological beliefs, and conceptions of teaching and learning is relevant, might be shown in further studies that address this issue with samples from knowledge domains that more fundamentally differ from one another than the domains in our sample.

\section{Chapter 4: The identification of constructivist pedagogy in different learning environments}

Pedagogical practices that fit in a constructivist framework stress the importance of active, constructive, and collaborative learning. The study in chapter 4 aimed at answering the question if evidence could be found for constructivist pedagogy in four different learning environments: problem-based learning, project work, workplace learning, and action learning. To identify constructivist pedagogy in the different learning environments, a questionnaire developed by Tenenbaum, Naidu, Jegede, and Austin (2001), was filled out by students and instructional designers.

Results of this study showed that the just below midpoint score of the students on a five-point scale cannot be considered as strong evidence for the existence of constructivist pedagogy and leaves ample room for improvement. However, problem-based learning did receive a significantly higher mean score on the constructivism scale than the three other conditions. More specifically, significant differences could be noticed between problem-based learning and workplace learning. The structures and procedures at the workplace seem to limit the opportunities for self-management and self-directed learning and consequently lower the degree of perceived constructivism. The workplace is a necessary condition but obviously no sufficient guarantee for constructivist learning to take place. The structures and processes at the workplace are designed for the work that has to be done, and learning comes second. Problem-based learning has a distinct focus on learning and takes problems and tasks from the world of work as starting point for a structured learning process and offers students ample opportunities for self-directed and collaborative learning.

Instructional designers positively assessed the application of constructivist principles with an overall mean score above the midpoint of the scale. Contrary to the students, 
instructional designers perceived no significant differences between the four learning environments. The internalization and application of the same set of educational principles by instructional designers to the design of constructivist learning environments might accentuate similarities rather than differences between educational formats. It could be the case that the theoretical framework of constructivism has not yet filtered through to the practice of educational designers. So, there is still a lot of work to do in convincing instructional designers of the benefits of constructivist pedagogy.

Instructional designers and students perceive problem-based learning as consistent with constructivist views of learning and problem-based learning is considered as the educational practice that best fits into a constructivist framework. Learning by solving problems in PBL-groups supports active knowledge construction and furthers in-depth understanding (Camp, 1996; Dolmans, Wolfhagen, Van der Vleuten, \& Wijnen, 2000; Savery \& Duffy, 1996). The study in chapter 4 has shown that both instructional designers and students perceive problem-based learning as most complying to constructivist pedagogy and continuation of capitalizing on the constructivist principles of problem-based learning is suggested.

\section{Chapter 5: Critical task characteristics in problem-based learning}

142 The study in chapter 5 focused on different factors that characterize tasks in a problem-based learning and aimed at developing a questionnaire to identify factors that are characteristic for PBL-tasks. Learning from solving real-world tasks is one of the main objectives of problem-based learning (Barrows \& Tamblyn, 1980; Boud \& Feletti, 1991; Jonassen, 1997; 2000). It is generally assumed that the quality of tasks in problem-based learning is one of the key factors that stimulate students to identify learning issues and influence the quality of learning (Jacobs, Dolmans, Wolfhagen, \& Scherpbier, 2003; Jacobs, Wolfhagen, Dolmans, \& Scherpbier, 2004; Schmidt \& Gijselaers, 1990). Tasks are triggers for generating learning issues and the type of task determines largely if students address specific learning issues. One of the instructional design issues in problem-based learning is whether generic task characteristics, which influence student's learning process, can be identified. Which design features of PBL-tasks can be discerned that explain student learning? Few empirical studies exist on how the design of PBL-tasks influences learning (Jacobs et al,, 2004). The majority of the design principles seems to be more experience-based than evidence-based and consists of practical guidelines with little reference to empirical studies. A literature study revealed nine different characteristics that might contribute to the analysis of the quality of PBL-tasks: prior knowledge, structuredness, presentation, complexity, domain specificity, internal coherence, personal relevance, cooperation, and professional 
relevance (Dochy, Segers, \& Buehl, 1999; Dolmans and Snellen-Balendong, 1997; Dolmans, Snellen-Balendong, Wolfhagen, \& Van der Vleuten, 1997; Duch, 2001; Hernandez-Serrano \& Jonassen, 2003; Jacobs et al., 2004; Jonassen, 1997; 2000; 2003; Petraglia, 1998; Schmidt \& Moust, 1996; Ten Berge, Ramaekers, \& Pilot, 2004; Van der Vleuten, Dolmans, \& Scherpbier, 2000; Williams, 1992).

In the present study, a questionnaire covering nine factors (complexity, structuredness, cooperation, domain specificity, presentation, professional relevance, personal relevance, prior knowledge, and internal coherence) for measuring PBL-tasks was developed. The data were analyzed using the Multiple Group Method of confirmatory factor analysis (Kiers, 2002; Nunnally, 1978). Results showed that the hypothesized nine factors that are characteristic for PBL-tasks did not emerge and only six factors seem to cover the key characteristics of PBL-tasks. Three hypothesized factors did not satisfy the criteria: complexity, domain specificity, and presentation. The factor complexity, which is generally considered as a main characteristic and outstanding feature of PBL-problems, did not emerge in our research. This finding is in line with Jacobs et al. (2003), who replaced the two-factor, structuredness and complexity, model by a three-factor model with the factors too simple, too difficult, and too structured. The theoretical relevance of the construct complexity still lacks empirical support. Analysis of the data also showed no firm empirical support for the factors domain specificity and problem representation. The factors professional relevance, prior knowledge, and internal coherence found empirical confirmation indicating that Jacobs et al. (2003) suggestions for further research of these characteristics of PBL-problems turned out to be very relevant. Moreover, the results on the remaining two factors, cooperation and personal relevance, indicated that students could clearly distinguish these factors as $\mathrm{PBL}$-problem characteristics. Further research is needed to cross-validate the questionnaire and to reduce the length of the questionnaire to serve as a checklist for the quality of tasks in problem-based learning.

Significant differences were found on six dimensions between performance and importance ratings indicating that students systematically value the importance characteristics on all factors higher than the actual performance on these factors. Results on the t-tests indicated significant differences on four of the six dimensions between the performance and importance ratings of the instructors. Instructors rated the performance on the factors prior knowledge, internal coherence, cooperation, and personal relevance lower than the importance ratings. The imbalance between the performance and importance ratings of PBL-tasks suggests that further improvement of performance is necessary. However, an importance rating cannot be simply used as criterion for a performance rating. 
Comparison between students' and instructors' mean performance ratings showed no significant differences on the performance rating and only one significant difference was found on the importance ratings. Both students and instructors valued the importance of the factors cooperation, internal coherence, and personal relevance higher than the factors professional relevance, structuredness, and prior knowledge. Further research is needed to investigate the exact nature of the points of agreement and disagreement between importance and performance ratings.

How students perceive and value PBL-tasks influences what and how they will learn. A one-size-fits-all approach to PBL-tasks is not recommended because variation in tasks stimulates students' learning. Problem tasks address different learning issues than application or discussion tasks. However, more research into the characteristics of PBL-tasks is needed to find out which factors influence and further students' learning and meet instructors' expectations. The relative weight of each factor in the tasks varies and research is needed to fine-tuning tasks to optimize students' learning. For instance, tasks for $1^{\text {st }}$ year students demand more structuredness, more internal coherence and should more explicitly relate to the prior knowledge of the students than the unstructured and authentic tasks at the end of a programme.

Problem-based learning is an integrated perspective on the curriculum, which implicates that the design of tasks is closely connected to the objectives of the

144 curriculum. Designing problem-based learning in the different programme phases calls for task variety that evokes intended learning issues. Further research is needed to assess if and how the tasks designed by the instructor and the intended learning issues correspond to how students experience the tasks and if the tasks challenge students to attain learning objectives.

\section{Conclusions}

In the present thesis, significant relationships could be established between dimensions of personal epistemology and conceptions about teaching and learning. Students epistemological beliefs and conceptions about teaching and learning have important implications for educational practice. Reviewing the research question regarding the investigation of students' epistemological beliefs and conceptions of teaching and learning we come to the following main conclusion. The majority of the students have epistemological beliefs and constructivist conceptions about teaching and learning that show remarkable correspondence with an educational philosophy grounded in social constructivism and exemplified by problem-based learning. It has been shown in this thesis that problem-based learning is a good example of constructivist pedagogy. Students perceive problem-based learning as more complying to constructivist 
principles than other learning environments. Results indicate that the majority of the students in our studies have epistemological beliefs and constructivist conceptions about teaching and learning that correspond with core ideas about problem-based learning. Essential in problem-based learning is that students learn from solving problems and become able to transfer and apply knowledge to new problems and to other contexts. Therefore, task characteristics are an important issue in the studies on problem-based learning. The study reported in chapter five has demonstrated the relevance of several task characteristics for challenging and motivating students to engage in collaborative learning and active knowledge construction. The studies in this thesis have shown that challenging tasks in a well-designed problem-based curriculum are not only important for student learning but are in line with students' epistemological beliefs and conceptions about teaching and learning.

\section{Implications for educational practice}

Students' knowledge construction processes in constructivist learning environments like problem-based learning call for careful facilitation and support by qualified lecturers during PBL-sessions. Special attention should be paid to students, who are educated in traditional learning environments and are accustomed to lectures-based education. These students may experience difficulties because the communication and problem solving skills that they bring into the PBL-setting may not suffice to fully benefit from problem-based learning. Especially, students who are not used to self-directed learning, find it difficult to formulate learning goals and to monitor their own learning process. The beliefs about knowledge and conceptions of teaching and learning that students hold influence the way they approach learning tasks. Sophisticated epistemological beliefs and constructivist conceptions of teaching and learning are important for successful student participation in learning environments that require self-direction and collaboration. Discussions between students and lecturers about the basic ideas behind constructivism and embedded skills training in a constructivist conceptual framework may advance students' assimilation to demands of higher education and further understanding of constructivism and problem-based learning (Kaartinen-Koutaniemi \& Lindblom-Ylänne, 2008; Kember, 2001).

The mean of the students' scores on the EBQ dimension authority/expert knowledge below the midpoint of the scale and the well above the midpoint mean score on the learning effort/process dimension of the EBQ indicate that students value self-directed learning processes. The relationship of both EBQ dimensions with the constructivist dimension of the TLCQ provides evidence for a correspondence between the beliefs and conceptions that students hold. Students have more constructivist than traditional conceptions of teaching and learning indicating that students' conceptions are in line 
with the educational context, which is based on constructivist principles and the integration of problem-based learning in the curriculum. Students from different backgrounds show beliefs and conceptions that enable active and productive participation in problem-based learning.

Tasks are important drivers for the learning process in problem-based learning. We have demonstrated several characteristics of PBL-tasks. For instance, unstructured tasks that are derived from the work field are often judged by students as difficult and unclear, because students find it hard to define the exact problem. The multiple options to solve the problem create a constructive friction between what students already know and what they want to know, and stimulate individual and collaborative learning. The solutions and results that students produce are not always consistent and perfect, which may cause uncertainty and dissatisfaction in students who are looking for the right solution and the right answer. However, further research is needed to establish structural relations between epistemological beliefs, conceptions of teaching and learning, and problem-based learning. Solving unstructured tasks may cause cognitive overload and instructional designers should take the prior knowledge and study skills of the students into account in the design of learning tasks (Van Merriënboer \& Sweller, 2005). In the initial phase of a problem-based curriculum expert guidance in problem-based learning and consciousness-raising of students' beliefs about knowledge and knowing, and their conceptions about teaching and learning might enhance the effectiveness of student learning.

\section{Suggestions for future research}

Beliefs about the nature of knowledge and knowing are intimately related to beliefs about learning. Studies of epistemological beliefs often include both beliefs about knowledge and learning (Chan \& Elliott, 2004a; Hofer \& Pintrich, 1997;

Schommer-Aikins \& Easter, 2006). Moreover, conceptions about teaching and learning focus on two related but different aspects of the learning process. Though structural relationships between epistemological beliefs and conceptions of teaching and learning could be established in the studies in chapter two and three, future research could more clearly distinguish between beliefs of knowledge and knowing on the one hand and conceptions of teaching and conceptions of learning on the other hand. A clear distinction between epistemological beliefs, conceptions of teaching, and conceptions of learning, might contribute to improved understanding of the beliefs and concepts, and their interrelations.

Research on epistemological beliefs has neglected philosophical issues and the need for in-depth understanding and discussion of the ontological and epistemological 
underpinnings of epistemological beliefs has been acknowledged (Alexander, 2006; Muis, Bendixen, \& Haerle, 2006; Schraw, 2001; Tsai, 1999). Though constructivism tries to remain agnostic towards traditional epistemological questions, philosophical assumptions and statements about reality and knowledge abound. For instance, the statement that the reality, the world, is a construction and we cannot have knowledge of a world that exists independently of our minds, involves a philosophical position. Likewise, the statement that we interdependently construct our own world and our own truth, because we can only compare our conceptions of reality to other conceptions and not with reality itself clearly implicates that constructivism does not claim truth but only how viable a cognitive solution may seem and consequently raises epistemological questions. Research of epistemological beliefs could be improved by addressing epistemological issues related to constructivism.

Further evidence is needed to show if constructivist pedagogical approaches are more effective and efficient than traditional educational approaches, and yield better learning results and more in-depth knowledge. So far, meta-analyses have not shown conclusive evidence on the effectiveness of problem-based learning. Students in a PBL-curriculum generate and gain knowledge equivalent to the amount of knowledge that is gained in lecture-based approaches. There are indications that students in a problem-based curriculum have acquired the necessary competencies and feel better prepared for professional practice than students in a traditional curriculum (Albanese \& Mitchell, 1993; Gijbels et al., 2005; Newman, 2006; Prince, 2006; Vernon \& Blake, 1993). We want to underline the importance of empirical research to demonstrate the effectiveness and efficiency of problem-based learning to educate students for professional practice. 


\section{References}

Albanese, M.A., \& Mitchell, S. (1993). Problem-based learning: a review of literature on its outcomes and implementation issues. Academic Medicine, 68, 52-79.

Alexander, P. A. (2006). What would Dewey say? Channeling Dewey on the issue of specificity of epistemic beliefs: A response to Muis, Bendixen, and Haerle (2006). Educational Psychology Review, 18(1), 55-65.

Anderson, J. R., Greeno, J. G., Reder, L. M., \& Simon, H. A. (2000). Perspectives on learning, thinking, and activity. Educational Researcher, 29(4), 11-13.

Barrows, H. 5., \& Tamblyn. R. M., (1980). Problem-based learning: An approach to medical education. New York: Springer.

Bentler, P. M. (2006). EQS 6 Structural equations program manual. Encino, CA: Multivariate Software Inc.

Bereiter, C. (1994). Constructivism, socioculturalism, and Popper's world 3. Educational Researcher, $23(7), 21-23$

Billett, S. (1996), Situated learning: Bridging sociocultural and cognitive theorizing. Learning and Instruction, 6(3), 263-280.

Boud, D., \& Feletti, G. (Eds.). (1991). The Challenge of Problem-based Learning. London: Kogan Page.

Camp, G. (1996). Problem-based learning: A Paradigm shift or a passing fad. Medical Education Online, 1(2). Retrieved May 21, 2009 from http://www.med-ed-online.org/volume1.htm

148 Chan, K-W. (2000). Teacher education students' epistemological beliefs: A cultural perspective on learning and teaching. Sydney: Paper presented at the AARA 2000 conference.

Chan, K-W. (2001). Validation of a measure of personal theories about teaching and learning. Perth: Paper presented at the AARE 2001 conference.

Chan, K-W. (2003). Hong Kong teacher education students' epistemological beliefs and approaches to learning. Research in Education, 69(1), 36-50.

Chan, K-W. (2004). Pre-service teachers' epistemological beliefs and conceptions about teaching and learning: cultural implications for research in teacher education. Australian Journal of Teacher Education, 29(1), 1-13.

Chan, K-W. (2008). Hong Kong teacher education students' epistemological beliefs and their relations with conceptions of learning and learning strategies. The Asia Pacific Education Researcher, 16(2), 199-214.

Chan, K-W., \& Elliott, R. G. (2002). Exploratory study of Hong Kong teacher education students' epistemological beliefs: cultural perspectives and implications on beliefs research. Contemporary Educational Psychology, 27, 392-414.

Chan, K-W., \& Elliott, R. G. (2004a). Relational analysis of personal epistemology and conceptions about teaching and learning. Teaching and Teacher Education, 20, 817-831.

Chan, K-W., \& Elliott R. G. (2004b). Epistemological beliefs across cultures: Critique and analysis of beliefs structure studies. Educational Psychology, 24(2), 123-142. 
Chan, K-W., Tan, J., \& Khoo, A. (2007). Pre-service teachers' conceptions about teaching and learning: A closer look at Singapore cultural context. Asia-Pacific Journal of Teacher Education, 35(2), 181-195.

Cho, W., Schmelzer, C. D., \& McMahon, P. S. (2002). Preparing Hospitality Managers for the 21st century: education, critical thinking, and collaborative learning. Journal of Hospitality \& Tourism Research, 26(1), 23-37.

Clarebout, G., Elen, J., Luyten, L., \& Bamps, H. (2001). Assessing epistemological beliefs: Schommer's questionnaire revisited. Educational Research and Evaluation, 7(1), 53-77.

De Corte, E. (1995). Fostering cognitive growth: A perspective from research on mathematics learning and instruction. Educational Psychologist, 30(1), 37-46.

De Corte, E. (2000). Marrying theory building and the improvement of school practice: a permanent challenge for instructional psychology. Learning and Instruction, 10(3), 249-266.

Dochy, F., Segers, M. \& Buehl, M. M. (1999). The relation between assessment practices and outcomes of studies: the case of research on prior knowledge. Review of Educational Research, 69(2), 145-186.

Dochy, F., Segers, M., Van den Bossche, P., \& Gijbels, D. (2003). Effects of PBL; A meta-analysis. Learning and Instruction, 13(5), 533-568.

Dolmans, D. H. J. M., \& Snellen-Balendong, H. (1997). Constructie van taken in probleemgestuurd onderwijs. Groningen: Wolters-Noordhoff.

Dolmans, D. H. J. M., Snellen-Balendong, H., Wolfhagen, I. H. A. P., \& Van der Vleuten, C. P. M. (1997). Seven principles of effective case design for a problem-based curriculum. Medical Teacher, 19(3), 185-190.

Dolmans, D. H. J. M., Wolfhagen, I. H. A. P., Van der Vleuten, C. P. M., \& Wijnen, W. H. F. W. (2000). Probleemgestuurd Onderwijs in het Hoger Onderwijs: Een Hype of een Paradigmaverandering? In J. Van der Linden and E. Roelofs (Eds.), Leren in dialoog. Een discussie over samenwerkend leren in onderwijs en opleiding (pp. 179-195). Groningen: Wolters-Noordhoff.

Duch, B. J. (2001). Writing problems for deeper understanding. In B. J. Duch, S. E. Groh \& D. E. Allen (Eds.), The Power of Problem-based Learning (pp. 47-53). Sterling: Stylus Publishing.

Gijbels, D., Dochy, F., Van den Bossche, P., \& Segers, M. (2005). Effects of problem-based learning: a meta-analysis from the angle of assessment. Review of Educational Research, 75(1), 27-61.

Gijbels, D., Van de Watering, G., Dochy, F, \& Van den Bossche, P. (2006). New learning environments and constructivism: The students' perspective. Instructional Science, 34, 213-226. Hancock, G. R., \& Mueller, R. O. (2005). Structural equation modeling. A first course. Rotterdam: Erasmus University Medical Center.

Hendry, G.D.H., Frommer, M., \& Walker, R.A. (1999). Constructivism and Problem-based Learning. Journal of Further and Higher Education, 23(3), 359-371.

Hernandez-Serrano, J., \& Jonassen, D. H. (2003). The effects of case libraries on problem solving. Journal of Computer Assisted Learning, 19, 103-114.

Hofer, B. K., \& Pintrich, P. R. (1997). The development of epistemological theories: beliefs about knowledge and knowing and their relation to learning. Review of Educational Research, 67(1), 88-140. 
Jacobs, A.E. J. P., Dolmans, D. H. J. M., Wolfhagen, I. H. A. P., \& Scherpbier, A. J. J. A. (2003). Validation of a short questionnaire to assess the degree of complexity and structuredness of PBL problems'. Medical Education, 37, 1001-1007.

Jacobs, A. E. J. P., Wolfhagen, I. H. A. P., Dolmans, D. H. J. M., \& Scherpbier, A. J. J. A. (2004). Meten van complexiteit en gestructureerdheid van pgo-problemen. Onderwijsinnovatie, 1, 17-24.

Jonassen, D. H. (1997). Instructional design models for well-structured and ill-structured problem-5olving learning outcomes. Educational Technology Research and Development, 45(1), 65-94.

Jonassen, D. H. (2000). Toward a design theory of problem solving. Educational Technology Research and Development, 48(4), 63-85.

Jonassen, D. H. (2003). Using cognitive tools to represent problems. Journal of Research on Technology in Education, 35(3), 362-381.

Kaartinen-Koutaniemi, M., \& Lindblom-Ylanne, S. (2008). Personal epistemology of psychology, theology and pharmacy students: A comparative study. Studies in Higher Education, 33(2), 179-191.

Kember, D. (2001). Beliefs about knowledge and the process of teaching and learning as a factor in adjusting to study in higher education. Studies in Higher Education, 26(2), 205-221.

Kiers, H. (2002). De Multipele Groep Methode. Groningen: Unpublished document. Lave, J., \& Wenger, E. (1991). Situated learning. Legitimate peripheral practice. Cambridge: Cambridge University Press.

McCuddy, M. K., Van den Bosch, H., Martz, Wm. B., Matveev, A. V., \& Morse, K. O. (Eds.), (2007). The challenges of educating people to lead in a challenging world. Dordrecht: Springer.

Muis, K. R., Bendixen, L. D., \& Haerle, F. C. (2006). Domain-generality and domain-specificity in personal epistemology research: Philosophical and empirical questions in the development of a theoretical model. Educational Psychology Reviews 18(1), 3-54.

Nunnally, J. C. (1978). Psychometric Theory. New York: McGraw-Hill.

Petraglia, J. (1998). Reality by Design. The Rhetoric and Technology of Authenticity in Education. Mahwah: Lawrence Erlbaum Associates.

Phillips, D. C. (Ed.), (2000). Constructivism in Education. Opinions and second opinions on controversial issues. Ninety-ninth Yearbook of the National Society for the Study of Education. Part 1. Chicago, II: The University of Chicago Press.

Savery, J. R., \& Duffy, T. M. (1996). Problem based learning: An instructional model and its constructivist framework. In B. G. Wilson (Ed.), Constructivist learning environments: Case studies in instructional design (pp. 35-48). Englewood Cliffs, Nf: Educational Technology Publications.

Schraw, G. (2001). Current themes and future directions in epistemological research: $A$ commentary. Educational Psychology Review, 13(4), 451-464.

Schmidt, H. G., \& Gijselaers, W. H. (1990). Causal Modeling of Problem-based Learning. Boston: Paper presented at the Annual Meeting of the American Educational Research Association. 
Schmidt, H., \& Moust, J. (1996). Construeren van probleemtaken voor probleemgestuurd leren. VELON, Tijdschrift voor Lerarenopleiders, 17(3), 5-7.

Schommer, M. (1990). Effects of beliefs about the nature of knowledge on comprehension. Journal of Educational Psychology, 82(3), 498-504.

Schommer-Aikins, M., \& Easter, M. (2006). Ways of knowing and epistemological beliefs: Combined effect on academic performance. Educational Psychology, 26(3), 411-423.

Schraw, G. (2001). Current themes and future directions in epistemological research: $A$ commentary. Educational Psychology Review, 13(4), 451-464.

Simons, R. J., Van der Linden, J., \& Duffy, T. (2000). New learning: Three ways to learn in a new balance. In R. J. Simons, J. van der Linden \& T. Duffy (Eds.), New Learning (pp. 1-10). Dordrecht: Kluwer Academic Publishers.

Ten Berge, H., Ramaekers, S., \& Pilot, A. (2004). The design of authentic tasks that promote higher order learning. Paper presented at the EARLI-SIG Higher Education/KIT-conference.

Tenenbaum, G., Naidu, S., Jegede, O., \& Austin, J. (2001). Constructivist pedagogy in conventional on-campus and distance learning practice: An exploratory investigation. Learning and Instruction, 17(2), 87-111.

Terhart, E. (2003). Constructivism and teaching: a new paradigm in general didactics. Curriculum Studies, 35(1), 25-44.

Tsai, C. C. (1999). "Laboratory exercises help me memorize the scientific truths": A study of eighth graders views and learning in laboratory activities. Science Education, 83(6), 654-674.

Van der Vleuten, C. P. M., Dolmans, D. H. J. M., \& Scherpbier, A. J. J. A. (2000). The need for evidence in education. Medical Teacher, 22(3), 246-250.

Van Merriënboer, J. J. G., \& Sweller, J. (2005). Cognitive load theory and complex learning: Recent developments and future directions. Educational Psychology Review, 17(2), 147-177.

Vernon, D. T., \& Blake, R. L. (1993). Does problem-based learning work? A meta-analysis of evaluative research. Academic Medicine, 68, 550-563.

Von Glasersfeld, E. (1995). Radical Constructivism: A way of Knowing and Learning. London: The Falmer Press.

Von Glasersfeld, E. (2005). Thirty years of radical constructivism. Constructivist Foundations, 1(1), $9-18$.

Williams, S. M. (1992). Putting case-based instruction into context: Examples from legal and medical education. The Journal of the Learning Sciences, 2(4), 367-427.

Zhang, Z., \& Brunton, M. (2007). Differences in living and learning: Chinese International students. Journal of Studies in International Education, 11(2), 124-140. 
Summary 


\section{Summary}

Knowledge, learning, and teaching are the main issues that are investigated in the present thesis. What is knowledge, how do students know what they know, how do students learn, which are the characteristics of learning environments and tasks for constructive learning? Theories and ideas about knowledge and learning in higher education have been influenced by constructivist views on what knowledge is, and how students gain knowledge and understanding through dialogue and collaboration. When knowledge is a human construction that does not represent an objective reality and cannot be absolutely true, but only viable, the question arises how learners are able to construct shared understandings and come to agreement on which knowledge really counts. The present thesis researches the consequences of constructivist views on higher education for the design of learning environments, and students' perceptions on the level of constructivism and its impact on learning.

Several questions emerge when researching how students perceive characteristics of knowledge and its implications for teaching and learning. For example, the question can be raised about what students think about how objective knowledge is, and how certain they are that teachers teach the 'right' knowledge. Why should students believe in the expertise of teachers and in their authority when constructivist views claim that knowledge is not a true representation of the world outside, but just a viable human construction? Research on the beliefs that students hold about the nature of knowledge and knowing may provide insight into what they believe knowledge is and how it is acquired.

One of the central issues in the present study was the potential impact of students' epistemological beliefs on their conceptions of teaching and learning. Students get involved in learning environments, which confront them with real-life tasks that challenge their thinking and engage them in purposeful learning activities. We tried to develop enhanced understanding of what kind of learning environments fit best in a constructivist framework, and stimulate active and constructive learning in collaboration with other students. Problem-based learning is considered to be prototypical for constructivist learning environments. Problem-based learning confronts students with authentic learning tasks that reflect the complexity of the future work situation. Students learn best when they participate in activities that they perceive as useful and relevant. Real-life tasks are considered as essential elements for stimulating learning activities. The type of task largely determines if, how, and what students are learning.

In the present thesis, research on the relations between knowledge, learning, and teaching was conducted based on two perspectives. The first line of research (chapter 2 
and 3) focused on the beliefs about knowledge and knowing that students hold and their conceptions of teaching and learning. Students' epistemological beliefs and their conceptions of teaching and learning served as a frame of reference from which students interpret the demands of the learning environment. What are the epistemological beliefs and conceptions of teaching and learning that students hold? Do students endorse constructivist views about teaching and learning or do they still hold on to traditional ideas about teaching and learning? The second line of research dealt with educational practice and constructivist learning environments. Chapter 4 and 5 described research on constructivist pedagogy in four different learning environments and the characteristics of tasks as challenges for learning.

\section{Chapter 1: The structural relationship between students' epistemological beliefs and conceptions of teaching and learning.}

How students construct knowledge, how students know what they know, and what kind of beliefs students hold about knowledge and knowing have become major issues for higher education. The epistemological beliefs that students hold about the nature of knowledge and knowing, are important for influencing their learning activities. Epistemological beliefs are conceptualized as a system of multidimensional beliefs that are more or less independent from one another and may develop asynchronously. The multidimensional conception of epistemological beliefs includes both beliefs about knowledge and beliefs about learning. Previous research on epistemological beliefs confirmed the multidimensionality of epistemological beliefs. In the present study, a 30-item Epistemological Beliefs Questionnaire (EBQ) that distinguishes four dimensions of epistemological beliefs was used.

1. The innate/fixed ability dimension assesses the belief in knowledge as inborn and fixed as compared to the belief that knowledge is not inborn and changeable.

2. The learning effort/process dimension refers to the belief in learning by drill and practice at one end or learning as a process of understanding and learning how to learn at the other.

3. The authority/expert knowledge dimension evaluates whether knowledge is being handed down by experts or whether knowledge is created through personal experience and justification.

4. The certainty of knowledge dimension reflects the belief that knowledge is unchangeable and certain at one end or whether knowledge is considered changeable and uncertain at the other.

The present study aimed at establishing structural relationships between students' epistemological beliefs and conceptions of teaching and learning. The participants in the study were 617 students from nine different bachelor programs that have a 
problem-based approach to the curriculum as a common characteristic. Students filled out a questionnaire that consisted of three sections: a section that supplied demographic data, a section on epistemological beliefs, the Epistemological Beliefs Questionnaire (EBQ), and a section on conceptions of teaching and learning, the Teaching and Learning Conceptions Questionnaire (TLCQ). Results showed that structural relationships could be established between three dimensions of students' epistemological beliefs, and the traditional and constructivist conception of teaching and learning. Satisfactory goodness of fit indices indicated a well-fitting model showing a strong positive relationship from the authority/expert knowledge dimension to the traditional conception of teaching, a negative relationship from the authority/expert dimension to the constructivist conception, a positive relationship from certainty of knowledge to the traditional conception of teaching and learning, a positive relationship from the learning process/effort dimension to the constructivist conception of teaching and learning, and a negative relationship from the learning effort/process dimension to the traditional conception of teaching and learning. No significant relations could be established between the dimension innate/fixed ability and conceptions of teaching and learning.

The present study provides evidence for the multidimensionality of epistemological beliefs and supports the characterization of personal epistemology as a system of more or less independent dimensions. A clear distinction could be made between the traditional and constructivist conception of teaching and learning, and our results show that the majority of the students hold a constructivist conception of teaching and learning, which is in line with a problem-based approach to the curriculum. Though not all students in a problem-based learning environment subscribe to constructivist principles of teaching and learning, the structural relationships between epistemological beliefs and conceptions of teaching and learning show a consistent pattern. The significant relationships from the dimensions of epistemological beliefs to the traditional and constructivist conception of teaching and learning that we found in our structural model, are in agreement with the principles of constructivism and represent an important step in understanding the relations between knowledge, learning, and teaching.

\section{Chapter 3: International hospitality management students' epistemological beliefs and conceptions of teaching and learning.}

The provision of high contact services to a wide variety of international guests in the highly globalized hospitality industry can only be successful if hospitality managers and employees are service-driven, empowered, committed, and last but not least well-educated. The question can be raised how to design hospitality management 
education that meets the demands from the industry? How can students gain understanding of the globalized hospitality industy in a school setting? Graduates from international hospitality management schools should not only have acquired a comprehensive body of knowledge and skills but must also be competent in leadership. team work, collaboration, intercultural sensitivity, ethical decision making, and problem solving. It is said that the practice of hospitality management calls for a perspective that regards learning as a personal and social knowledge construction process that is integrated in and inseparable from cultural practice. In this way, it opposes the view that knowledge is independent of its social context, can be codified, and can be transmitted through education which takes place outside practice. Some have claimed that constructivist learning designs may meet those demands but the question is whether these learning environments are in alignment with students' epistemological beliefs, and conceptions of teaching and learning.

Our research shows that many students have relatively sophisticated epistemological beliefs. Next, their conceptions of teaching and learning are in line with constructivist educational principles. When looking into more detail, our findings showed that international hospitality management students generally tend not to believe in the authority and expertise of the teacher, and there are indications that they tend to believe that knowledge is certain. International hospitality management students believe that investing time and energy in learning might lead to study success, which is

158 in line with the relatively high mean scores on the constructivist conception of teaching and learning, and the low mean scores on the traditional conception of teaching and learning. Analysis of the findings in the present study brings two issues to the fore. First, it has often been argued that problem-based learning does not fit the cultural and educational background of non-Western students, because these students have been educated in a teaching-learning culture that focuses on passive learning and memorization. The present study shows that international hospitality management students from different cultural and educational backgrounds have conceptions of teaching and learning that enable them to positively experience problem-based learning. Hence, we can conclude that problem-based learning can be used effectively with students from different cultural backgrounds. Second, the issue of the domain specificity or domain generality of epistemological beliefs has often been debated. When we compare the model of structural relations from epistemological beliefs to conceptions of teaching and learning of higher education students with international hospitality management students, we may conclude that de model was not influenced by the domain specific nature of the sample of international hospitality management students. Studying in higher education requires considerable effort and skills. It seems unlikely that cultural factors rather than educational factors explain differences in students' beliefs of knowledge, and conceptions of teaching and learning. 


\section{Chapter 4: The identification of constructivist pedagogy in different learning environments.}

Learning environments that fit in a constructivist framework are problem-based learning, action learning, project work, and workplace learning. Chapter 4 describes research about the question: Can we find evidence for constructivist pedagogy in four different learning environments?

Results of the present study showed that the just below midpoint score of the students on a five-point scale cannot be considered as strong evidence for the existence of constructivist pedagogy and leaves ample room for improvement. Compared to the other three conditions, students assigned the highest overall mean score to the problem-based learning condition. Problem-based learning takes tasks from the workfield as a starting point for a structured learning process and offers students opportunities for self-directed and collaborative learning. A significant difference could be noticed between the problem-based learning and workplace learning condition. The structures and procedures at the workplace seem to limit the students' opportunities for self-management and self-directed learning, and consequently lower the degree of perceived constructivism. The mere activities that students have to carry out at the workplace, are no guarantee for learning to take place, because work comes first and formost, and learning is more or less a by-product.

No significant differences between the four conditions could be established for instructional designers. Instructional designers positively assessed the application of constructivist principles with an overall mean score above the midpoint of the scale. Compared with students, instructional designers rated problem-based learning as significantly more conforming to constructivism. Though instructional designers positively assessed the application of constructivist principles, even their mean scores leave room for improvement. It could well be the case that the theoretical framework of constructivism has not yet filtered through to the practice of educational designers. So, there is still a lot of work to do in convincing instructional designers of the benefits of constructivist pedagogy and problem-based learning.

\section{Chapter 5: Critical task characteristics in problem-based learning.}

One of the instructional design issues in problem-based learning is whether critical task characteristics can be identified that play a key role in student learning. The majority of the principles for designing tasks in problem-based learning seems to be experience-based rather than evidence-based, and consists of practical guidelines with little reference to empirical studies. Though the importance of the PBL-task has been 
widely acknowledged, a lack of empirical findings and guidelines for the construction and evaluation of PBL-tasks can be noticed.

Our literature study revealed nine different characteristics that might contribute to the analysis of the characteristics of PBL-tasks: prior knowledge, structuredness, presentation, complexity, domain specificity, internal coherence, personal relevance, cooperation, and professional relevance. The main goal of this study was to develop a checklist for the construction and evaluation of PBL-tasks. A checklist with critical characteristics of PBL-tasks would serve two purposes. First, it might support instructional designers in constructing appropriate PBL-tasks. Second, it provides a tool for the evaluation of PBL-tasks. Data for the present study have been gathered in a sample of undergraduate students and instructors of a hospitality management programme. Students and instructors filled out a questionnaire with 94 importance and performance statements covering nine characteristics of PBL-tasks.

Results showed that an instrument with 44 items and six factors seems to cover the key characteristics of PBL-tasks. Three hypothesized factors did not satisfy the criteria: complexity, domain specificity, and presentation. The factor complexity that is generally considered as theoretical relevant and characteristic for PBL-tasks, did not emerge in our research and lacks empirical support. Analysis of the data also showed no empirical support for the factors domain specificity and problem representation. The factors

160 professional relevance, prior knowledge, cooperation, personal relevance, and internal coherence found empirical confirmation. However, significant differences were found between performance and importance ratings indicating that the performance ratings on several factors was significantly lower than the importance ratings, which leaves room for improvement. Further research is needed to cross-validate the questionnaire and to reduce the length of the questionnaire to serve as a checklist for the construction and evaluation of tasks in problem-based learning.

\section{Conclusions}

In the present thesis, two lines of empirical research were applied to examine the interplay between constructivist views on teaching and student learning. The first line of research concerned students' epistemological beliefs and conceptions of teaching and learning that serve as a frame of reference from which students interpret the demands of the learning situation. Our research has shown that the majority of the students in our studies have epistemological beliefs and conceptions of teaching and learning that correspond with core ideas about problem-based learning. The relationships from the dimensions of epistemological beliefs to the traditional and constructivist conceptions of teaching and learning that we established in our structural 
model, are in line with constructivist ideas of education and contribute to understanding of the relations between knowledge, learning, and teaching.

The second line of research emerged from the criticism of constructivism on the transmissibility of knowledge and underlined the urge for developing innovative learning environments. Our studies showed that students perceived problem-based learning as more complying to constructivist principles than other learning environments. The task is an essential factor that drives student learning activities in problem-based learning and our research on characteristics of tasks has demonstrated the relevance of a variety of task characteristics in a problem-based learning approach to the curriculum. 


\section{Curriculum Vitae}




\section{Curriculum Vitae}

Hans Otting was born on August 10, 1945 in Rotterdam. He finished his secondary education in 1962 at the Christelijk Lyceum in Delft. For several years, he worked in a wide variety of jobs before he started in 1972 as a sociotherapeutic assistent in the Rekkense Inrichtingen in Rekken. In 1976, he obtained a Bachelor in Social Work at Sociale Academie Twente. He continued his studies at the Radboud University in Nijmegen and received his bachelor degree (1978) and master degree (1982) in Educational Sciences. During his study at Radboud University, he worked as a teacher in social work and research assistant. His research concerned the relevance of Theme-centered Interaction (TCl) for group therapy and group pedagogy. Between 1981 and 1983, he worked as a curriculum designer at the Hogere Hotelschool Maastricht and contributed to the design of the first national curriculum for higher hospitality management education. From 1983 till 1986, he was responsible for the implementation of problem-based learning (PBL) at the Academie Mens-Arbeid in Deventer.

Hans Otting was one of the founding fathers of the Hotel Management School Leeuwarden (1987) and the Retail Management School Leeuwarden (1992). He introduced problem-based learning to the International Hospitality Management program. He was a member of the board of directors of the Faculty of Economics and Management at the Christelijke Hogeschool Nederland from 1992 till 1998. Since 1999, he is a senior educational consultant and researcher at Stenden University of Applied Sciences in Leeuwarden. His current research is about constructivist conceptions of education and problem-based learning. 